ARGONNE NATIONAL LABORATORY

9700 South Cass Avenue, Argonne, Illinois 60439

ANL/EES-TM-320

RADIOACTIVE WASTE ISOLATION IN SALT:

PEER REVIEW OF THE GOLDER ASSOCIATES DRAFT

TEST PLAN FOR IN SITU TESTING IN AN

EXPLORATORY SHAFT IN SALT

ANL/EES-TM--320

DE87 005927

by

D.F. Hambley, D.Z. Mraz, R.R. Unterberger, J.C. Stormont, S.P. Neuman, J.E. Russell, C.H. Jacoby, A.B. Hull, B.H.G. Brady, J.D. Ditmars,

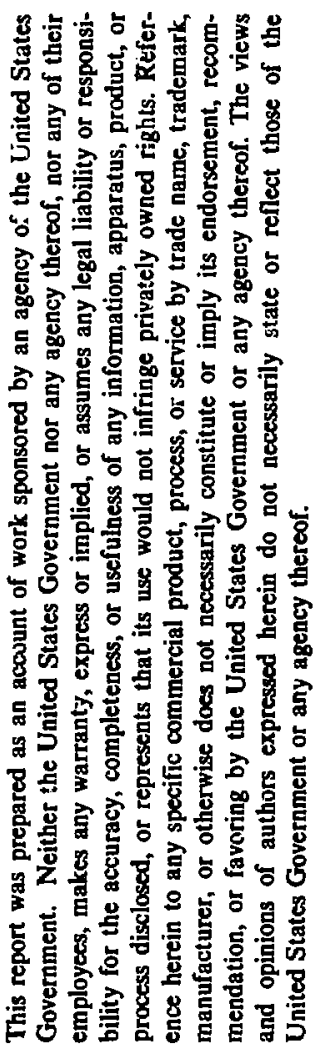

D.M. Rote, J.B. Farr, D.I. Leap, T.R. Harper, W. Harrison,

G.B. Baecher, M.G. Seitz, C.H. Dowding, D.F. Fenster,

R.A. Paddock, L.W. Braile, G.R. Keller, J.S. Busch,

R.M. Bateman, and A.W. Hatheway*

Energy and Environmental Systems Division

Engineering Geosciences Group

Completed July 1985 (except for App. C)

Published January 1987

work sponsored by

U.S. DEPARTMENT OF ENERGY

Office of Civilian Radioactive Waste Management

Salt Repository Project Office

*Authors' affiliations are listed on pages xi-xii. 
Department of Energy

Chicago Operations Office

November 19,1986

Salt Repository Project Office

505 King Avenue

Columbus, Ohio 43201-2693

Commercial (614) 424-5916

F.T.S. 976-5916

\section{NOTICE TO READERS}

At the request of the Salt Repository Project Office (SRPO), Argonne National Laboratory carried out a review of a document entitled "Draft Test Plan for In Situ Testing in an Exploratory Shaft in Salt," dated March 1985. This document was prepared by Golder Associates, Inc., Redmond, Washington. This report outlines a proposed program of in situ testing which constitutes part of the overall effort to determine site suitability for the development of a repository, provide data for repository design and performance assessments, and prepare licensing documentation for radioactive waste in salt.

DOE requested that the ANL review address the following items:

- The general technical adequacy of both the document and the activities described within it

- The internal consistency of the plan

- The consistency of the plan with general programmatic goals such as those stated in the NWPA, 10 CFR 60, 40 CFR 100, and the Mission Plan

- The ability of the plan to provide information indicated in the SCP Annotated Outline, Sections 8.3.1 and 8.3.2.

Argonne was also asked to review the test plan to see if it provided:

- A description of tests that could use radioactive materials

- A description of tests that might affect the capability of the site to isolate waste

- A discussion of instrumentation and monitoring requirements

- The application of expected test results to the development of follow-up testing

Valuable comments were provided by the panel. Resolution of the comments and recommendations are included in Appendix $C$ of this report.

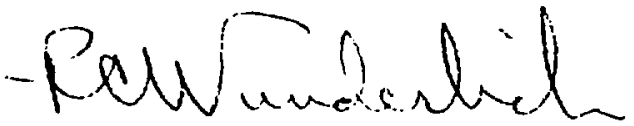

R. C. Wunderlich 


\section{FOREWORD}

Documents are being submitted to the Salt Repository Project Office (SRPO) of the U.S. Department of Energy (DOE) by Battelle Memorial Institute's Office of Nuclear Waste Isolation (ONWI), by Golder Associates, Inc., arij by other contractors to satisfy milestones of the Salt Repository Project of the Civilian Radioactive Waste Management Program. Some of these documents are being reviewed by multidisciplinary groups of peers to ensure DOE of their adequacy and credibility. Adequacy of documents refers to their ability to meet the requirements of the U.S. Environmental Protection Agency and the U.S. Nuclear Regulatory Commission, as enunciated in 40 CFR Part 191 and 10 CFR Part 60, respectively, as well as those of the Nuclear Waste Policy Act of 1982. Credibility of documents refers to the validity of the assumptions, methods, and conclusions, as well as to the completeness of coverage.

Since late 1982, Argonne National Laboratory has been under contract to DOE to conduct multidisciplinary peer reviews of program plans and reports covering research and development activities related to siting and constructing a mined repository in salt for high-level radioactive waste. This report summarizes Argonne's review of a March 1985 draft report by Golder Associates entitled Draft Test Plan for In Situ Testing in an Exploratory Shaft in Salt.

Argonne was requested by DOE to review the Golder Associates report on March 19, 1985 (see App. A). The review procedure involved obtaining written comments on the report from 17 extramural and eight Argonne experts in relevant research areas. The Argonne core peer review staff met at Argonne on May 8, 1985, and reviewer comments were integrated into this report by the review session chairman, with the assistance of Argonne's core peer review staff. Panelists did not contact ONWI personnel, and none of the panelists have been involved in any programs sponsored by DOE or directed by ONWI such that their participation in the review could be construed as a conflict of interest. All of the peer review panelists were asked whether they concur in the way in which their comments, where incorporated, are represented in this report (see App. B). A draft of this report was sent to SRPO on May 31, 1985. Action statements based on Golder's response to this review report are presented in App. C. 


\section{PREVIOUSLY PUBLISHED REPORTS IN THE SERIES}

\section{"RADIOACTIVE WASTE ISOLATION IN SALT"}

ANL/EES-TM-242 Peer Review of the Office of Nuclear Waste Isolation's Geochemical Program Plan (Feb. 1984)

ANL/EES-TM-243 Peer Review of the Office of Nuclear Waste Isolation's Socioeconomic Program Plan (Feb. 1984) (revised July 1984)

ANL/EES-TM-246 Peer Review of the Office of Nuclear Waste Isolation's Plans for Repository Performance Assessment (May 1984)

ANL/EES-TM-254 Peer Review of the Office of Nuclear Waste Isolation's Reports on Preferred Repository Sites within the Palo Duro Basin, Texas (June 1984)

ANL/EES/TM-256 Special Advisory Report on the Status of the Office of Nuclear Waste Isolation's Plans for Repository Performance Assessment (Oct. 1983)

ANL/EES-TM-258 Peer Review of the Office of Nuclear Waste Isolation's Plan to Decommission and Reclaim Exploratory Shafts and Related Facilities (July 1984)

ANL/EES-TM-259 Peer Review of the Office of Nuclear Waste Isolation's Final Report on the Organic Geochemistry of Deep Groundwaters from the Palo Duro Basin, Texas (Aug. 1984)

ANL/EES-TM-260 Peer Review of the Texas Bureau of Economic Geology's Report on the Petrographic, Stratigraphic, and Structural Evidence for Dissolution of Upper Permian Bedded Salt, Texas Panhandle (Aug. 1984)

ANL/EES-TM-261 Peer Review of the Office of Nuclear Waste Isolation's Report on Functional Design Criteria for a Repository for High-Level Radioactive Waste (Aug. 1984)

ANL/EES-TM-262 Peer Review of the D'Appolonia Report on Schematic Designs for Penetration Seals for a Repository in the Permian Basin, Texas (Sept. 1984)

ANL/EES-TM-263 Peer Review of the Office of Nuclear Waste Isolation's Report on Multifactor Life Testing of Waste Package Materials (Sept. 1984)

ANL/ES-147 Rationale and Methodology for Argonne-Conducted Reviews of Site Characterization Programs (July 1985) 


\section{PREVIOUSLY PUBLISHED REPORTS IN THE SERIES}

"RADIOACTIVE WASTE ISOLATION IN SALT" (Cont'd)

ANL/EES-TM-290 Geochemistry of Brine in Rock Salt in Temperature Gradients and Gamma-Radiation Fields -- A Selective Annotated Bibliography (July 1985)

ANL/EES-TM-292 Peer Review of Westinghouse Electric Corporation's Report on Reference Conceptual Designs for a Repository Waste Package (Oct. 1985)

ANL/EES-TM-316 Peer Review of the Office of Nuclear Waste Isolation's Draft Report on an Issues Hierarchy and Data Needs for Site Characterization (Dec. 1986)

ANL/EES-TM-319 Peer Review of the Office of Nuclear Waste Isolation's Draft Report on a Multifactor Test Design to Investigate Uniform Corrosion of Low-Carbon Steel (Jan. 1987) 


\section{CONTENTS}

PEER REVIEW PANEL MEMEERS . . . . . . . . . . . . . . . . . . .

1 INTRODUCTION $\ldots \ldots \ldots \ldots \ldots \ldots \ldots \ldots \ldots \ldots \ldots \ldots \ldots \ldots \ldots \ldots \ldots \ldots \ldots \ldots$

2 GENERAL COMMENTS .............................. 4

2.1 Definition and Use of the Term "In Situ"................... 4

2.2 Technical Soundness $\ldots \ldots \ldots \ldots \ldots \ldots \ldots \ldots \ldots \ldots \ldots \ldots \ldots \ldots \ldots \ldots \ldots$

2.3 Internal Consistency $\ldots \ldots \ldots \ldots \ldots \ldots \ldots \ldots \ldots \ldots \ldots \ldots \ldots \ldots \ldots \ldots \ldots \ldots$

2.4 Reasonableness of the Durations of the Tests .................

2.5 Information Needed for the Site Characterization Plan ............. 2.5.1 Tests Using Radioactive Materiais .....................

2.5.2 Tests Affecting Isolation of Wastes $\ldots \ldots \ldots \ldots \ldots \ldots \ldots \ldots \ldots$

2.5.3 Other Requirements ..........................

2.6 Use of Previous Testing Experience $\ldots \ldots \ldots \ldots \ldots \ldots \ldots \ldots \ldots \ldots \ldots \ldots \ldots$

2.7 Mechanjeal Properties of Salt Rocks ........................

2.8 Bedded versus Domal Salt $\ldots \ldots \ldots \ldots \ldots \ldots \ldots \ldots \ldots \ldots \ldots \ldots \ldots \ldots \ldots \ldots$

2.9 Consolidation Behavior of Crushed Salt ......................

2.10 Rationale for Test Selection ..........................

2.11 Data Requirements for Model Validation ....................



3 TECHNICAL PROBLEMS $\ldots \ldots \ldots \ldots \ldots \ldots \ldots \ldots \ldots \ldots \ldots \ldots \ldots \ldots \ldots \ldots \ldots \ldots \ldots \ldots$

$3.1 \quad$ Geology $\ldots \ldots \ldots \ldots \ldots \ldots \ldots \ldots \ldots \ldots \ldots \ldots \ldots \ldots \ldots \ldots \ldots \ldots \ldots \ldots \ldots \ldots \ldots \ldots \ldots . . . \ldots$

3.1.1 Geophysical Well Logging $\ldots \ldots \ldots \ldots \ldots \ldots \ldots \ldots \ldots \ldots \ldots \ldots \ldots \ldots$

3.1.2 Underground Gravity Surveys $\ldots \ldots \ldots \ldots \ldots \ldots \ldots \ldots \ldots \ldots \ldots \ldots \ldots$

3.1.3 Radar Probing $\ldots \ldots \ldots \ldots \ldots \ldots \ldots \ldots \ldots \ldots \ldots \ldots \ldots \ldots \ldots \ldots \ldots \ldots . \ldots \ldots$

3.1.4 Seismic Surveys $\ldots \ldots \ldots \ldots \ldots \ldots \ldots \ldots \ldots \ldots \ldots \ldots \ldots \ldots \ldots \ldots \ldots \ldots$

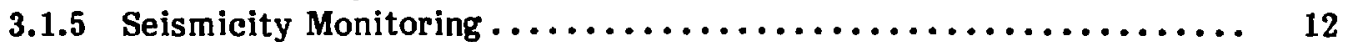

3.1.6 Block Sampling $\ldots \ldots \ldots \ldots \ldots \ldots \ldots \ldots \ldots \ldots \ldots \ldots \ldots \ldots \ldots \ldots \ldots \ldots$

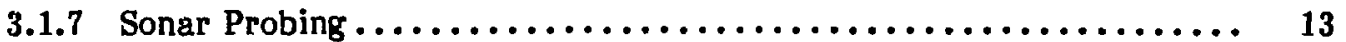

3.2 Geomechanics $\ldots \ldots \ldots \ldots \ldots \ldots \ldots \ldots \ldots \ldots \ldots \ldots \ldots \ldots \ldots \ldots \ldots \ldots \ldots \ldots \ldots \ldots 14$

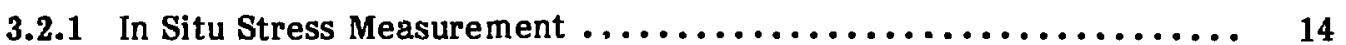

3.2.2 Torsional Shear Test $\ldots \ldots \ldots \ldots \ldots \ldots \ldots \ldots \ldots \ldots \ldots \ldots \ldots \ldots \ldots \ldots \ldots$

3.2.3 Mine-By Test $\ldots \ldots \ldots \ldots \ldots \ldots \ldots \ldots \ldots \ldots \ldots \ldots \ldots \ldots \ldots \ldots \ldots \ldots \ldots$

3.2.4 Rock-Bolt Pullout Test.......................... 15

3.2 .5 Block Test $\ldots \ldots \ldots \ldots \ldots \ldots \ldots \ldots \ldots \ldots \ldots \ldots \ldots \ldots \ldots \ldots \ldots \ldots \ldots$

3.3 Thermomechanics $\ldots \ldots \ldots \ldots \ldots \ldots \ldots \ldots \ldots \ldots \ldots \ldots \ldots \ldots \ldots \ldots \ldots \ldots \ldots \ldots$

3.3.1 Canister-Scale Heater Test ...................... 17 


\section{CONTENTS (Cont'd)}

3.3.2 $\quad$ Room-Scale Heater Test $\ldots \ldots \ldots \ldots \ldots \ldots \ldots \ldots \ldots \ldots \ldots \ldots \ldots, 17$

3.3.3 Room-Backfill Performance Test ...................... 18



3.4.1 Single-Borehole Hydraulic Conductivity Test $\ldots \ldots \ldots \ldots \ldots \ldots \ldots, 20$

3.4.2 Cross-Hole Hydraulic Conductivity Test $\ldots \ldots \ldots \ldots \ldots \ldots \ldots \ldots, 21$

3.4.3 Cross-Hole Tracer Test $\ldots \ldots \ldots \ldots \ldots \ldots \ldots \ldots \ldots \ldots \ldots \ldots \ldots, 21$

3.4.4 Tracer Diffusion Test $\ldots \ldots \ldots \ldots \ldots \ldots \ldots \ldots \ldots \ldots \ldots \ldots \ldots, 22$

3.4.5 Borehole-Seal Performance Test $\ldots \ldots \ldots \ldots \ldots \ldots \ldots \ldots \ldots \ldots, 23$

3.4.6 Room-Seal Performance Test ........................ 23

3.4.7 Brine Migration Test.............................. 24

3.4.8 Grout Injection Tests $\ldots \ldots \ldots \ldots \ldots \ldots \ldots \ldots \ldots \ldots \ldots \ldots \ldots \ldots, 25$

3.5 Geochemistry ..................................... 25

3.5.1 Formation Fluid Sampling $\ldots \ldots \ldots \ldots \ldots \ldots \ldots \ldots \ldots \ldots \ldots, 25$

3.5.2 Characterization of Sample Blocks of Rock Salt ............ 26

4 REGULATORY CONSIDERATIONS $\ldots \ldots \ldots \ldots \ldots \ldots \ldots \ldots \ldots \ldots \ldots \ldots \ldots, 29$

5 PAGE-BY-PAGE COMMENTARY $\ldots \ldots \ldots \ldots \ldots \ldots \ldots \ldots \ldots \ldots \ldots \ldots \ldots, 35$

REFERENCES $\ldots \ldots \ldots \ldots \ldots \ldots \ldots \ldots \ldots \ldots \ldots \ldots \ldots \ldots \ldots \ldots \ldots \ldots \ldots \ldots, 62$

APPINDIX A: U.S. Department of Energy Letter Requesting Peer Review ..... 65

APPENDIX B: Concurrence Sheet $\ldots \ldots \ldots \ldots \ldots \ldots \ldots \ldots \ldots \ldots \ldots \ldots \ldots \ldots \ldots, 69$

APPENDIX C: Action to Be Taken on the Argonne Peer Review Panel



APPENDIX D: Credentials of Peer Review Panel Members $\ldots \ldots \ldots \ldots \ldots \ldots \ldots \ldots$. 139

FIGURES

1 Suggested Revision to the Underground Layout of the Exploratory Shaft Facility $. . \ldots \ldots \ldots \ldots \ldots \ldots \ldots \ldots \ldots \ldots \ldots \ldots \ldots \ldots, 16$

2 Proposed Layout for Room-Backfill Performance Test $\ldots \ldots \ldots \ldots \ldots \ldots \ldots \ldots$ 19

3 Integrated Approach to Determining Site-Specific Brine Inflow

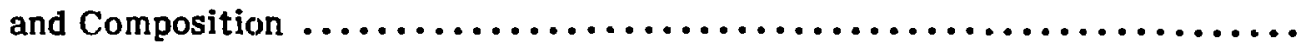




\section{TABLES}

$1 \quad$ Application of Individual Logging Methods $\ldots \ldots \ldots \ldots \ldots \ldots \ldots \ldots \ldots \ldots, 10$

$2 \quad$ Borehole Conditions under Which Logging Methods will Operate $\ldots \ldots \ldots \ldots 11$

C.1 Information to Be Interpreted from Individual Logging Methods ......... 79

C.2 Borehole Conditions Appropriate for Individual Logging Methods ......... 80

A microfiche copy of the following unpublished report is attached to the inside back cover of this report: Draft Test Plan for In Situ Testing in an Exploratory Shaft in Salt, prepared by Golder Associates, Inc., for Office of Nuclear Waste Isolation, Battelle Memorial Institute, Columbus, Ohio (March 1985). 


\section{PEER REVIEW PANEL MEMBERS}

Dr. Gregory B. Baecher

Massachusetts Institute of Technology

Cambridge, Massachusetts

Mr. Richard M. Bateman

VIZILOG, INC.

Houston, Texas

Dr. Barry H.G. Brady

Vermont South, Victoria

Australia

Dr. Lawrence W. Braile

Department of Geoseiences

Purdue University

West Lafayette, Indiana

Dr. Joseph S. Busch

Raymond Kaiser Engineers

Oakland, California

*Dr. John D. Ditmars

Engineering Geosciences Group

Energy and Environmental Systems

Division

Argonne National Laboratory

Dr. Charles H. Dowding

Department of Civil Engineering

Northwestern University

Evanston, Illinois

Dr. John B. Farr

Houston, Texas

$\ddagger_{\text {Mr. David F. Fenster }}$

Roy F. Weston, Inc.

Washington, D.C.

$\S_{\text {Mr. Douglas F. Hambley }}$

Engineering Geoscierces Group

Energy and Environmental Systems

Division

Argonne National Laboratory
Dr. Timothy R. Harper

GEOSPHERE, LTD.

Virginia Water, Surrey

United Kingdom

${ }^{+}$Dr. Wyman Harrison

Associate Director for

Engineering Geosciences

Energy and Environmental Systems

Division

Argonne National Laboratory

Dr. Allen W. Hatheway

Department of Geological

Engineering

University of Missouri at Rolla

Rolla, Missouri

*Ms. Amy B. Hull

Engineering Geosciences Group

Energy and Environmental Systems Division

Argonne National Laboratory

Mr. Charles H. Jacoby

Jacoby and Associates

Waxhaw, North Carolina

Dr. G. Randy Keller

Department of Geological jciences

University of Texas at El Paso

El Paso, Texas

Dr. Darrell I. Leap

Department of Geosciences

Purdue University

West Lafayette, Indiana

Mr. Dennis Z. Mraz

Mraz Project Consuitants, Ltd.

Saskatoon, Saskatchewan

Canada 


\section{PEER REVIEW PANEL MEMBERS (Cont'd)}

\author{
Dr. Shlomo P. Neuman \\ College of Earth Sciences \\ Department of Hydrology and \\ Water Resources \\ University of Arizona \\ Tucson, Arizona \\ *Dr. Robert A. Paddock \\ Engineering Geoseiences Group \\ Energy and Environmental Systems \\ Division \\ Argonne National Laboratory \\ *Dr. Donald M. Rote \\ Engineering Geosciences Group \\ Energy and Environmental Systems \\ Division \\ Argonne National Laboratory
}

\author{
Dr. James E. Russell \\ Petroleum Engineering Department \\ Texas A\&M University \\ College Station, Texas \\ *Dr. Martin G. Seitz \\ Chemical Technology Division \\ Argonne National Laboratory \\ Mr. John C. Stormont \\ Waste Management Technology \\ Department \\ Sandia National Laboratories \\ Albuquerque, New Mexico \\ Dr. Robert R. Unterberger \\ Department of Geophysics \\ Texas A\&M University \\ College Station, Texas
}

The credentials of the panel members are sum marized in App. D.

*Member of core peer review staff.

${ }^{\ddagger}$ Former member of core peer review staff.

$\$_{\text {Review session chairman and membei of core peer review staff. }}$

${ }^{+}$Review panel chairman and member of core peer review staff. 


\section{ACKNOWLEDGMENTS}

The authors acknowledge the assistance of L. Williams, formerly of the Engineering Geosciences Group staff. The authors also acknowledge B. Salbego, E. Bremner, E. Gawenda, L. Kickels, J. Parnell, B. Rogowski, and R. Walker for wordprocessing services and $M$. Warren and $F$. Bennett for editorial services. 


\section{RADIOACTIVE WASTE ISOLATION IN SALT:}

\section{PEER REVIEW OF THE GOLDER ASSOCIATES DRAFT TEST PLAN FOR IN SITU TESTING IN AN EXPLORATORY SHAFT IN SALT}

by

D.F. Hambley, D.Z. Mraz, R.R. Unterberger, J.C. Stormont, S.P. Neuman, J.E. Russell, C.H. Jacoby, A.B. Hull, B.H.G. Brady, J.D. Ditmars, D.M. Rote, J.B. Farr, D.I. Leap, T.R. Harper, W. Harrison, G.B. Baecher, M.G. Seitz, C.H. Dowding, D.F. Fenster, R.A. Paddock, L.W. Braile, G.R. Keller, J.S. Busch, R.M. Bataman, and A.W. Hatheway

\section{SUMMARY OF RECOMMENDATIONS}

This report documents the peer review conducted by Argonne National Laboratory of a document entitled Draft Test Plan for In Situ Testing in an Exploratory Shaft in Salt, prepared for Battelle Memorial Institute's Office of Nuclear Waste lsolation by Golder Associates, Inc. In general, the peer review panelists found the test plan to be technically sound, although some deficiencies were identified. The following recommendations for improving the test plan were abstracted from the body of this review report.

\section{GENERAL COMMENTS}

1. Define the term "in situ" where it first occurs. In addition, consider changing the title to Subsurface-Based Test Plan or Draft Plan for Testing in in Exploratory Shaft Facility in Salt.

2. Give more consideration to the urique mechanical and thermomechanical behaviors and properties of salt, especially the rate of time-dependent deformation and mechanisms of fluid migration. Revise the test descriptions accordingly.

3. Show more explicitly how the tests described in App. $C$ were selected, given the test methodology developed in Sec. 4 and Tables B-1 and B-2.

4. Although presenting the details of individual tests is not within the scope of the test plan, indicate that subsequent detailed test plans will consider the cost and technical trade-offs among different types of tests, the number of tests to be conducted, and the confidence with which performance can be predicted.

5. Consider eliminating long horizontal exploration holes, as they could interfere with the ability of the repository to isolate waste. 
6. Give more consideration to the differences in mechanical and hydrological behavior of domal and bedded salt, and to the effect these differences could have on the evaluation of test results.

7. Indicate that the tests selected will ensure that data needs for model development and validation will be satisfied.

\section{TECHNICAL COMMENTS}

8. Revise Tables $\mathrm{C}-1$ and $\mathrm{C}-2$, which concern well logging, as suggested in this report.

9. Expand the discussion of radar probing to include very high frequency and microwave pulse radars. The impulse radar described in the test plan has its place but is limited to approximately $50 \mathrm{ft}$ or less of penetration.

10. Add a section on sonar probing.

11. Reexamine the usefulness of hydrofracturing for determining the stress field in salt rocks, and consider eliminating such tests from the test plan.

12. Consider revising the testing layout so that the mine-by and room-scale heater tests could be conducted concurrently. This strategy would lengthen the duration of both tests.

13. Add a block test having a configuration identical to the canisterscale heater test, but have the test conducted at ambient conditions.

14. Revise the rock-bolt pullout test so that the bolts to be tested are the ones that will be used in the repository.

15. Consider revising the room-backfill performance test so that creep closure assists in compacting the backfill.

16. Improve the descriptions of the borehole and room-seal performance tests.

17. Reevaluate the utility of the geohydrologic tests, especially the tracer diffusion test, in light of salt's extremely low permeability.

18. Consider using the approach outlined in this report for determining site-specific brine inflow and composition.

19. Consider taking block samples of salt for geochemical characterization purposes. 


\section{INTRODUCTION}

The document prepared for Battelle Memorial Institute's Office of Nuclear Waste Isolation (ONWI) by Golder Associates, Inc., entitled Draft Test Plan for In Situ Testing in an Exploratory Shaft in Salt, presents a generic program of underground tests to be carried out in an exploratory shaft facility as part of a site characterization program for a repository in salt for high-level radioactive waste. The peer review of the test plan was conducted by Argonne National Laboratory and involved obtaining written critiques of the document : im 17 extramural and eight Argonne experts in relevant research areas. The eigh $\therefore$ onne core peer review staff and one extramural reviewer, Dennis $Z$. Mraz, met at Argonre on May 8, 1985, to review and discuss all of the written comments, after which the review session chairman drafted the present report. Although no specific guidance was provided to Argonne by the U.S. Department of Energy (DOE) on how to conduct the review, DOE's Salt Repository Project Office requested that certain items be addressed (see App. A). 


\section{GENERAL COMMENTS}

\subsection{DEFINITION AND USE OF THE TERM "IN SITU"}

Even though definitions are given in the Glossary for "in situ," "in situ tests," and "in situ test program," each of these terms should also be defined in the text the first time it is used. The failure to do this resulted in much confusion on the part of the reviewers, particularly with regard to the scope of the document and the types and locations of the tests to be included.

The use of the term "in situ test plan" has some precedent in the Salt Repository Project (SRP). However, a better title for the report might have been Subsurface-Based Test Plan, which would be parallel to the title of the companion document entitled Surface-Based Test Plan. Another alternative title is Draft Plan for Testing in an Exploratory Shaft Facility in Salt. Either suggested title would reduce the confusion concerning the scope of the test plan. A further difficulty with the present title is that the acronym for in situ test plan -- ISTP -- is the same as that used by the U.S. Nuclear Regulatory Commission (NRC) for its issue-oriented site technical positions.

\subsection{TECHNICAL SOUNDNESS}

For the most part, the material presented in the test plan is technically sound, but technical difficulties were identified regarding several of the proposed tests (see Sec. 3 of this report). Many of these difficulties can be traced to the unique mechanical behavior of salt, some aspects of which remain rather controversial. Two of the more controversial ones are the rate of time-dependent deformation around openings in salt formations and mechanisms of fluid migration.

The test plan does not address the need to evaluate the effect of gamma radiation on the salt immediately surrounding the waste containers. However, since Sec. $113(\mathrm{c})(2)(\mathrm{A})$ of the Nuclear Waste Policy Act of 1982 (NWPA) prohibits the ". . use [of] any radioactive material at a candidate site unless the Commission [NRC] concurs that such use is necessary to provide data for the preparation [1] of the required environmental reports and [2] an application for a construction authorization for a repository at such candidate site," it is understandable that such testing was overlooked. Nevertheless, pertinent laboratory tests should be mentioned, as should the fact that radioactive sources will be used at the Waste Isolation Pilot Plant (WIPP) site in New Mexico and that they are being used at the Asse mine in the Federal Republic of Germany.

Another important omission is the lack of waste package corrosion testing. Although it would admittedly be difficult to obtain meaningful data regarding corrosion rates in the short time available, some insight might be gained as to the operative corrosion mechanisms. 


\subsection{INTERNAL CONSISTENCY}

The test plan is generally well written. In addition, the structure of the report, with the bulk of the analyses and test descriptions contained in the appendixes, shows careful thought and organization. One minor inconsistency occurs between the test descriptions in Sec. 5 and those in App. C; that is, the uniqueness of salt's geomechanical and geohydrologic properties is properly recognized in App. C, but not in Sec. 5. The descriptions in Sec. 5 should also be more explicit about the effectiveness of the various tests in salt. Furthermore, although an elaborate procedure for test selection is established in Sec. 4 and App. B, the rationale for selecting the tests discussed in App. C is not given.

\subsection{REASONABLENESS OF THE DURATIONS OF THE TESTS}

The following tests may not generate meaningful data in the short times proposed: (1) mine-by test, (2) rooin-scale heater test, (3) room-backfill performance test, and (4) brine migration test. Suggested changes are discussed in Sec. 3 of this report. Even though NWPA imposes a very tight schedule on site characterization activities, testing will continue after the construction authorization application is submitted to NRC.

\subsection{INFORMATION NEEDED FOR THE SITE CHARACTERIZATION PLAN}

Several of the tests proposed in the test plan have no precedent, except in the limited testing already carried out for various programs related to radioactive waste storage. In those cases, alternative test methods and data analyses do not exist. Just interpreting the data from the tests may prove difficult.

The test plan, which is one of the documents supporting the site characterization plan (SCP), must address all SCP information needs for which subsurface testing is appropriate. The following requirements, as listed in Secs. 8.3.1 and 8.3.2 of U.S. Department of Energy (1985), are adequately addressed:

- Why the test study or analysis is planned, and what data or information will be obtained.

- How the results will be used to resolve specific information needs.

- What methods, techniques, and data analyses will be used.

- Which significant alternative test methods and data analyses will be considered.

Requirements in U.S. Department of Energy (1985) that are not addressed are discussed in Secs. 2.5.1-2.5.3. 


\subsubsection{Tests Using Radioactive Materials}

used:

The following tests would provide more information if radioactive sources were

- Brine migration test.

- Canister-scale heater test.

- Room-backfill performance test.

- Tracer diffusion test.

- Borehole-seal performance test.

- Room-seal performance test.

However, as mentioned in Sec. 2.2 of this report, NWPA prohibits the use of radioactive sources unless NRC concurs that their use is necessary. Although tests at the WIPP site and at the Asse mine using radioactive sources will provide some data, the behavior of salt is rather site specific. Therefore, such data will only roughly approximate the behavior of salt at candidate sites.

\subsubsection{Tests Affecting Isolation of Wastes}

Two activities were identified as potentially interfering with the site's ability to isolate waste, namely: hydraulic fracturing (see Sec. C.2.J of the test plan) and horizontal exploratory drill holes at the repository horizon (see Sec. C.1.2 of the test plan). Hydraulic fracturing is of little value for measuring stress in salt. Furthermore, if care is not taken to ensure that the injection pressure in the borehole hydrologic tests is kept low, hydraulic fracturing could occur inadvertently. Finally, if the induced cracks are invariably horizontal, hydrofracturing in vertical boreholes will at best only provide the magnitude and direction of the minimum principal stress.

Horizontal holes driven from the exploratory shaft facility could constitute a preferential pathway for radionuclide migration because they are difficult to seal. Such holes will be particularly disadvantageous if the exploratory shaft facility does not become part of the repository.

\subsubsection{Other Requirements}

Additional information needs inadequately addressed in the test plan include: (1) special instrumentation requirements necessitated by the chemically and thermally hostile environment; (2) follow-up testing, especially with respect to the need to revise tests as a result of data analysis; and (3) corrosion-related tests that could be performed underground. 


\subsection{USE OF PREVIOUS TESTING EXPERIENCE}

Although Sec. 2.2 of the test plan shows that the authors are aware of the findings of previous test programs, more has been learned than is indicated. In the case of the WIPP site, for example, the stated information is rather out of date (see Stormont et al., 1984). Section 2.2 should also discuss the unresolved issues raised in each test program, as well as the way those issues will be affected by subsequent site characterization.

\subsection{MECHANICAL PROPERTIES OF SALT ROCKS}

Baar (1977) and others have shown that salt will flow when subjected to stress differences as low as 150 psi under underground loading conditions. Therefore, under such conditions, the elastic properties used in standard rock mechanics calculations are mostly meaningless for salt. For example, standard rock mechanics parameters exhibit the following behavior in salt:

- Compressive strength varies as a function of the rate of loading.

- Young's modulus and Poisson's ratio vary as functions of the rate of loading. At loading rates characteristic of the repository design, the entire strain will come from the plastic flow component. (In a perfectly plastic material, Poisson's ratio is 0.5 by definition.)

- Shear and deformation moduli vary as functions of the rate of loading.

Traditional creep tests on salt rocks also fail to address all of the issues.

In Sec. C. 2 of the test plan, the authors recognize that the above parameters take singular values only in nonsalt rocks, but this recognition is not consistently maintained throughout the test plan. Moreover, the time- and temperature-dependent creep behavior of salt rocks is only vaguely referred to.

\subsection{BEDDED VERSUS DOMAL SALT}

The test plan appears to treat bedded and domal salt as similar entities. Although both rock types are of sedimentary origin, the similarity ends there. Bedded salt contains clays and other evaporite rocks such as anhydrite and potash. The subhorizontal bedding planes are therefore planes of weakness. Domal salt of the Gulf Coast region, on the other hand, is remarkably pure halite, with only minor amounts of anhydrite (<3\%). This salt is coarsely crystalline, with the original sedimentary layers recrystallized, folded, or otherwise deformed. The folding is characteristically isoclinal, with axial planes nearly vertical (Halbouty, 1979, p. 44). The margins of domes contain shears, gas pockets, and other inhomogeneities. Such features affect the utility of geophysical surveys. Indeed, the differences between bedded and domal salt may require different geophysical surveying methods. 


\subsection{CONSOLIDATION BEHAVIOR OF CRUSHED SALT}

Although replicating in situ loading conditions in the laboratory is difficult, predictions of salt behavior based on the results of laboratory tests might provide a rough estimate of actual deformation. In particular, a relatively extensive laboratory program will probatly be needed to explore the consolidation behavior of crushed salt, about which little is known. Thus, tests that depend on the consolidation of salt backfill for their effectiveness (i.e., room-backfill performance test [Sec. C.3.4], borehole-seal performance test [Sec. C.4.5], and room-seal performance test [Sec. C.4.6]) may not be effective if the expected compaction does not occur.

\subsection{RATIONALE FOR TEST SELECTION}

Although an elaborate procedure is established in Sec. 4 and Tables B-1 and B-2 of the test plan for determining which tests need to be performed to satisfy regulatory requirements, the rationale for selecting the tests discussed in App. $\mathrm{C}$ is not given.

\subsection{DATA REQUIREMENTS FOR MODEL VALIDATION}

Claims are made throughout the test plan that data will be collected to support model validation activities. In most cases, however, little real understanding is evident of the data requirements for validation or of the possibility that validation may be impossible.

\subsection{DATA ACQUISITION ACTIVITIES}

Plans for data acquisition are generally handled in the abstract. They do not consider that measurements in the exploratory shaft facility can sometimes be guided by or compared with measurements outside the shait or in laboratory settings (e.g., hydrogeological and geochemical testing). Also, the links between data acquisition, predictions, and specifications for additional data acquisition seem to be ignored. 


\section{TECHNICAL PROBLEMS}

The test plan is generally well coriceived and well presented. Although the tests considered in Secs. 3.1-3.5 of this report are either inadequately or inappropriately discussed in the test plan, the problems are not major. The tests are discussed in the order in which they appear in the test plan.

\subsection{GEOLOGY}

\subsubsection{Geophysical Well Logging}

Table $\mathrm{C}-1$ contains several errors of omission. Table 1 incorporates reviewer modifications to this table. Table 2 is a similarly corrected version of Table C-2. Note that conventional resistivity-measuring devices, with the sole exception of induction devices, require a hole filled with mud or other liquid. Also, gamma-gamma tools do not provide reliable measurements through steel casings. Contrary to the statement in Sec. C.1.3.2.1, horizontal logging devices are used by several companies.

One or more boreholes and pilot holes should be drilled before sinking the shaft, and geophysical logs of all types should be available from those holes. Borehole logs will be analyzed to map the geological structure, that is, the spatial configuration of identical or time-equivalent rock units.

\subsubsection{Underground Gravity Surveys}

This section of the test plan should be retitled Gravity Surveys. Also, data reduction procedures should be discussed in more detail. Underground measurements are straightforward, but the corrections required to produce anomaly values are not. Borehole gravity measurement, which is potentially a very powerful technique, merits more discussion.

Detailed gravity surveys (sometimes called "microgravity surveys") could be extremely valuable in repositories sited in salt domes or bedded salt swhere the density contrast between the salt and surrounding rocks is quite high.

Panelists disagreed with the statement that gravity would only be useful in reconnaissance studies. Also, it is not true that gravity contrasts will not be detectable if the depth to the top of a feature is "much greater" (not defined) than its diameter. Detectability depends on the magnitude of the contrast as well as on the depth. The discussion tends to belittle the value of gravity surveys in a way that is not justified for shafts and drif ts in salt.

The authors recognize that borehole gravity surveys are to be used in conjunction with measurements made on drift floors. They should clarify whether they are also considering boreholes external to the im mediate repository workings. 


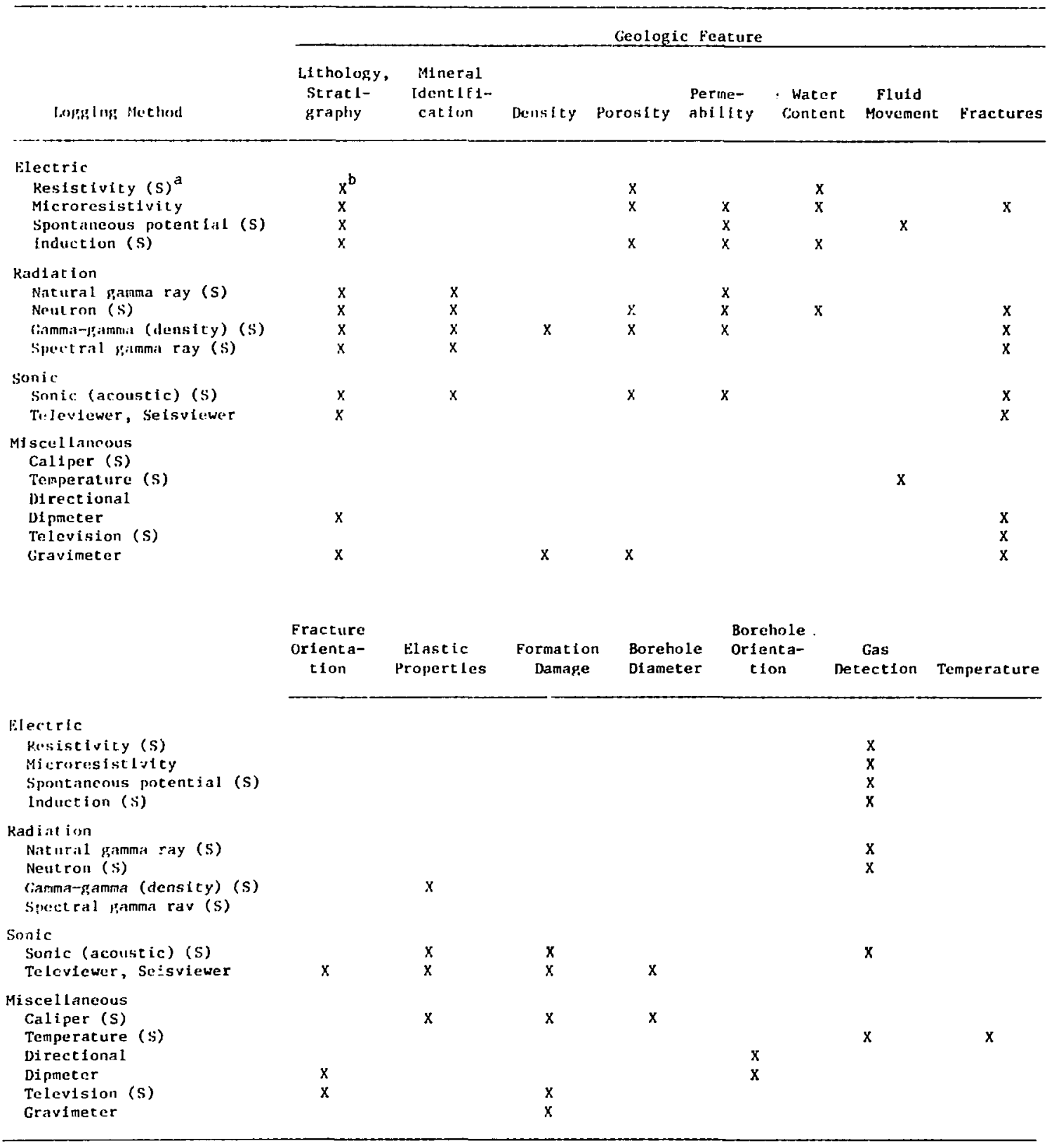

$a_{S}=$ tool comes in diameters of $3 \mathrm{ln}$. or less.

$\mathbf{b}_{\mathrm{X}}=$ applicablitty for spectfic purpose. 
TABLE 2 Borehole Conditions under Which Logging Methods Will Operate

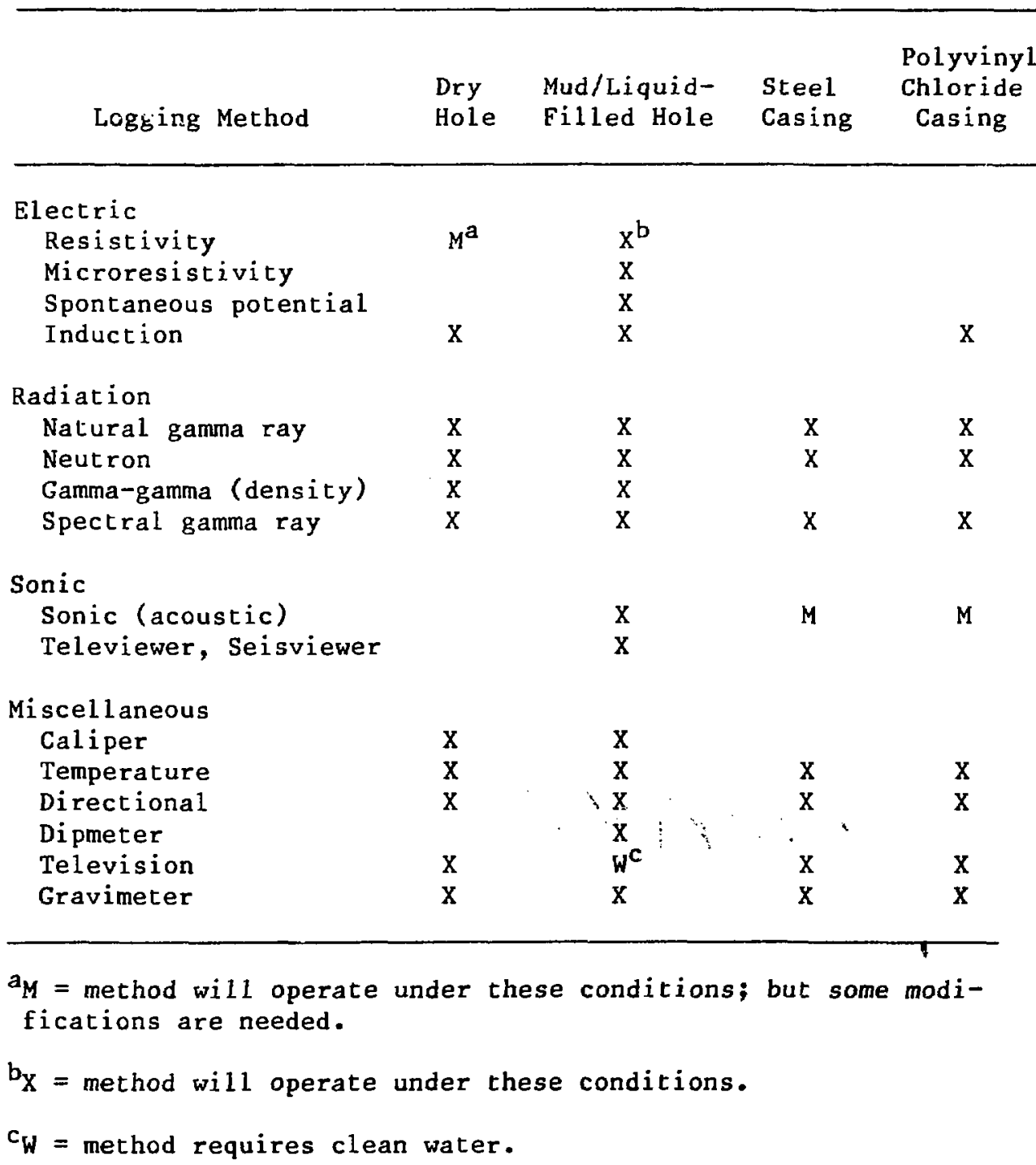

\subsubsection{Radar Probing}

The account of radar probing is incomplete. The authors apparently have access to information regarding short-range, high-resolution radar equipment. This very short range instrument should be useful for ranges up to $50 \mathrm{ft}$ in salt. The problems are high frequency, low power, and a broadband antenna. Nevertheless, this type of radar could still be useful.

However, the authors are apparently less familiar with the many tests that have been carried out in salt mines in both North America and Europe using very high 
frequency pulse radar (Cook, 1972; Unterberger 19?4, 1980; Nickel, 1980; Thierbach and Mayrhofer, 1980). Ranges of up to several thousand feet were obtained in these studies. For radar to be effective, however, the water content of the salt must be low. If the water content is high enough to interfere with radar probing, sonar could be used (see Sec. 3.1.7 of this report).

No single radar system can do everything. Low-frequency (10-30 MHz) radars are used for long-range, low-resolution tasks, whereas continuous-wave FM radar systems using microwave frequencies $(4300 \mathrm{MHz}$ ) are used for high-resolution work at short range (e.g., for detecting fractures in the rock immediately surrounding a tunnel).

Radar has been used successfully in salt mines for mapping the top and edges of salt domes, detecting discontinuities ahead of mining faces, detecting boreholes in pillars, detecting brine pockets, and detecting stringers of sand and anhydrite (Unterberger, 1974, 1980, 1985). Incorporating such radar-probing systems would enhance the test plan. Furthermore, such probing might reduce requirements for exploratory boreholes. Such boreholes are potentially disruptive to the ability of the repository to isolate waste.

\subsubsection{Seismic Surveys}

Multichannel seismic surveys do not necessarily imply explosive sources. In many instances, hammer-type sources could be used with multichannel recording.

The seismic surveys mentioned in App. C of the test plan appear to be restricted to underground surveys along drifts or in holes drilled from drifts. As a result, the reader is left with the impression that surface-based seismic surveys are not being considered. The text should clarify that they are not mentioned because they are discussed in a companion plan that deals with surface-based testing.

Omitting seismic-reflection profiling that uses the ground surface as a source or receiver location apparently results from interpreting "in situ" to mean within the shaft or drifts. However, surface seismicity monitoring, as opposed to seismic reflection profiling, is referred to in conjunction with in situ monitoring. Also, surface-to-drift and surface-to-borehole electrical measurements are mentioned. Thus, omission of surface seismic and gravity measurements is seemingly inconsistent.

A regional high-resolution seismic survey using state-of-the-art surface-tosurface reflection techniques is absolutely essential for adequate characterization of repository sites. If such surveys are not meant to be covered in the test plan, that fact should be clearly stated.

\subsubsection{Seismicity Monitoring}

The test plan does not appear to distinguish between the monitoring of seismic hazards and the monitoring of seismic events. Monitoring of hazards involves detecting the signals produced by the fine cracking associated with stress relief caused by mining 
activities. Much higher frequencies $(\geq 500 \mathrm{~Hz})$ are used for monitoring of hazards than for monitoring of earthquakes $(0.05-5 \mathrm{~Hz})$. Monitoring for earthquakes cannot take place during repository construction, whereas monitoring of hazards must take place during construction to protect life. As different equipment and different analytical techniques are required for the two monitoring activities, they should be discussed separately.

The test plan states that "geophones and accelerographs will be located at several depths in the repository." The authors should clarify whether they mean at several levels within the proposed repository horizon or at several geologic units intersected at different depths by the exploratory shaft. Section C.1.8.3.1 (page C-40) implies that geophones and accelerographs will be installed only at the proposed repository horizon.

Accelerometers with a broad-band (2-2500 $\mathrm{Hz}$ minimum) response are required to measure microseismic activity (Blake and Leighton, 1970). Also, a network of at least seven geophones is required to locate an event (Blake, 1979).

\subsubsection{Block Sampling}

In several salt mines, blocks exceeding the size designated in the test plan have been obtained through normal blasting and mucking procedures. Further, simple water jets are often more effective in cutting salt than are chain saws, drills, or other mechanical devices, which can crack or otherwise stress the salt. If a roadheader or continuous miner is used, large blocks will not be created. In this case, special samples will have to be cut.

A representative block sample cannot be obtained from the faces or walls of underground openings in salt. The salt will be fractured to a depth of up to $3 \mathrm{ft}$ into the wall, depending on the depth below surface and the type of salt rock. Samples should be taken from large-diameter cores at depths into the wall of $\mathbf{5} \mathrm{ft}$ or more.

\subsubsection{Sonar Probing}

The use of sonar -- a valuable exploration technique in salt -- has been overlooked entirely. Bedded salt usually contains more impurities than domal salt; hence, bedded salt transmits radar poorly if at all. However, the most serious barrier to radar probing of bedded salt is water because of its dipole moment, which is torqued by the electromagnetic wave. The wave loses energy, attenuates, and heats the salt, all of which are unwanted effects. Domes can also be "wet" (e.g., Weeks Island and Belle Isle domes in Louisiana).

Investigators have achieved ranges of $100 \mathrm{ft}$ to $300 \mathrm{ft}$ with sonar in the Belle Isle dome. Under Lake Huron in Canada, 1000-ft ranges have been obtained with sonar. This range represents the maximum effectiveness achieved with current equipment. In any case, sonar can be used in "wet" salt mines for the same purposes that radar is used in "dry" salt mines. 


\subsection{GEOMECHANICS}

The types of tests selected to address geomechanics issues are generally satisfactory, at least as far as the test objectives are concerned. However, more details should be provided regarding test procedures and methods for analyzing data. In addition, the test descriptions in Sec. 5 fail to consider the nonelastic behavior of salt. This failure was rectified to some extent in the more detailed descriptions in App. C.

The relationships should be clearer between geomechanies objectives, which must include waste containment, and the definitions, methods, and limitations of the tests required. In particular:

- Stress gradients (disequilibrium of the stress tensor) and the expected ability to define them are not discussed.

- The behavior of the shaft is potentially relevant to waste containment. Consideration should be given to monitoring displacements associated with shaft construction. For example, inclinometers could be installed and monitored before, during, and after shaft construction.

- How the volume of rock to be modeled will be determined should be discussed.

- How point measurements of stress will be interpreted in terms of the stress values at the boundaries of the model, and the variations in stress values within the model should be discussed.

\subsubsection{In Situ Stress Measurement}

The test plan satisfactorily describes and technically justifies the tests and their objectives, as well as the methods and equipment required. Also, the limitations of the various techniques are recognized. However, the test plan does not always reflect the state of the art as far as measurement techniques.

The value of hydrofracturing may be overstated, especially in view or its admitted limitations and potential problems. Because hydrofracturing is not a proven technique for stress measurement in nonelastic media like salt, its use should be reconsidered. Eliminating it from the testing program may be best.

Because existing models for salt behavior are unsatisfactory, stress-change monitoring will probably be used for model development rather than for model verification. This approach to model development has been used with some success by Mraz and Dusseault (1985). With regard to stress-change monitoring in the immediate vicinity of rooms, the most reliable method is to use grouted flatjacks. They can be aligned to measure horizontal, vertical, or radial stresses. 


\subsubsection{Torsional Shear Test}

Both the data needs addressed by the torsional shear test and the test objectives are proper. However, the test plan correctly notes that using this test to determine the shear strength of discontinuity surfaces is unproven. There are also theoretical difficulties. For example, in any rotational movement, elements along a given radius will have loads corresponding to different points on the peak-residual-resistance curve according to the distance from the center of rotation. This situation could be overcoine by using a thin-walled cylinder of rock as the test specimen, but sample preparation would be difficult.

The test as described should be adequate for determining the residual strength of discontinuity surfaces. The procedure, schedule, equipment requirements, and data reduction are satisfactorily described. However, because this test is not one of the more commonly used tests, references regarding its use (e.g., Sellers, 1974) should be supplied.

\subsubsection{Mine-By Test}

The test plan satisfactorily covers the objectives, technical justification, conceptual design, and procedures to be implemented for the mine-by test. However, the way in which the results of the test are to confirm the validity of the geomechanical model needs to be clarified.

Although the technical details concerning the proposed test are satisfactory, three months may not be enough time to obtain meaningful results. Since the short time period was dictated by the need to carry out the room-scale heater test, the facility layout should be modified as shown in Fig. 1 so that both tests could be conducted concurrently. This change would add several months to the duration of each test, thereby significantly increasing the probability of obtaining meaningful data.

\subsubsection{Rock-Bolt Pullout Test}

The description of the rock-bolt pullout test is vague about the type of bolts to be used. In any case, the bolts installed and tested should be the same as those to be used in the repository. The performance of rock bolts in salt will depend in part on the moisture present.

In selecting the types of bolts to use, the test designers should consider that bolts with mechanical anchors are useful for periods of less than one year. Friction-type bolts, such as Split Sets or Swellex, are useful for periods of 5-10 years. (The equipment shown in Fig. C-6 of the test plan would require considerable modification if friction-type bolts were used.) Finally, bolts for "permanent" use (>10 years) should have grouted anchors, corrosion-resistant construction, and yieldable base plates. 


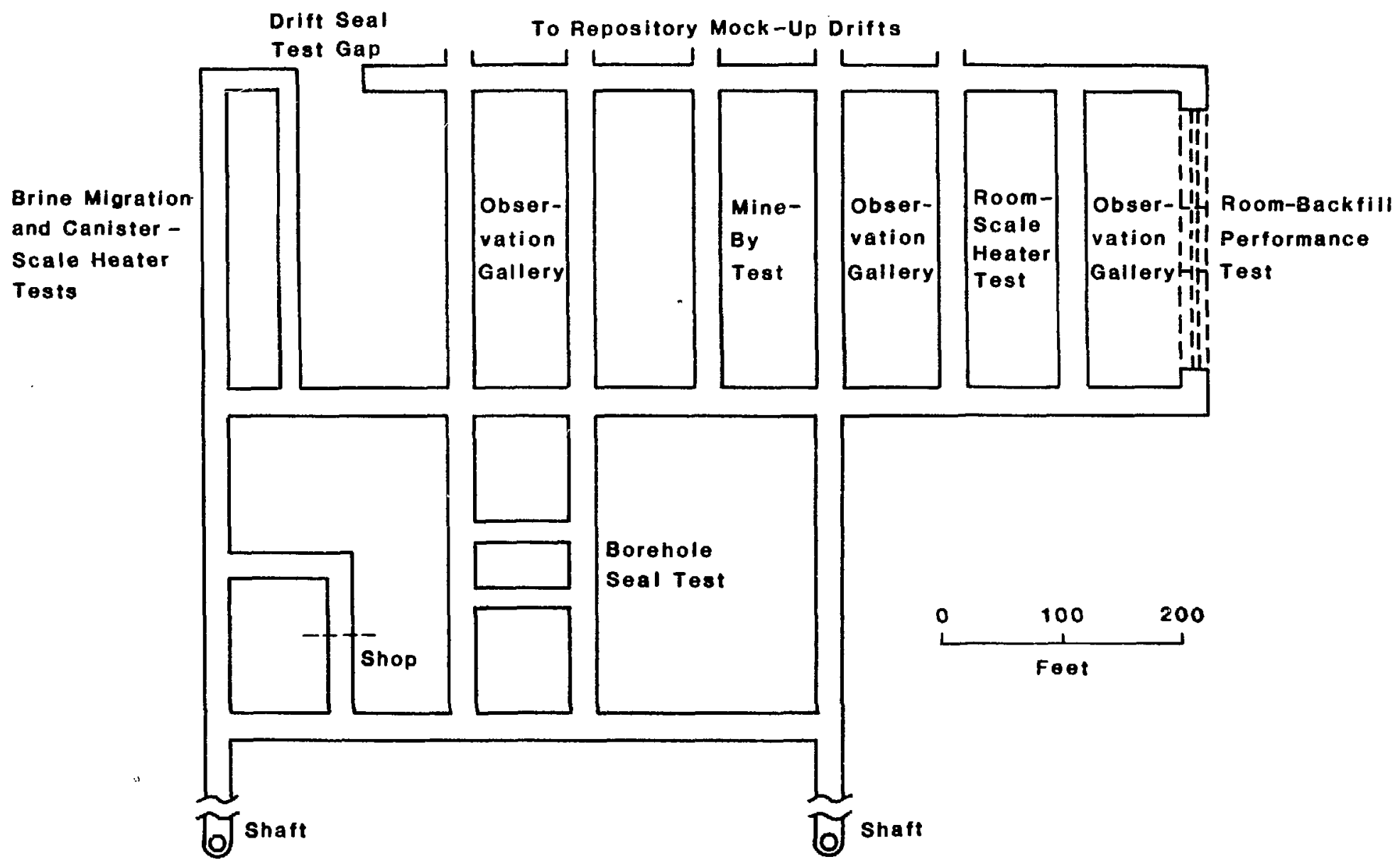

FIGURE 1 Suggested Revision to the Underground Layout of the Exploratory Shaft Facility 


\subsubsection{Block Test}

Both canister-scale and room-scale heater tests are proposed. For consistency, tests at a similar scale should be conducted for geomechanical loading alone. The mineby test involves room-scale loading; a canister-scale loading test (i.e., a block test of at least $1.5-\mathrm{m}$ square in section by $4 \mathrm{~m}$ in depth) at room temperature is required to complete the data set.

\subsection{THERMOMECHANICS}

\subsubsection{Canister-Scale Heater Test}

Although page $\mathrm{C}-116$ indicates that corrosion tests will be concucted in conjunction with the canister-scale heater test, no details are given and fluids monitoring is not mentioned. Because this test appears to be the only in situ test that addresses corrosion, more discussion is needed. One of the objectives of this test is to study brine migration in a mock-up of a single canister.

\subsubsection{Room-Scale Heater Test}

As noted in Sec. 3.2.3 of this report, the proposed duration of the room-scale heater test is too short. Figure 1 shows how two separate rooms could be excavated for the mine-by and room-scale heater tests so that these tests could run concurrently instead of sequentially. This modification would extend the duration of each test by several months.

Although the test plan stresses the need for "accelerated thermal loading conditions," it does not mention what means of acceleration will be used or what precautions will be taken to avoid introducing processes not expected under normal stress conditions. If further research and development is required, details should be provided.

A change is needed in the assumption that accelerated heating of the test area will induce a deformational response typical of what will occur over the operational life of the repository. The deformational response will actually be influenced by both temperature and deviatoric stress. Although the test temperatures may approximate those expected in a repository, it is unlikely that the stress field will be similar, particularly in a repository in bedded salt. Arching in the overlying strata may redistribute the overburden stress such that the load on the pillars is greatly reduced.

Finally, the proposed heater configuration is not the same as the waste-container configuration in the repository. Therefore, the temperature distribution will not approximate that in a real repository, although the magnitudes of the temperatures should do so. The disparity will be especially great in bedded salt if insoluble or clay layers are present. 


\subsubsection{Room-Backfill Performance Test}

The test plan states that backfill is "to compact and eventually lithify such that the repository environment is effectively returned to the preexcavation condition (i.e., salt monolith)." This statement is speculative and probably too strong. Recent modeling suggests that lithification of some backfills may not result in essentially intact salt, which means that significant porosity and permeability could persist (Zeuch et al., 1985). Salt backfill can probably be engineered to lithify significantly (e.g., by adding water), but it is not clear that a "salt monolith" can be achieved.

The test plan contends that because "the time required for full backfill compaction and lithification is estimated to be on the order of hundreds of years, it is necessary to accelerate the test by various methods in order to provide a useful demonstration of the phenomenon." (It then goes on to discount real-time and geometry tests.) This very strong stance is not adequately supported. The calculations referred to are presumably from Kelsall et al. (1982) or a subsequent iteration. These calculations are so approximate (i.e., grossly simplified models, short-time data, and a small and scattered data base) that using them to justify accelerated testing is unwarranted.

The accelerated testing will not necessarily be the "demonstration" it purports to be, primarily because the test conditions will necessarily be very different from those in a repository. In addition, accelerated testing may emphasize unimportant processes and mask crucially important ones.

The use of "appropriately validated thermomechanical models" is proposed, but it is not clear how the models will be validated. If they are to be validated with data from the room-backfill performance test, in which the salt in the test room will have been lithified at higher temperatures than will occur in the repository, it may not be possible to identify the correct model.

The test plan proposes to increase the backfill density in the test to a value "somewhat above that considered achievable under repository conditions." It is not clear why the density at which backfill is emplaced in an actual repository would be less than what had been achieved in field testing. To assume that a lower emplacement density would be obtained implies that the best available backfill techniques will not be used in the actual repository.

The proximity of the two heading faces would result in destressing of the intervening plug, which means that creep would not enhance compaction. Figure 2 presents a revised layout that would result in closure to assist in backfill compaction. The order of operations is as follows:

- Initially, leave a longer plug.

- Drill the hole and emplace the backfill.

- Excavate the rooms on both ends up to the test areas, using the "initial" high rates of creep resulting from room excavation to accelerate the closure of the borehole. 
Elevation Vlew

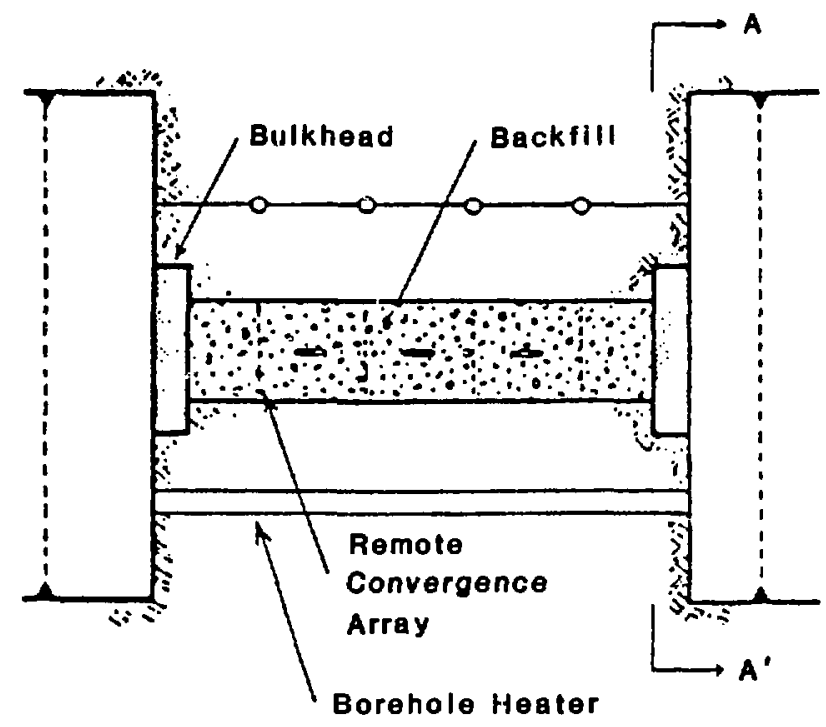

Section A-A

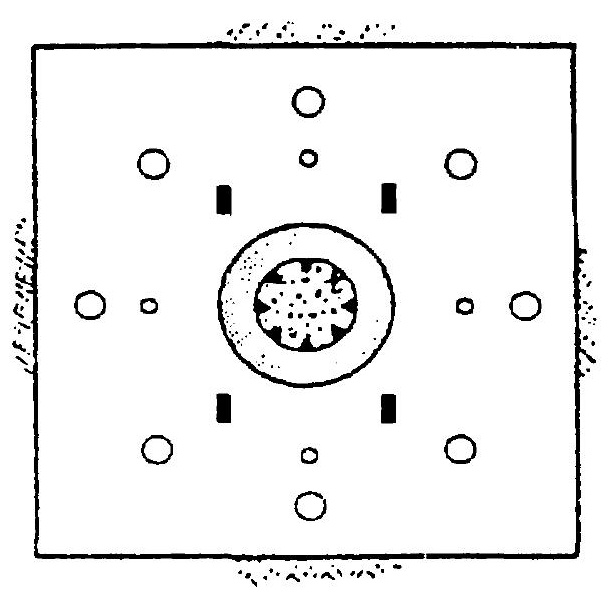

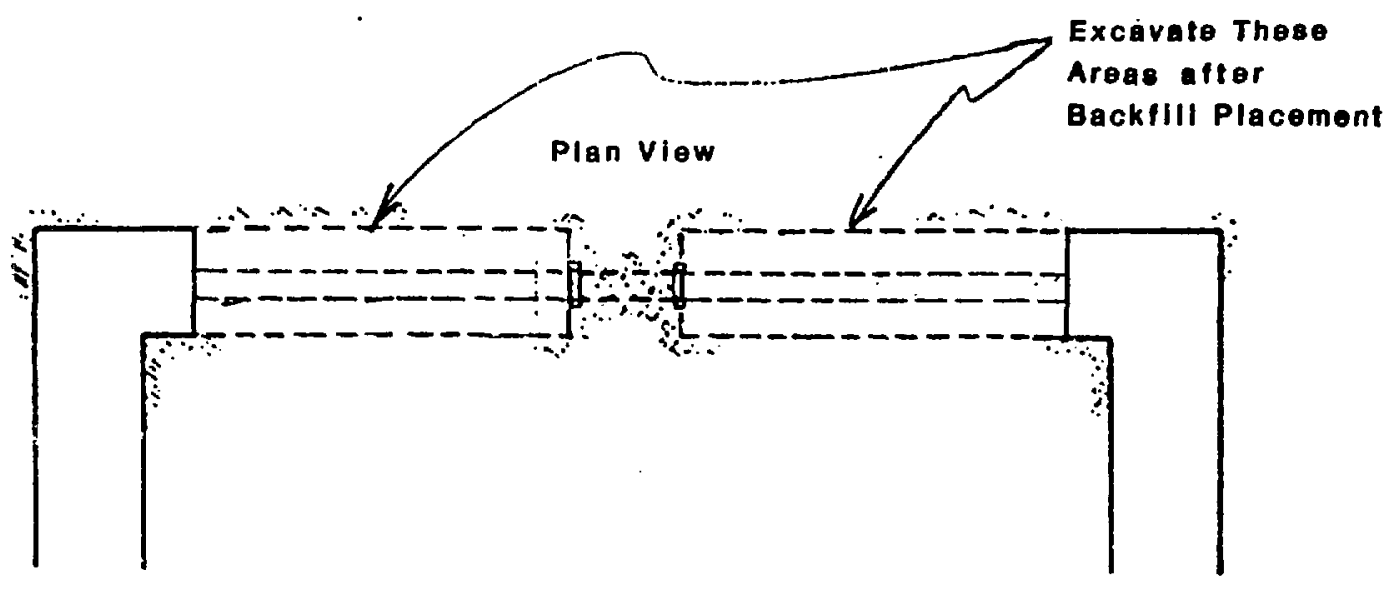

Borehole Heater

- Load Cell

- Convergence Station

Thermocouples Located

in Boreholes

- Borehole Pressure Cells with Thermocouples

FIGURE 2 Proposed Layout for Room-Backfill Performance Test 
This procedure would provide about 0.5 in. of total closure in the test area, which would contribute to compaction; however, the potential difficulties in interpreting the test results would not be eliminated.

This test is not a direct in situ demonstration because the heat content, stress level, configuration, and initial condition of the backfill do not necessarily represent what will exist in a repository but rather are upper bounds to the expected conditions. An accelerated test may be warranted, but the arguments presented in the test plan are not wholly convincing, especially in view of the potential difficulties in interpreting the data.

\subsection{GEOHYDROLOGY}

Panelists identified difficulties with many of the tests proposed for geohydrologic characterization. The extremely low permeability of salt at repository depths is at the root of most of the identified problems.

\subsubsection{Single-Borehole Hydraulic Conductivity Test}

The use of "guarded" zones in permeability testing is strongly recommended. Such zones indicate the effectiveness of the packer seal, which is the biggest practical problem in borehole permeability measurements. They also allow measurements that indicate the amount of tangential flow caused by anisotropy, wellbore damage, or a combination of the two. In a test of this type, pressure may also be important. If possible, test pressures should be as close as possible to those expected in credible breach scenarios, as well as to ambient conditions.

A gas like nitrogen should be considered for this type of test. If sufficient correlation exists between gas and brine permeability measurements, the cheaper, faster, and easier gas measurement could suffice most of the time. However, it may prove difficult to establish such a correlation.

The time required for each test is estimated to be one or two days. In this amount of time, the distance from the wellbore permeated by the working fluids, particularly brine, may be very short $(<1 \mathrm{~m})$. Also, the potential for hydrofracturing the salt during these tests, together with how this problem could be detected and accounted for, has not been addressed.

Some standard testing and analysis methods reported in the literature and not included in Table $\mathrm{C}-5$ include the Hvorslev test and numerous packer tests. In addition, several state-of-the-art techniques were presented at a conference sponsored by th.e International Association of Hydrogeologists, which was held in January 1985 in Tucson, Arizona. It appears that the options presented in the test plan could be expanded. 


\subsubsection{Cross-Hole Hydraulic Conductivity Test}

The limitations of this type of testing are not adequately covered in the test plan. Also, it is not clear which of the several groundwater flow equations the authors are referring to. Finally, it might be prudent to place pressure-monitoring devices on either side of the discontinuity during the cross-hole hydraulic conductivity test to determine whether the discontinuity can always be treated as a confined system.

Panelists do not agree that ". . .an effort should be made to use these (porous media) solutions." The method chosen should depend primarily on the physical nature of the rock and not on a desire to simplify the tests, as the text implies. Tests other than those for porous media (e.g., fractured-rock tests) are well documented.

Figure $\mathrm{C}-16$ in the test plan does not show transducers outside the packed-off intervals. Pressures should be monitored below the bottom packer and above the top packer to detect leakage past the packers, whether along the wall of the borehole or along fractures extending into the rock.

\subsubsection{Cross-Hole Tracer Test}

The discussion of the cross-hole tracer test should be expanded to include specific tests for specific hydrogeologic conditions. Although many radial flow techniques could be explored, the authors may have described the only reasonable tracertest method for this situation. Examples should be given of the specific tracer and sensing systems that might be used. Also, the potential effects of temperature on diffusion in the real case are not considered in terms of the test case. Finally, the possibility of matrix diffusion effects is mentioned, but the consequences for the test are not estimated.

On page $\mathrm{C}-169$, the text states that "the cross-hole tracer test. . .provides the only method of measuring a large-scale value of effective porosity in situ." Even though the "large-scale" part of this statement is doubtful, it is true that tracer tests are the only way to measure effective porosity. Therefore, the discussions about measuring effective porosity by geophysical logging and various other nontracer means seem superfluous.

The cross-hole tracer test, like the cross-hole hydraulic conductivity test, is concerned with individual discontinuities rather than networks of discontinuities. Effective porosity and dispersivity determined in a simple fracture will not necessarily be representative of the same properties for the bulk rock.

On page 90 , the test plan describes the cross-hole tracer test as being performed under "pseudo-steady state" conditions. If this term means that hydraulic heads remain nearly constant over time, the requirement is much too stringent. All that is needed is for the pressure gradients to stabilize, a condition that happens very early in the test and long before the pressures themselves approach constant values. On the other hand, if the term is used in its reservoir-engineering context to mean the period during which pressure declines linearly with time in a closed reservoir, the requirement is even more unnecessarily stringent. 
Figure $\mathrm{C}-17$ in the text plan does not show transducers to monitor leakage past the packers. No methods are specified for sampling for tracer concentrations within the injection and monitoring intervals, a most important aspect of the test. Only scintillometers for radioactive tracers are mentioned on page C-167. Nonradioactive tracers should be considered.

\subsubsection{Tracer Diffusion Test}

The relationship of the tracer diffusion test to real repository conditions and the value of data gathered during the test for predicting repository performance are unclear. If the intent is to determine a molecular diffusion coefficient for a conservative tracer in brine, the experiment could be carried out in the laboratory. Despite the discussion of "connectivity" determinations with this test, it is not clear that the tracer concentration data will provide information about dispersivity, molecular diffusion, connectivity, brine migration, or intercrystalline flow.

The proposed method of analysis assumes a saturated porous medium, but that assumption is not discussed. Also, the integrity of the tracer distribution during overcoring and core depressurization is not discussed.

The adequacy of this test for in situ determination of the connectivity of intact rock pore space is questionable. The cross-hole tracer test will yield more information about this property than the diffusion test, simply because diffusion is such a slow process. Detection limits and variations in concentration preclude the level of accuracy needed to determine the connectivity of the enclosing rock mass. The diffusion test should be used only to determine the diffusion constant.

The tracer should be injected at the rock pore pressure to ensure that true molecular diffusion is taking place. Overpressuring the injection hole may cause advective transport of the solute. True molecular diffusion takes place in response to chemical gradients, not hydraulic gradients.

It is important to demonstrate by calculation that the pressure gradient imposed during the matrix diffusion test will not affect the calculation of the matrix diffusion coefficient. If the pressure effect is significant, it may not be possible to correct for it using theoretical means.

It is not clear how effective porosity can be determined from a diffusion test. The matrix diffusion coefficient depends not only on effective porosity, but also on tortuosity. It is virtually impossible to isolate these two factors, unless one of them is determined by independent means.

The need for a long-term, in situ diffusion experiment is not entirely clear. Matrix diffusion is one parameter that can probably be determined, with sorne confidence, using core samples in the laboratory. 


\subsubsection{Borehole-Seal Performance Test}

Brine flow will probably alter the salt, which might make it difficult to compare the results of tests at different times at the same location. Also, it is not straightforward to drill two small-diameter holes from opposite directions so that they meet, especially when the holes are horizontal. A different configuration may be needed.

The test plan does not specify which parameters, if any, will be varied in the several tests of this type to be conducted. The failure to do so is a serious deficiency. Since the purpose of the test is confined to testing borehole seals, the authors should at least consider the effects of varying the borehole diameter (to include the expected range of borehole sizes to be drilled), the seal material (to test candidate seal materials), and the seal length (to investigate the scaling effects of seal length). Also, the rationale for conducting multiple tests should be clear.

On pages $\mathrm{C}-180$ and $\mathrm{C}-183$, the authors confuse porosity and specific storage, which are very different physical quantities. A transient flow test without tracers cannot be used to compute the effective porosity, and it is incorrect to say that a knowledge of porosity will enable one to calculate hydraulic conductivity from transienthead data.

\subsubsection{Room-Seal Performance Test}

The approach with regard to seal performance is inadequate. It is unreasonable to expect to understand seal behavior sufficiently well to validate codes and models with laboratory testing and one in situ room-seal performance test. The difficulty of the problem may have been underestimated. In particular, the three fundamental types of proposed seals cannot be evaluated in a single test. Appropriate test techniques and durations depend on both the seal material and the design. Interestingly, gas is not part of the test, even though one objective of room sealing, given on page C-184, is "to inhibit the passage of groundwater and gas. ..." This comment also applies to the borehole-seal and room-backfill performance tests.

Panelists questioned why the room-seal performance test was not designed more like the borehole-seal performance test, that is, one test between two rooms on two sides of a salt pillar, followed by removal of the pillar and replacement with a seal.

The program should be more comprehensive, with provisions for conducting a full-scale test on each of the major seal types. As a practical matter, it would be wise to begin by conducting a suite of small-scale tests to obtain the data and experience necessary to design and conduct the fuli-scale tests. In addition to providing information on the hydrologic performance of the seals, the tests should help elucidate the structural interaction of the seal and host formation.

D'Appolonia's seal designs, which are referenced in the test plan, take credit for time-dependent processes (e.g., radial stress buildup on a stiff bulkhead). Some type of monitoring is necessary to establish whether these time-dependent processes occur and 
to demonstrate seal behavior over the operational life of the facility. Leaving the test on-line could ensure that the fundamental behavior of the seal will be well understood.

The actual repository will remain open for a significant period prior to seal emplacement.* During this time, closure of the excavation will probably alter the formation's permeability. The test fails to address this issue.

After being exposed for a long period of time, the excavation wall will be "contaminated" by ventilation air carrying diesel fumes and other pollutants. This situation, which could result in a poor interface bond, should be addressed, even though it is not likely to affect the seal core.

One purpose of the test is to help validate models that predict the hydrologic performance of the seal system. Therefore, it is imperative that the relative contributions of each of the flow paths (i.e., seal, interface, disturbed zone, and intact formation) be decoupled. The test design apparently relies on collecting fluids on the downside to discern flow paths (i.e., in a mass balance, flow in - flow out = formation flow). Even at best, this approach will not allow flow through the disturbed zone, interface, and seal to be discerned explicitly. Furthermore, it is probable that a steadystate condition will probably not be achieved, meaning that retention of water by the seal could confuse subsequent analysis. Therefore, the gross formation permeability should be measured before seal emplacement.

Determining the permeability of a salt seal by measuring the moisture content of air collected by a ventilation system (see page $\mathrm{C}-188$ ) could yield spurious values. Ventilation will cause the water to evaporate and deposit salt, which may reduce the permeability of the surface of the opening, thereby creating a low-permeability "skin." A practice that worked in granite at the Stripa test facility in Sweden may not necessarily work in salt.

\subsubsection{Brine Migration Test}

The brine migration test, which is quite well thought out, is very reminiscent of the in situ brine inigration tests at the Asse mine in the Federal Republic of Germany. Preliminary results there indicate that gamma radiation does have a pronounced effect on brine migration. The regulations that prevent inclusion of this experimental variable will roduce the value of the test results. As stated on page C-206, the brine migration testing using heaters will at best provide baseline conditions for subsequent tests that incorporate the influence of radiation.

Specific computer codes were not covered in the discussion of modeling brine migration. Because the conceptual foundation varies from one code to another, codes must be reviewed for applicability and accuracy prior to their use. Furthermore, unless

\footnotetext{
*It may be possible with NRC approval to backfill individual rooms within several years after their capacity is exhausted; however, the repository facility will remain open at least for its 20 -year projected life.
} 
the information (input) requirements for a particular code are carefully considered, the data required to check an approach on a code may not be collected.

The test plan does not mention the salt block methodology presented in Hohlfelder (1980) and other publications. A salt block III test would perhaps be appropriate for examining brine migration; it would certainly be much less expensive.

The moisture content of the host rock in the immediate vicinity (i.e., within about 3-6 ft) of the simulated waste package should be directly measured, perhaps by means of borehole-to-borehole radar probing using, for example, the waste-canister borehole and one of the guard-heater boreholes. Such a measurement is needed both before and after the heater tests are performed, and perhaps periodically for several months thereafter. Such testing would give some idea of the effect of heating on the disturbed zone.

Although the test plan acknowledges the limited understanding of the fundamental processes at work, it is not clear that the planned test adequately accounts for the uncertainties. Even though radiation effects are likely to be handled in the laboratory, the link between such tests and the in situ tests should be presented. Also, brine chemistry is not discussed. The test setup calls for vapor removal without discussing its potential to artificially enhance brine transport in the vapor phase. Finally, the relationship of the proposed test to current or planned tests at other sites or laboratories is not considered.

\subsubsection{Grout Injection Tests}

Care must be taken in selecting grout composition, especially with regard to earthen and cementitious materials. When placed in contact with salt, some of these materials will ferment. All cementitious formulations must be of an expanding type to ensure a good bond. In the vicinity of salt strata, they must also be brine-based so they will bond to salt strata.

\subsection{GEOCHEMISTRY}

Section C.5 of the test plan is supposed to address geochemistry, but formation fluid sampling is the only geochemical aspect addressed. Nonetheless, the text implies that such efforts as block sampling, geophysical well logging, the canister-scale heater test, and the brine migration test all fulfill geochemical information needs. Although the line between geohydrology and geochemistry may sometimes be difficult to draw, formation fluid sampling should not be the only in situ geochemical test.

\subsubsection{Formation Fluid Sampling}

The discussion of formation fluid sampling is unclear. Standard wireline formation testers are not mentioned. Instead, an apparatus is described that purports to measure flow rates and to sample fluids from holes drilled with air. The borehole 
extends upward at an angle of about $45^{\circ}$ and a ppears to be short and of small diameter. It seems unlikely that this system will yield the required data. References that document the success or utility of this procedure should be supplied. If the formation penetrated with an air drill has pore spaces filled with fluid, the fluid will immediately flow down such a borehole under the influence of gravity. Curtailing such flow will be impossible because loading an uphole with drilling mud is impossible. If no flow occurs during drilling, then the experimental procedure described will certainly not induce flow.

Certain fundamental problems in methodology should have been addressed. The text should include the precautions that will be taken to prevent sample contamination. It should indicate whether the accuracy of the instrument readings in a highly corrosive environment will be ensured by the data loggers making "continuous records of temperature and pressure." It should also say whether suspended solids will be collected, and whether there is a filtering system.

The saturation index (page $\mathrm{C}-225$ ) is based on the solution's distance from equilibrium. A suspended, microparticulate phase is sufficient to cause erroneous solubility determinations that could lead to incorrect definition of the saturation index.

Chemical characterization of unfiltered formation fluids cannot provide information to "quantify reaction rates for dissolution" or to establish a legitimate "saturation index." The reaction rates for solution cannot be determined from the chemical characterization of a fluid in which the solution of the species under study has already occurred. The solution kinetics of salt should not be an issue anyway, considering how rapidly it dissolves.

The rationale for the formation fluid sampling is sound; however, it is important to know the chemical composition of the brine within the repository salt environment. The protocol proposed for chemical characterization may not adequately avoid the problem of sample contamination. The fluid release rate should also be quantified using the same instrumentation. A much less costly method for direct evaluation of formation fluids is shown in Fig. 3.

\subsubsection{Characterization of Sample Blocks of Rock Salt}

Large-sized block samples similar to those discussed in Sec. C.1.9 of the test plan should also be obtained for the purpose of geochemical characterization. Thorough chemical analysis of the salt is required. Calcium and magnesium chloride impurities are largely responsible for the deliquescent action of salt, which results in the exhaust air being nuch drier than the intake air -- the reverse of conditions in mines in nonsalt rocks.

Determining the presence of arenaceous insoluble lenses or facies changes is important because such features could cause excessive consumption of the blades on undercutters and continuous miners. Also, the presence of anhydrite, shale, and dolomitic particulate matter could affect the physical properties of a particular salt. Trace levels of certain compounds like bromides have been of scientific concern for several years. 


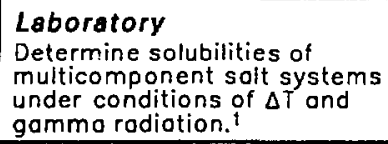

\section{Site-Specific Fiold Tost}

Obtain block sample and determine relotive obundonce of each water type $2.3(x)$ from the same block, and do $x$-roy diffraction and microprobe onalyses to quantify relotive mineral campositions $(M)$ and elemental impurities.

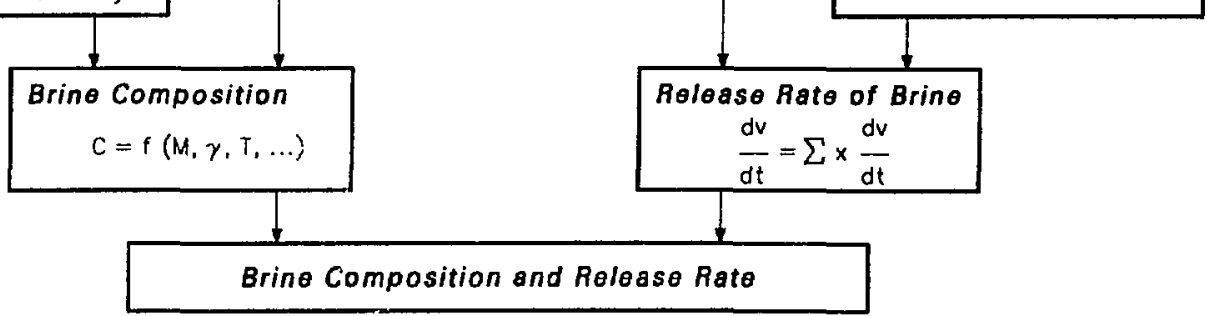

1. Hull, A.B., 1985, Argonne National Laboratory, unpublished information.

2. Fisher, S., April 17-19, 1985, Amount and Nature of Occluded Water in Bedded Salt, Palo Duro Basin, Texas, presented at Salt Repository Project Brine Migration Workshop, University of California at Berkeley.

3. Knouth, P.L., April 17-19, 1985, ASU Testing of Water in Salt, presented at Salt Repository Project Brine Migration Workshop, University of California at Berkeley.

4. Pigford, T.ll., 1982, Migration of Brine Inclusions in Sall, Nuclear Technology, 56:93-101.

5. Oiander, D.R., A.J. Machiels, and E. Muchowski, 1981, Migration of Gas-Liquid Inclusions in single Crystals of Potassium and Sodium Chlorides, Nuclear Science and Engineering, 79:212-227.

6. Jackson, K.J., and T.J. Wolery, 1985, Extensions to the EQ3/6 Computer Codes to Geochemical Modeling of Brines, in Scientific Basis for Nuclear Waste Management VII, C.M. Jantzen et al., eds., Materials Research Society, Pittsburg్ti, pp. 507-514.

7. Simonson, S.A., and W.L. Kuhn, 1984, Predicting Amounts of Radiolytically Produced Species in Brine Solutions, in Scientifje Basis for Nuelear Waste Management VIl, G.L. MeVay, ed., Elsevier, New York, pp. 17-25.

8. Ratigan, J.L., 1984, A Finite Element Formulation for Brine Transport in Rock Salt, International J. Numerical and Analytical Methods in Geomechanics, 3:225-241.

9. MeTigue, D.F., April 17-19, 1985, Salt as a Porous Thermoelastic Material: Laboratory and Field Applications, presented at Salt Repository Project Brine Migration Workshop, University of California at Berkeley.

\section{FIGURE 3 Integrated Approach to Determining Site-Specific Brine Inflow and}

\section{Composition}


Chemical characterization should include determining the identities and percentages of evaporite minerals, the composition and percentages of impurities, the water content and type, and the composition of the gas phase. 


\section{REGULATORY CONSIDERATIONS}

The test plan was reviewed to see how well it complies with relevant regulatory requirements. Some general comments on the regulatory aspects of the test plan are followed by more specific comments on Table A-1 and an evaluation of the completeness of coverage.

The rationale for the test plan is presented briefly in Sec. 4. The text notes that the test plan was developed based on information needs derived from relevant regulatory requirements. In Table $\mathrm{A}-1$, the relevant regulatory requirements, as contained in NWPA, 10 CFR (Code of Federal Regulations) 60, 40 CFR 191, 10 CFR 960, 10 CFR 20, and $30 \mathrm{CFR}$ 57, are classified as performance, information, testing, or other requirements. Performance requirements are restated as performance issues that must be addressed to demonstrate compliance. However, Sec. 4 does not explain how the individual performance issues in Table A-1 were formulated.

In general, the stated rationale for development of the test plan is logical, and pertinent regulatory requirements are incorporated. However, Subpart E, Sec. 60.131(b)(9), of 10 CFR 60 calls for compliance with 30 CFR, Chapter 1, Subchapters D, $\mathrm{E}$, and $\mathrm{N}$, which include many parts in addition to part 57 as cited on page 48 of the test plan. These additional parts are included, with few exceptions, in Table A-1; consequently, the citation for 30 CFR 57 on page 48 should be revised.

Although examples of performance, information, and testing requirement are given, Sec. 4.1 does not explain how the authors determined that a particular regulatory citation should be addressed through a performance issue, an information requirement or a testing requirement. Furthermore, the logical relationship is not apparent between the performance issues devised to develop the in situ test program and performance issues appearing in other programmatic documents. However, a detailed comparison of the issues contained in the test plan with those appearing elsewhere is beyond the scope of this review report. Discussion of the above points in Sec. 4 would clarify the rationale for the test program.

Within Table A-1, approximately 40 performance issues are listed and correlated with specific regulatory citations. Most of these issues are broadly defined, encompassing a large number of information requirements. Consequently, the same issues and sometimes the same information requirements appear repeatedly throughout the table, but associated with different regulatory citations. In some instances, the correspondence between issues and regulations is confusing; for example, a regulatory citation may require information different from that required by a citation elsewhere in the table, yet the same performance issue appears for both. Thus, some of the issues and information requirements appear to lack a unique definition or interpretation.

More specifically, it is of ten unclear in Table A-1 how the "type of regulatory requirement" was determined. A hierarchy exists that extend; from the broadly defined performance issues to the specific test requirements. Also, some regulatory statements are broad in scope, whereas others are quantitative and fairly specific. In many cases, however, the correspondence between a regulatory citation and the identified "type of 
regulatory requirement" is not clear, and there appear to be internal inconsistencies in assignment. A regulatory citation is sometimes categorized as "performance" in one part of the table when a similar citation is categorized as "information" in another part. These apparent discrepancies should be resolved to make the table internally consistent.

Many of the regulatory citations in Table A-1 are not directly related to development of the test plan. However, all regulatory considerations were apparently incorporated into the table for completeness and to put those relevant to in situ testing in perspective. If the intent was to present all regulatory considerations, the table is incomplete because some portions of regulatory documents are not included. If certain regulatory aspects were purposefully omitted because they do not bear directly on the test plan, the rationale for those omissions should be presented (perhaps in footnotes), and some of the regulatory citations in Table A-1 should be deleted.

The level of detail, in terms of listed performance issues and information and test requirements for individual regulatory citations, is uneven. Some citations have extensive listings of performance issues and information requirements associated with them, while others having seemingly equal regulatory importance and a similar relationship to in situ testing have only a small number of listed items. Furthermore, some citations that are not cbviously related to the test program may have several items listed as being required, whereas others of apparently similar relevance to the program may be dismissed in a footnote or not even listed. If there are no logical rensons for the unevenness of coverage, the problem should be resolved. If there are reasons for such unevenness, they should be discussed.

Finally, the term "hydrogeology" should be replaced by "geohydrology" in the descriptions of performance issues and information needs. This change would make these descriptions more consistent with programmatic usage.

The following comments are specific to the content of Table A-1.

1. The citations should be checked to eliminate typographical mistakes and errors of omission. A few errors were noted during this review, even though correspondence was not carefully checked (e.g., in citation 960.4-2-1(b)(4)(i) "hydrologic" should read "hydraulic"; in citation 960.4-2-3(c)(1), several words are missing).

2. The nine performance issues listed in the table for citation 960.42-1(b)(2) are also listed for 960.4-2-1(a). However, 960.4-2-1(b)(2) specifically pertains to Quaternary hydrologic processes, whereas 960.4-2-1(a) does not. This example is one of several where the same issues are used for citations that require different information, analyses, or interpretations.

3. Citation 960.4-2-1(b)(4)(iv) requires information on likely flow paths, which is not indicated.

4. Citations 960.4-2-2(b)(2), (3), and (4) appear to be at about the same hierarchical level in terms of the type of information 
required. However, two of these citations are designated "performance," whereas the third is designated "information." This example is one of many where it is unclear how the type of regulatory requirement was determined and why one type was chosen instead of another.

5. Opposite citations $960.4-2-3(\mathrm{c})(1),(2)$, and (3) are lists of performance issues. The wording in the citations indicates that information requirements could also have been listed. However, opposite citation 960.4-2-4(a), both performance issues and information requirements are listed. This unevenness in detail is found in many parts of the table.

6. Citation 960.4-2-4(a) pertains to future climatic conditions at the site, and the identified performance issue deals with the "impact of surface hydrology on site hydrogeology." Although climatic change will certainly induce surface hydrologic change, other aspects must also be considered (e.g., effect on erosion rates and other geomorphic responses). Throughout the table, this issue is listed as addressing regulatory citations pertaining to climatic considerations. The same issue is also associated with citations related to surface-water conditions, characteristics, and changes. An issue more directly related to climatic conditions would be preferable. Furthermore, some regulatory concerns appear to be related to climatic and surface-water conditions in their own right (e.g., flood hazards to surface facilities), rather than to those conditions' direct effect on the geohydrologic system.

7. Citation $960.4-2-4(b)(2)$ is another example where information pertaining to the Quaternary Period is required. The listed information requirements are the same as those listed elsewhere for citations requiring somewhat different information. Information on processes during the Quaternary Period is identified in several regulatory citations, but there is no information requirement in the table that explicitly pertains to the Quaternary.

8. Citation 960.4-2-7(a) pertains to future tectonic activity, and one of the associated performance issues is "thermomechanical loading of waste cackage." Elsewhere, this issue is listed for citations related to waste package performance with regard to containment requirements and preclosure environment. These uses of the same issue do not appear to be consistent. Also, applying this issue to a regulatory concern about tectonic activity seems illogical. Earthquake eifects should be the main concern.

9. Citation 960.4-2-8 pertains to future human interference with waste containment and isolation, but the listed performance issue pertains only to activities that affect site hydrogeology. This issue appears to be too narrow for the citation. 
10. Citation 960.4-2-8-1 is not appropriately addressed by the listed performance issues and information requirements. The presence of natural resources other than groundwater should be considered.

11. Citation 960.5-1(a)(3) pertains to ease and cost of repository siting, construction, operation, and closure. It is unclear how costs can be a performance issue in the same sense as the other issues listed. Furthermore, the citation incorporates aspects other than the costs involved.

12. Citation 960.5-2-8(a) is associated with the "costs" performance issue, which includes only part of the regulatory content. Also, it is unclear why subsection (b) is dismissed with a footnote, whereas subsections (a) and (c) have performance issues associated with them.

13. Citation 191.14(b) mentions social and economic considerations, but none of the many regulatory requirements identified with this citation pertain to these considerations. The same lack of treatment of social and economic concerns in NWPA and other regulatory documents is evident in other portions of Table A-1. Although these concerns are not directly related to in situ testing, numerous listed citations, some of which have regulatory requirements associated with them, are also unrelated. The rationale for these apparent discrepancies and the uneven coverage is unclear.

14. Subpart A (General Provisions) of $10 \mathrm{CFR} 60$ is not included in Table A-1. This material is unrelated to in situ testing, but other portions of $10 \mathrm{CFR} 60$ that are included are likewise unrelated to such testing.

15. Section 60.11, Subpart B, of 10 CFR 60 , which deals with the site characterization report, is not included in Table A-1.

16. Section 60.21, Subpart B, of 10 CFR 60, pertaining to the content of a license application, is included, and a number of regulatory items are identified in association with the content of a safety analysis report. It is unclear why this detail is presented for inclusion in the SCP. All of the performance issues listed in this section of the table are presented elsewhere.

17. Sections $60.22,60.23$, and 60.24 , Subpart $B$, of 10 CFR 60 are not included. Although these sections are procedural in nature, similar types of citations are presented elsewhere. 
18. Sections $60.33,60.41,60.42,60.43,60.44,60.45,60.46,60.51$, and 60.52 of Subpart B and all of Subpart C of 10 CFR 60 are not included.

19. Sections $60.71,60.73$, and 60.75 of Subpart D of $10 \mathrm{CFR} 60$ are not included.

20. One performance issue is identified for Sec. 60.111 of Subpart E of $10 \mathrm{CFR} 60$, but iwo additional issues are identified for the citation to Sec. 191.03, Subpart A, of 40 CFR 191. Because these two citations are similar, the rationale for listing different issues is unclear.

21. Several of the performance issues listed for the various subsections of 60.122 do not appear to apply to the content of the particular subsection. Merely repeating a nearly complete list of issues for subsections with different content does not appear to be appropriate in all instances. Furthermore, when entire lists of issues are not repeated, it seems that some issues that are included do not always correspond to the content of the citation. For example, the citation of $60.122(\mathrm{c})(3)$ concerns the "potential for natural phenomena such as landslides. . .that large-scale surface-water impoundments could be created that could change the regional groundwater flow system. ..." The performance issue "impact of surface hydrology on site hydrogeology" does not actually address the intent of the regulatory citation; this same issue is used elsewhere to address other concerns related to surface hydrology. Furthermore, the citation for Sec. 60.122(c)(5) refers to site conditions and the potential for natural changes in hydrologic conditions. Issues listed here are also listed for citations pertaining to the potential effects on the waste package and on postclosure activities. This pattern is neither consistent nor appropriate. Another example is provided by citation 60.122(c)(16), which pertains to evidence for extreme erosion during the Quaternary Period. The information requirements for this evidence of erosion in the Quaternary are listed as "stratigraphy/lithology" and "structure." This illogical and inadequate listing is yet another example where the same information needs are listed in one place for one citation and elsewhere for another citation with much different content.

22. The coverage of NWPA is uneven and inconsistent. Several sections of the law are not included in Table A-1, while others are treated in detail. Considerations involving natural resources, population, proximity to national parks, and similar subjects are avoided. Additionally, many of the citations that are primarily procedural could be eliminated from the table. 
23. Much of the content of Table A-1 related to 10 CFR 20 is of questionable applicability at this stage in the repository-licensing process. The provisions for protection against radiation must be satisfied during the operations phase, and assurance will have to be provided that these standards will be met before a license will be issued. However, unless radioactive materials will be used during the testing program developed for the exploratory shaft facility, the regulations contained in 10 CF 20 are not directly applicable at this point. Furthermore, only a portion of $10 \mathrm{CFR}$ 20 is incorporated into Table $\mathrm{A}-1$ as being pertinent.

24. The coverage of $30 \mathrm{CFR}$, Chapter 1 , is uneven. Section 60.131(b)(9) of 10 CFR 60 pertains to compliance with $30 \mathrm{CFR}$, Chapter 1, Subchapters D, E, and N. Most of this material is included in Table $\mathrm{A}-1$, but the majority of the citations are not directly related to development of the in situ test plan, and this fact is duly indicated. It appears questionable that all of this material should be incorporated. Furthermore, "safety and health inspections" does not seem to be a testing requirement, as the term is used elsewhere for particular geotechnical tests. 


\section{PAGE-BY-PAGE COMMENTARY}

\begin{tabular}{|c|c|c|}
\hline Page(s) & $\underline{\text { Line(s) }}$ & Comment \\
\hline 2 & & $\begin{array}{l}\text { The bulleted statements beside the boxes should be } \\
\text { edited for parallelism. For example, "identify" (in the } \\
\text { first line) is not the same part of speech as "plans" (in } \\
\text { the second line). }\end{array}$ \\
\hline 3 & & $\begin{array}{l}\text { In the absence of radioactive species, } 10 \text { CFR } 20 \text { is not } \\
\text { applicable to a subsurface test plan (line } 7 \text { ). Also, } \\
10 \mathrm{CFR} 60 \text { and the other citations in the top box should } \\
\text { be briefly described. }\end{array}$ \\
\hline 4 & & $\begin{array}{l}\text { "Recommended In Situ Tests" should read "Recommended } \\
\text { Subsurface Tests." }\end{array}$ \\
\hline 6 & & $\begin{array}{l}\text { The title should be changed to reflect the fact that some } \\
\text { of the items listed are not in situ tests. }\end{array}$ \\
\hline 9 & & $\begin{array}{l}\text { It is unclear why hydrofracturing is included under "In } \\
\text { Situ Stress Measurements." Also, the acronym DEIS } \\
\text { should be defined, and "In Situ Test Schedule" should be } \\
\text { changed to "Subsurface Characterization and In Situ Test } \\
\text { Schedule." }\end{array}$ \\
\hline 11 & $12-13$ & $\begin{array}{l}\text { "National Waste Terminal Storage (NWTS)" should be } \\
\text { replaced by "Office of Civilian Radioactive Waste } \\
\text { Management (OCRWM)." }\end{array}$ \\
\hline 13 & $14-16$ & $\begin{array}{l}\text { "Site Characterization Plan" should be used in place of } \\
\text { "Site Characterization Report." }\end{array}$ \\
\hline 14 & $1-8$ & "In situ tests and investigations" should be defined here. \\
\hline 14 & $20-21$ & $\begin{array}{l}\text { The phrase "generic to salt" should be replaced by "a } \\
\text { generic plan for a test program in salt" or some similar } \\
\text { expression. }\end{array}$ \\
\hline 17 & $2-6$ & This paragraph should be clarified. \\
\hline 17 & $7-20$ & $\begin{array}{l}\text { The subject information may have been included in early } \\
\text { drafts of the environmental assessments, but all of it is } \\
\text { not explicitly included in the draft environmental } \\
\text { assessments published in December } 1984 \text { (U.S. Depart- } \\
\text { ment of Energy, 1984). }\end{array}$ \\
\hline
\end{tabular}




\begin{tabular}{|c|c|c|}
\hline Page(s) & Line(s) & Comment \\
\hline 18 & $25-30$ & $\begin{array}{l}\text { Only single-phase brine inclusions were observed to } \\
\text { migrate to the heat source; two-phase inclusions tend to } \\
\text { move away from the heat source. Also, "constitutive } \\
\text { relationship" should be changed to "empirical creep law." }\end{array}$ \\
\hline 19 & 3 & $\begin{array}{l}\text { Section 2.2.1 should note that Project Salt Vault also } \\
\text { confirmed that pillar shortening in salt is temperature- } \\
\text { sensitive (the heated-pillar test was the largest-scale } \\
\text { confirmation of the temperature sensitivity of salt that } \\
\text { had been conducted) and that radioactive material in the } \\
\text { form of fuel rods could be emplaced and retrieved from } \\
\text { openings in the floor of a salt mine with no particular } \\
\text { difficulties. }\end{array}$ \\
\hline
\end{tabular}

195

$20 \quad 8-12$

The text should state when and by whom the field experiments at Avery lsland were conducted.

Although longer-duration laboratory creep tests may provide more reliable parameters, it will still be impossible to model the performance of the "corejack" test without an adequate constitutive model. A new constitutive law is probably needed, which may require data from tests other than creep tests. Of course, one of the requirements for $\mathrm{q}$ new formulation is that it must hold at lower temperatures.

13-15 See the comments on radar in Sec. 3.1.3 of this report.

Sealing tests are being conducted at the Asse mine, as well as at other salt facilities in the Federal Republic of Germany; however, documentation is extremely scarce.

The significance of the WIPP technology experiments is understated. The majority of the tests proposed by Golder are quite similar to the WIPP tests, in which vast practical knowledge has been gained concerning the design and implementation of in situ experiments.

Although the salt anticlines are not themselves pierced, they may pierce overlying strata. The phrasing should refer to "piercement and nonpiercement."

For technical accuracy, the phrase should read: "bordered by areas that are structurally more complex." 


\begin{tabular}{|c|c|c|}
\hline Page(s) & Line(s) & Comment \\
\hline 25 & $12-16$ & $\begin{array}{l}\text { The depth of these "shallow" aquifers should be } \\
\text { specified. Also, the "upper hydrostratigraphic unit" } \\
\text { should not be called "shallow" when it extends to a depth } \\
\text { of about } 1400 \mathrm{ft} \text {. Finally, the Honaker Trail Formation is } \\
\text { Pennsylvanian in age. }\end{array}$ \\
\hline 25 & $21-25$ & $\begin{array}{l}\text { The term "hydraulic conductivity" should not be } \\
\text { shortened to "conductivity." The first sentence should be } \\
\text { changed to: "The middle hydrostratigraphic unit is } \\
\text { composed of the Paradox Formation, which is a lower } \\
\text { hydraulic conductivity unit that contains stringers of } \\
\text { interbedded dolomite that have higher hydraulic } \\
\text { conductivities." }\end{array}$ \\
\hline 25 & $30-33$ & $\begin{array}{l}\text { The supersaturation saline content for water should be } \\
\text { indicated. }\end{array}$ \\
\hline 25 & 34-35 & The "lower hydrostratigraphic unit" should be defined. \\
\hline 26;28 & & $\begin{array}{l}\text { The depths and thicknesses of individual stratigraphic } \\
\text { units should be shown in Figs. } 3-1 \text { and } 3-2 \text {. Also, the } \\
\text { present ground elevation for the site should be } \\
\text { indicated. (This comment also applies to the other } \\
\text { stratigraphic columns.) }\end{array}$ \\
\hline $27-30$ & & $\begin{array}{l}\text { In Secs. } 3.1 .2 \text { and } 3.1 .3 \text {, each site description should be } \\
\text { accompanied by a figure showing the simplified regional } \\
\text { geologic and tectonic relationships discussed in the text. }\end{array}$ \\
\hline 27 & 32 & $\begin{array}{l}\text { The term "upper high conductivity unit" is inappropriate. } \\
\text { The draft environmental assessment for the Deaf Smith } \\
\text { County Site (U.S. Department of Energy, 1984) uses } \\
\text { "upper aquifer." }\end{array}$ \\
\hline
\end{tabular}

27;29 34;1-2 The sentence that begins "The lower high conductivity unit. .." uses an unfortunate mix of lithologic, geologicseries, and geologic-system names. The stratigraphic names should be standardized.

"Slake" should be inserted between "Low" and "durability," if that is the intent.

The word "faulting" should be replaced by "faults." Faulting connotes newly generated faults and associated earthquake ground rupture. 
Page(s)

32

Line(s)

17-18

2

33-34

16-18

6-10

24-27

1
15

\section{Comment}

Be specific, if possible, about the nature of the chemical anomaly.

\section{Define "sheaths."}

Clarify whether the expression "sheath materials" re $e^{r}$ rs to a geologie structure or to a lithologic material.

The word "has" should be replaced with "have."

See Hambley et al. (1984) for a critique of the D'Appolonia seal designs.

Removal of the waste from the "overpack" (proposed by Westinghouse) is impractical. See Rote et al. (1985).

If the generic designs really did "satisfy conditions" at each site, there would be no need for further work. The statement should be clarified and referenced.

Very little is said in the reviewed document about leaching. It is not clear whether the term "corrosion," as used here and elsewhere in the document, refers only to attack on metals, or whether it is used in a more general sense to include leaching and dissolution of waste form materials.

This passage suggests that the overpack is a sleeve used to "prevent buckling and collapse." The function of the overpack is to provide containment of the waste form for the first 300 to 1000 years. It is, of course, also supposed to be able to withstand buckling and collapse. "Overpack" should be replaced by "container" to conform to the terminology agreed to at the DOE Mission Plan Working Group Session of February 7, 1985. This terminology, explained in Stein (1985), may require NRC concurrence before it is adopted by DOE. The authors should track the evolution of this DOE-preferred terminology.

Change "remote handling" to "identification and remote handling."

Replace "NWTS" by "OCRWM." 
Page(s)

61

61

69

69

72

72-73

73

73-74

74

75

75

76

76-77
Line(s)

14

22

12-17

24-33

19

28-30;1-16

6-8

17-32;1-17

18-30

14-16

17-20

1

1

Comment

Replace "in situ" with "subsurface."

Replace "in situ" with "subsurface."

The text should be more specific than "monitored for a considerable time." It is not clear how or why monitoring would be terminated. Monitoring would presumably take place throughout the site characterization phase (and thereafter at the site for which construction authorization was approved).

Features in bedded and domal salt should be contrasted.

The term "brine inclusions" is sometimes used where "brine pockets" is meant.

See comments on radar probing in Sec. 3.1.3 of this report.

See Sec. 3.1.7 of this report for comments about sonar exploration in "wet" salt.

See comments on seismic surveys in Sec. 3.1 .4 of this report.

Section 5.1.1.8 (Seismicity Monitoring) should discuss potential problems with other site activities that may generate noise. Also, the text should indicate whether this type of monitoring has been successful at other sites. Finally, the sensors should be high-frequency accelerometers, rather than low-frequency geophones. Low-frequency geophones are for earthquake detection.

Strength properties are irrelevant. See comments on mechanical properties of salt in Sec. 2.7 of this report.

Fracturing in salt occurs only in the immediate proximity of openings if at all.

Rock strength is irrelevant in salt. See Sec. 2.7 of this report.

31-34;1-3 See comments in Sec. 3.2.1 of this report regarding in situ stress measurement in salt. 
Page(s)

77

4-24

77

15-24

78

(3)

\section{Comment}

Here, Golder recognizes the limitations of stressmeasurement methods in inelastic materials. See Stormont et al. (1984) regarding difficulties with stress gages.

This discussion seems to refer to devices capable of measuring stress without material properties being known.

Sellers (1974), which describes the torsional shear test, should be referenced.

The text should point out that modeling of the mine-by test requires a knowledge of the in situ stress.

See comments in Sec. 3.2.4 of this report regarding the rock-bolt pullout test.

A clearer wording would be: "The results will be backanalyzed using the theory of transient conductive heat flow to find the thermal conductivity."

One of the objectives of the canister-scale heater test is to study brine migration in a mock-up of a single canister.

This sentence should be amended as follows: "The thermal and thermomechanical responses in the very near field depend on the areal thermal loading and the rate of heat generation of the waste container." Because waste will be placed in discrete containers with a spacing of several feet between them, a thermal gradient will be set up that results in increased stresses in the rock. The combination of increased stresses and temperatures causes the creep rate to increase. Also, delete the sentence that begins with "The latter effect. ..."

This sentence is unclear; a drawing would be helpful. 


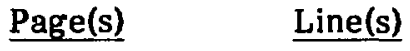 \\ $\underline{\text { Comment }}$ \\ This sentence is incorrect. The deformational response is influenced by both temperature and deviatoric stress. While it may be possible to induce temperatures that approximate those expected in a repository, it seems doubtful that the stress field will be similar (since the heater configuration is not the same as the placement configuration of waste), particularly in a bedded salt repository. This comment should not be construed to mean that a heated-room test should not be conducted. It suggests rather that not too much should be expected from such a test.}

19-21 The text should clarify whether the models are to be validated with data from this test. Since the salt in the test room will have lithified at a higher temperature, it will be difficult to know if one has the correct model.

A diagram would greatly enhance the explanation.

The cross-hole trocer test is discussed as being performed under "pseudo-steady state" conditions. If this statement means that the hydraulic heads are to remain nearly constant with time, the requirement is much too stringent. All thet is needed is for the hydraulic (pore) pressure gradients to stabilize, which happens very early in the test (long before the pressures themselves approach constant values). If, on the other hand, the term is used in the context of reservoir engineering to indicate the period during which pressure declines linearly with time in a closed reservoir, the requirement is even more unnecessarily stringent.

The authors should consider whether transport by diffusion is realistic. By the time radionuclides -- with their small diffusion lengths in rock -- reached the accessible environment, their "activities" would probably meet the maximum concentraticus allowed under $10 \mathrm{CFR}$ 20.

An explanatory drawing would make the discussion of the test methodology more easily understood.

This test is also known as a chamber test.

See Sec. 3.4.8 of this report for comments on grout composition. 


\begin{tabular}{|c|c|c|}
\hline Page(s) & $\underline{\text { Line(s) }}$ & Comment \\
\hline 96 & $23-27$ & $\begin{array}{l}\text { The text should clarify how the in situ conditions will be } \\
\text { preserved in the blocks once they have been removed. }\end{array}$ \\
\hline 98 & & $\begin{array}{l}\text { The time requirements are apparently based on an } \\
\text { advance rate of } 730 \mathrm{ft} / \text { month. This rate is consistent } \\
\text { with } 10 \mathrm{ft} \text { per shift in a two-shift, five-day-week } \\
\text { operation with two production units. This rate is } \\
\text { extremely conservative for mechanical excavation. }\end{array}$ \\
\hline 106 & 17 & $\begin{array}{l}\text { The preparer of the project management plan should be } \\
\text { given. }\end{array}$ \\
\hline 121 & & $\begin{array}{l}\text { The terms "performance requirement," "information } \\
\text { requirement," and "testing requirement" should be } \\
\text { defined in the Glossary. }\end{array}$ \\
\hline
\end{tabular}

Appendix A: Information Needs Analysis - Supporting Data

A-4 14-15 Under "(a) Qualifying Condition," delete "(see Appendix I of this Part)" at the end of the paragraph.

A-103-A-108

Instead of "Methods Available for Resolving Performance Issues," the table heading should be "Methods Available for Addressing Performance Issues."

A-104

Thermomechanical loading of a waste package cannot be resolved primarily by numerical analysis. Numerical analysis may be able (fortuitously) to predict the loads, but it cannot resolve the behavior.

A-105

The term "disturbed zone" is inadequate. Groundwater flow in the disturbed zone around a container can probably be determined in a demonstration, but groundwater flow in the disturbed zone around the entire repository probably cannot because of the large time and space scales involved.

Although the second column is labeled "Conceptual Model," its entries are merely slightly expanded discussions of the performance issue entries in the first column. Conceptual models of the physicochemical processes involved are not given. The entries under the second column fail to provide a conceptual framework for the mathematical modeling of the relevant performance issues. 
$\underline{\text { Page(s) }}$

$\underline{\text { Line(s) }}$

\section{Comment}

In the third column (Numerical Model), the descriptions are so vague and noncommittal (e.g., "mechanical response," "hydrologic response," and "geochemical response") as to put the utility of the entire table in question.

A-113

If best available proven technology is used and acceptance standards are specified, "poor construction techniques" cannot be a major reason for seal failure. For the purpose of design, limited coupling between the disturbing influences can be accepted as adequate (i.e., thermomechanical analysis, thermohydrologic analysis, and hydrochemical analysis). However, it will be highly desirable at some stage to perform a fully coupled thermal-hydraulic-mechanical-chemical analysis of the performance of key components of the repository system.

A-118

The thermomechanical loading of a waste package may be influenced by corrosion. If localized, this corrosion could cause the stiffness of the package to be asymmetric, which in turn might influence the loading.

A-121

A-122

The chemical composition of the brine in the vicinity of the waste package may be influenced by radiation.

Hydraulic head, included in the list of site characteristics, cannot be properly defined in cases where temperature and fluid density are variable. This fundamental problem occurs throughout the text. The appropriate quantity to measure and model when a nonhomogeneous brine migrates through a nonisothermal field is pressure, not hydraulic head.

A-131-A-140

The table heading of the third column should be changed to "Empirical Principle."

A-131

Many numerical models (e.g., for brine migration and creep) employ empirical equations; the distinetion is not entirely clear, either here or in Sec. 4.

A-132
For item (iii) under "Empirical Equation" (to be changed to "Empirical Principle"), include "Standard Mine Ventilation Formulae. Established Health and Safety Codes" in the entry. 


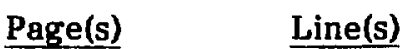

A-144

A-155-A-182

A-155

A-156

A-157
Surface boreholes should not intercept the repository excavations. Protective pillars should be left.

The information requirements in Table A-6 are consistent with all requirements previously established in this document. Additional information needs are correctly related to total requirements using statements of the current status of knowledge of candidate sites.

An introduction to this table should perhaps note that sufficient information is already available to support a very conservative repository design.

The first entry under the second column states that for both stratigraphy/lithology and structure that "each geologic unit may. . . be treated as relatively homogeneous with uniform response characteristics." It is not clear how these geologic characteristics, in conjunction with each other, define geologic units that must necessarily have uniform properties with respect to either structural or hydrologic behavior.

The text implies on pages 76-77 that none of the devices for measuring in situ stress work well in nonelastic rocks like salt, but that the best technique is to use inclusion cells. Then, on page B-28, major development needs for stiff inclusion cells are identified. The document treats in situ stress well. The need to measure it is identified, and the methods of measuring it are adequately discussed, as is the status of those methods.

Regarding rock strength, see comments in Sec. 2.7 of this report.

Regarding deformation moduli for salt, see comments in Sec. 2.7 of this report.

An "adequate" constitutive relation for rock salt is needed; no such relationship is available, even at laboratory scale for well-controlled tests. The overall water content and the distribution of water in the salt may be significant.

A-158

The density, as well as the thermal conductivity and specific heat, should be measured. 


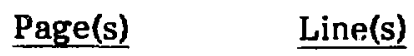

A-159

A-159

A-161

A-163
The need to "measure effective porosity at varying... scale[s]. . .along the flow path" is identified. Also, it is claimed that "effective porosity. . .has been measured in the laboratory on core...." As is true throughout the rest of the text, the authors seems to confuse interconnected pore space with kinematic porosity, referring to both as "effective porosity." Effective porosity is kinematic porosity. If it is multiplied by the seepage velocity (which controls contaminant transport), the product is equal to the Darcy flux. Kinematic porosity is generally smaller than the porosity of the interconnected void space. The tracer test permits determination of this very important parameter. Yet, throughout the text, the authors refer to a variety of tests that are supposed to yield a value for effective porosity. If the laboratory tests on page A-159 do not represent tracer tests, then the "effective porosities" obtained will be unreliable.

See comments on tracer tests in Sec. 3.4.3 of this report.

The statement that "specific storage is of interest with regard to transient flow conditions (e.g., dewatering or resaturation)" is misleading. Specific storage, which plays a role in transient flow only under saturated conditions, is totally inadequate to deal with dewatering or resaturation. The rate at which the backfilled repository will resaturate will be a complex function of the prevailing two-phase nonisothermal flow conditions. The authors do not refer to this phenomenon.

There is much less need to "measure specific storage at varying scale" than there is in the case of permeability, because specific storage is much less variable than permeability.

The text mentions the need to "measure adsorption/ retardation rates." It is not clear whether the authors mean "rates" or perhaps "coefficients," such as $\mathrm{K}_{\mathrm{d}}$. The latter is an equilibrium coefficient, whereas "rates" refer to kinetics. The text should also state how these rates (or coefficients) are measured.

Specific heat is strongly a function of water content, which in turn depends on effective porosity and water saturation. 
Page(s) $\quad \underline{\text { Line(s) }}$

A-165

A-166

A-167

A-168

A-171

A-172

A-176
Comment

The discussion of mechanical response of the shaft should mention the shaf $t$ liner if one is contemplated.

It seems unlikely that "a combination of coupled models may be sufficient" to properly describe radionuclide transport in the subsurface.

Load path effects on salt creep are not well understood.

The density, as well as the thermal conductivity and specific heat, should be measured.

The density, as well as the thermal conductivity and specific heat, should be measured.

It is not true that "the process of salt fracture. . . [is] generally well understood." Not enough is known to model such behavior numerically with certainty.

The density, as well as the thermal conductivity and specific heat, should be measured.

\section{Appendix B: Test Method Evaluation and Selection - Supporting Data}

B-2-B-18

B-3

B-4

B-4-B-6

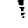

Strictly speaking, surface and surface borehole tests at a site are also in situ. Say "subsurface" -- if that is what is meant here -- instead of "in situ." Table B-1 implies that the salt ereep tests mentioned are constant-stress tests. The table does not mention other types of tests, such as stress-path-control tests and constant-strain-rate tests.

In considering the detection of man-made disturbances by surface-borehole testing, the authors may wish to add the use of pumping tests to detect abandoned boreholes. A pumping test developed by Witherspoon and Neuman that uses the theory of leaky aquifers has been used successfully for this purpose.

In discussing the measurement of strength properties, distinguish between salt and nonsalt rocks. "Strength" is meaningless in salt.

The value of uniaxial creep tests should be explained. Also, hydrofracturing is of limited use in salt. 
$\underline{\text { Page(s) } \quad \text { Line(s) }}$

B-7

B-8

B-9

B-10

$\mathrm{B}-11 ; \mathrm{B}-14$

B-17
It is not clear how the methods listed, most of which do not rely on tracers, will be used to determine effective porosity. This example clearly demonstrates the confusion in the text about the meaning of effective porosity.

Specific storage cannot be determined from tracer tests. Such tests are virtually always conducted with a steady-state flow regime, in which specific storage plays no role. Only before the tracer test proper can specific storage come into play. The same mistake appears on pages $\mathrm{B}-10$ and $\mathrm{B}-13$.

Under "Surface Borehole Testing" and "In Situ Testing," add the method of computation/prediction of large-scale dispersivity from spatially distributed small-scale permeability measurements discussed in the comment on page A-159. Make the same addition on page B-13.

No mention is made of the need for information regarding radiation effects on geochemical processes. It may not be possible to perform in situ studies involving radiation at this time, but the need for such information should be stated.

Laboratory tests cannot measure disturbed-zone properties. Also, the relationship between strength and creep tests needs to be explained. The authors may have meant "tertiary creep." Finally, one cannot extract a meaningful deformation modulus from creep-test data.

Conventional equipment for measuring porosity (such as a helium porosimeter) should be used to determine effective porosity.

Since the rooms and tunnels are in salt, strength testing is meaningless. Strength testing of the disturbed zone is also meaningless.

The backfill material will initially be crushed and granular; compressive strength in such a situation is meaningless. More importantly, if salt is used for the backfill, as is currently expected, strength is meaningless in any case. 
Page(s)

$\underline{\text { Line(s) }}$

B-19

B-21

B-22

B-23
The relative humidity of the room air (see "Repository Operating Systems") will presumably be monitored. The amount of hygroscopic water absorbed by exposed salt surfaces; including the backfill-material surfaces, should be measured.

The kinetics of chemical weathering is not well understood; thus, drilling will not provide effective resolution of questions concerning alteration/solution.

Add analysis of gamma-radiation damage.

Hydrofracturing has low rather than medium effectiveness in salt.

At least minor development and demonstration are needed to establish a credible, reasonably effective procedure for overcoring from surface boreholes.

Geophysical well logging can provide information about total porosity, but not about effective porosity.

More test development must be done before geochemical and hydrochemical information can be obtained from geophysical well logging.

Experience with head monitoring, hydraulic tests, and tracer tests in very-low-permeability formations is quite limited. The problems in a repository in salt are compounded by a number of factors, especially changing temperatures and brine (rather than fresh water) as the fluid of interest.

The effectiveness rating of the cross-hole tracer test in surface boreholes for determining adsorption/ retardation should not be as high as that for determining hydraulic head. Also, the rating for determining effective porosity should not be as high as those for hydraulic conductivity and specific storage. The same comments apply for pages B-33 and B-34.

More than minor test development is required before hydrochemical parameters can be well resolved through downhole probing in a salt environment. Reliable measurement of $\mathrm{pH}$ is very difficult in solutions with very high ionic strength. 


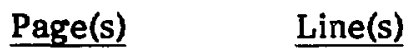

Comment

B-24

B-24-B-25

Unconfined compressive strength, triaxial compressive strength, and uniaxial creep tests are meaningless in salt.

Strength and deformation moduli are meaningless parameters in salt; therefore, the effectiveness of creep tests to determine these parameters is very questionable. This same comment applies to the heated pillar test discussed on page B-31.
\end{abstract}

B-25

B-27

In the sixth item in the first column, change the wording to "crushed and block salt testing with heat and gamma radiation."

The effectiveness of geophysical logs in providing values for ef fective porosity is listed as relatively high here and on page B-22. This rating may be appropriate for total porosity, but not for effective porosity.

B-28

Hydrofracturing is not very effective in salt.

Radar probing has a utility range exceeding that specified. See comments in Sec. 3.1.3 of this report.

The effectiveness of hydrofracturing as a stressmeasurement procedure is overstated. A bar showing parity with overcoring would be appropriate.

B-29

The torsional shear test is not very common; its value is relatively unproven.

Plate jacking may not be effective if creep occurs around the bearing plates. Plate jacking is used to find a modulus of deformation, which is a meaningless parameter in salt.

Strength is irrelevant in salt, because movement will occur under a deviatoric stress as low as $\mathbf{1 5 0}$ psi.

B-36

Add "effect of gamma radiation" to the discussion of the brine migration test.

B-38-B-39

The key to Table B-2 should precede the table to avoid confusion. 




Appendix C: Detailed Test Descriptions

C-4 3 The required equipment should include a "carpenter's rule" (since magnetic compasses may not be reliable) and preformatted mylar mapping sheets.

C-6 4-8 Revise sentence to read: "Boreholes initiated in the floor or walls of the exploratory shaft facility will be drilled. ..."

C-6 4-16 No mention is made of the very important need and desirability of determining structural domains as part of site characterization at the exploratory shaft facility.

C-7 1-16 Many geotechnical engineers consider geophysical logging to be as accurate as continuous sampling (and more cost effective) in all but the most critical areas.

C-7 7-11 Reword sentence to read: ". . .optimized by the extensive use of underground drifting. ..."

C-7-C-8 17-31;1-4 Specifications for drilling in a gassy environment should be mentioned.

C-8 27-28 The core should be marked to indicate the top, and induced fractures should be marked. Core dividers should note the depth at the base of the recovered core.

C-9 11-13 Petrographic tests should have been discussed much earlier in the test plan.

C-9 $16 \quad$ Delete "in situ" -- the phrase "geologic conditions" makes it redundant.

C-10 1 Change this title to read: "Geophysical Borehole Logging."

C-10 3-20

Note that one of the test objectives is to undertake nondestructive testing.

C-10

Add gravimeter to the list of miscellaneous logs.

C-11

Table C-1 contains a number of errors of omission. Table 1 in Sec. 3.1.1 is a suggested revision of this table.

Replace "permeability" with "hydraulic conductivity." 


\begin{tabular}{ccc} 
Page(s) & Line(s) & \multicolumn{1}{c}{ Comment } \\
C-12 & $3-4$ & $\begin{array}{l}\text { Instead of referring to both "well logging" and } \\
\text { "boreholes," use the term "borehole logging." }\end{array}$ \\
C-12 & $6-7$ & $\begin{array}{l}\text { Truck-mounted units have been brought underground with } \\
\text { little difficulty. }\end{array}$ \\
C-12 & $22-24$ & $\begin{array}{l}\text { Horizontal logging devices are now in use (see literature } \\
\text { from ENSCO and other companies). }\end{array}$ \\
C-13 & $25-27$ & $\begin{array}{l}\text { One or more boreholes and pilot holes will probably be } \\
\text { drilled before the sinking of the shafts. Geophysical logs } \\
\text { of all types should be available from them. }\end{array}$ \\
& $\begin{array}{l}\text { Table } 2 \text { in Sec. 3.1.1 is a suggested revision of Table C-2. } \\
\text { In particular, note that all conventional resistivity- } \\
\text { measuring devices (with the sole exception of induction } \\
\text { devices) require a hole filled with mud or other liquid. } \\
\text { Gamma-gamma tools do not provide reliable measure- } \\
\text { ments through steel casings. }\end{array}$
\end{tabular}
C-14 1-8 Procedural standards for borehole geophysical logging should be referenced.

C-14 10-12

C-15-C-16

$16-26 ; 1-7$

It is doubtful that logging can be conducted "independently" of other activities.

$\begin{array}{lr}\text { C-16 } & 9-20 \\ \text { C-17 } & 10-15\end{array}$

C-18

9-14

C-19

Section C.1.3.4.2 should discuss how the verticality of geophysical boreholes will be determined in cases where such a determination is needed for data reduction and evaluation.

See the comments on logging in Sec. 3.1.1 of this report.

The discussion of resolution of anomalous features is not very meaningful. Resolution depends on method, size, and shape of feature, and electrical-property contrast. Also, delete "(factor of 10)."

Clarify the use of the term "breakouts." Also, the following additions to the text (italics) are suggested: ".. .in surface boreholes of all inclinations, and in combinations of drifts and underground boreholes."

The term "faulting" in the column heading should be replaced by "faults." "Faulting" could be misunderstood in this context as suggesting the listing of newly created faults and accompanying earthquakes. 


\begin{tabular}{|c|c|c|}
\hline Page(s) & $\underline{\text { Line(s) }}$ & Comment \\
\hline C-20 & $22-28$ & See comments in Sec. 3 of this report. \\
\hline $\mathrm{C}-21$ & $2-7$ & $\begin{array}{l}\text { Specify the data format for the wireline logs in detail } \\
\text { (e.g., nine-track tape, } 800 \text { B.P.l., Lis Format with a } \\
\text { depth increment of "X" } \mathrm{mm} \text { [or in.]), and make this data } \\
\text { format part of the detailed logging specifications. }\end{array}$ \\
\hline C-22 & $2-5$ & $\begin{array}{l}\text { Radar should not be lumped with standard electrical } \\
\text { methods; indeed, it is covered in a separate section and } \\
\text { should be deleted from this section. Radar has a much } \\
\text { higher frequency; therefore, its penetration character- } \\
\text { istics are limited by the skin effect. }\end{array}$ \\
\hline $\mathrm{C}-23$ & 1 & Delete the word "underground" from this title. \\
\hline $\mathrm{C}-23$ & $2-16$ & $\begin{array}{l}\text { Detailed gravity surveys (sometimes called "microgravity } \\
\text { surveys") can be extremely valuable in salt domes or } \\
\text { bedded salt where the density contrast between salt and } \\
\text { surrounding rock materials is quite high. }\end{array}$ \\
\hline $\mathrm{C}-24$ & $6-8$ & Mention the required base-station calibration. \\
\hline$C-24$ & $17-18$ & Add "and earth tides." \\
\hline C-24 & $26-27$ & Add "and earth tides." \\
\hline C-25 & 6-7 & $\begin{array}{l}\text { Reword this sentence to read: ". . .the use of a } \\
\text { gravimeter, along with a small tower...." }\end{array}$ \\
\hline C-26 & $11-20$ & $\begin{array}{l}\text { Borehole gravimetry can provide an estimate of rock- } \\
\text { mass density in the volume of rock surrounding the } \\
\text { borehole, not just in the rock adjacent to the hole, as } \\
\text { with logging techniques. }\end{array}$ \\
\hline $\mathrm{C}-27$ & $19-22$ & $\begin{array}{l}\text { The discussion of "collapse features" should be expanded } \\
\text { slightly to include the conditions under which these } \\
\text { features might be encountered. }\end{array}$ \\
\hline $\mathbf{C - 3 0}$ & $7-15$ & Define "relative permettivity." \\
\hline C-30 & 13-15 & $\begin{array}{l}\text { The use of measured radar velocity in rock to convert } \\
\text { time measurements to distance to a reflection should be } \\
\text { mentioned. }\end{array}$ \\
\hline
\end{tabular}


Page(s)

Line(s)

C-32

26-30

C-33

C-34

C-34

29-33

$\mathrm{C}-35-\mathrm{C}-37$

C-35

C-36

C-36

$\mathrm{C}-36$

C-37

$\mathrm{C}-38$
22

3-5

6-33

8-13

2-22

\section{Comment}

The limit of penetration of seismics depends on attenuation in the subsurface and the chargo size rather than on geophone spacing.

In refraction surveying, the distance between the shot and the first geophone is large compared with the distance between successive geophones. The configuration shown in part "a)" is more typical of reflection seismics.

Vertical seismic profiling could be used between the test facility and surface, by using a borehole originally drilled to the level of the test facility.

At the short distances to be used between the source and the detector geophones, the arrivals of $\mathbf{S}$ and $\mathrm{P}$ waves would be very difficult to distinguish.

Additional information on the reflection method (e.g., geophone spacing, processing, and common-depth-poirt profiling) would be useful.

See comments on seismic surveys in Sec. 3.1.4 of this report.

See comments on seismic surveys in Sec. 3.1 .4 of this report.

The reasons for using $\mathbf{S}$ waves should be discussed explicitly, as it is unclear why they are needed.

"Wave forms" should be "waveforms."

The most useful tool to enhance signal-to-noise ratio is common-depth-point stacking. Developed by a geophysicist, this technique is not a statistical tool.

It is not clear whether the primary purpose is seismicity monitoring (microearthquakes) or vibration analysis. The instrumentation might not be the same for both. The relationship between this monitoring and "seismic design of the repository" is not clear because it is well known that low-frequency, high-amplitude events such as earthquakes have very little effect underground, whereas underground blast vibrations can cause considerable damage. 


\begin{tabular}{|c|c|c|}
\hline$\underline{\text { Page(s) }}$ & $\underline{\text { Line(s) }}$ & Comment \\
\hline C-38 & 25 & $\begin{array}{l}\text { Low frequency is a relative term. The meaning of } \\
1-30 \mathrm{~Hz} \text { should be clarified. It could be understood as } \\
\text { the range of response or the range of natural frequencies } \\
\text { of the transducers. For microseismic monitoring } \\
\text { response frequencies of } 2000-3000 \mathrm{~Hz} \text { or greater are } \\
\text { required. }\end{array}$ \\
\hline$C-39$ & $7-9$ & $\begin{array}{l}\text { The word "accelerograph" should be replaced by } \\
\text { "accelerometer." The array of accelerometers is } \\
\text { apparently distinct from that of the geophones } \\
\text { mentioned in the previous paragraph. This point should } \\
\text { be clarified. }\end{array}$ \\
\hline C-39 & 16 & The correct spelling is "propagation." \\
\hline C-39 & $27-29$ & $\begin{array}{l}\text { Calibrating the geophone packages during construction } \\
\text { will be nearly impossible because of the many ground } \\
\text { motions associated with those activities. }\end{array}$ \\
\hline $\mathrm{C}-40$ & 18 & "Air conditioned" should be "air-conditioned." \\
\hline$C-42$ & $1-9$ & $\begin{array}{l}\text { The block-sample location must undergo some pre- } \\
\text { excavation scanning. Blocks must be taken from a depth } \\
\text { of at least } 3-5 \mathrm{ft} \text { into the wall of the room. }\end{array}$ \\
\hline$C-42$ & 24 & The abbreviation for centimeters is "cm," not "cms." \\
\hline$C-43$ & 11 & $\begin{array}{l}\text { Change "cms" to "cm" and "carbide tipped" to "carbide- } \\
\text { tipped." }\end{array}$ \\
\hline$C-43$ & 16 & "Chain type" should be "chain-type." \\
\hline C-43 & $31-33$ & $\begin{array}{l}\text { Reword to read: "Specially designed nondestructive } \\
\text { tests, including...." }\end{array}$ \\
\hline C-45 & $8-13$ & $\begin{array}{l}\text { To check on dispersion, velocities measured at ultrasonic } \\
\text { frequencies could be compared with those measured at } \\
\text { low frequencies from seismics. }\end{array}$ \\
\hline C-47 & $20-26$ & $\begin{array}{l}\text { Stress-change monitoring equipment that uses vibrating } \\
\text { wires has limited usefulness in salt and similar materials. } \\
\text { Experience with such equipment at the WIPP site is } \\
\text { discussed in Stormont et al. (1984). }\end{array}$ \\
\hline$C-48$ & $18-20$ & $\begin{array}{l}\text { The reason adjacent elastic beds are chosen fol stress } \\
\text { measurements should be stated explicitly. }\end{array}$ \\
\hline
\end{tabular}




\begin{tabular}{|c|c|c|}
\hline$\underline{\text { Page(s) }}$ & Line(s) & Comment \\
\hline$C-48$ & $27-32$ & $\begin{array}{l}\text { If the domal salt and adjacent elastic rocks are subject } \\
\text { to different stress regimes, stress measurements in the } \\
\text { elastic beds are not likely t.o be very useful for } \\
\text { predicting stresses in salt. }\end{array}$ \\
\hline$C-49-C-50$ & $8-32 ; 1-11$ & $\begin{array}{l}\text { Hydrofracturing may not be an appropriate procedure } \\
\text { because it provides only the minimum principal stress in } \\
\text { salt. See comments about hydrofracturing in Secs. } 2.5 .2 \\
\text { and 3.2.1 of this report. }\end{array}$ \\
\hline$C-51-C-52$ & $20-34 ; 1-11$ & $\begin{array}{l}\text { See Stormont et al. (1984) for the experiences at the } \\
\text { WIPP site with stiff inclusion gages, as well as the } \\
\text { comments on this topic in Sec. } 3.2 .1 \text { of this report. }\end{array}$ \\
\hline C-57 & $27-29$ & $\begin{array}{l}\text { If overcoring does not apply in salt rocks, the authors } \\
\text { should justify its use. Overcoring was attempted at } \\
\text { WIPP (Stormont et al., 1984). }\end{array}$ \\
\hline C-63 & $16-21$ & $\begin{array}{l}\text { The experimental and analytical backup for Heuze's } \\
\text { model should be presented. U.S. Bureau of Mines test } \\
\text { work found the Goodman Jack to be quite unreliable. } \\
\text { R. de la Cruz, University of Wisconsin-Madison, has } \\
\text { developed a so-called improved Goodman Jack, but little } \\
\text { has been published to prove its effectiveness. In any } \\
\text { case, a deformation modulus is meaningless in salt. }\end{array}$ \\
\hline C-66 & $11-16$ & $\begin{array}{l}\text { When taking measurements over a period of time, } \\
\text { extreme care is required to ensure that the caliper is } \\
\text { reinserted in exactly the same manner as previously. } \\
\text { Otherwise, difficulties could arise in comparing readings } \\
\text { taken at different times. Calipers should be permanent } \\
\text { installations, if possible, in order to minimize the } \\
\text { problem. }\end{array}$ \\
\hline$C-69$ & $4-25$ & $\begin{array}{l}\text { Since the torsional shear test is not very common, a } \\
\text { reference would be appropriate. }\end{array}$ \\
\hline$C-74 ; C-75$ & $25 ; 7$ & A reference is required for these equations. \\
\hline$C-76$ & 22 & The kind of transducers used should be specified. \\
\hline C-83 & $4-6$ & $\begin{array}{l}\text { The objective of the mine-by test is not to confirm the } \\
\text { validity of the model, but the validity of the stresses and } \\
\text { displacements predicted by the model. (The correct } \\
\text { objective is given in lines } 10-12 . \text { ) }\end{array}$ \\
\hline
\end{tabular}




\begin{tabular}{|c|c|c|}
\hline Page(s) & Line(s) & Comment \\
\hline$C-84$ & $16-19$ & $\begin{array}{l}\text { This paragraph recognizes the importance of having the } \\
\text { spacing and dimensions of the test room coincide with } \\
\text { those in a repository. Because of the special physical } \\
\text { properties of salt, only a mine-by test that uses exact } \\
\text { room and pillar transverse dimensions will be useful for } \\
\text { predictive purposes. See comments in Sec. } 3.2 .3 \text { of this } \\
\text { report. }\end{array}$ \\
\hline C-87 & $27-30$ & $\begin{array}{l}\text { The text does not say whether a roadheader will be used } \\
\text { in the repository itself. If not, the same excavation } \\
\text { method should be used as will be used in the repository. }\end{array}$ \\
\hline $\mathrm{C}-88$ & $25-29$ & $\begin{array}{l}\text { Rock bolts may prove useless in salt. See comments in } \\
\text { Sec. } 3.2 .4 \text { of this report. }\end{array}$ \\
\hline$C-89$ & $12-14$ & $\begin{array}{l}\text { It may be difficult to keep an NQ ( } 2.98 \text { in. O.D.) borehole } \\
\text { exactly horizontal and on line over the } 230-\mathrm{ft} \text { room } \\
\text { length. Experience has repeatedly shown that long } \\
\text { exploration holes wander. }\end{array}$ \\
\hline C-90 & $5-10$ & $\begin{array}{l}\text { It is not clear which numerical codes are being } \\
\text { considered. Since there are no agreed-to constitutive } \\
\text { laws for salt, reviewers were skeptical that numerical } \\
\text { analyses of the data will be truly definitive. }\end{array}$ \\
\hline C-91 & 1 & $\begin{array}{l}\text { The rock-bolt pullout test assumes that rock bolts will be } \\
\text { used for support, which may not necessarily be the } \\
\text { case. See comments in Sec. } 3.2 .4 \text { of this report. }\end{array}$ \\
\hline C-91 & $17-21$ & $\begin{array}{l}\text { It is wrong to assume that rock bolts will prove effective } \\
\text { in salt. See comments in Sec. } 3.2 .4 \text { of this reports? }\end{array}$ \\
\hline C-92 & & The "b" part of Fig. C-6 is mislabeled. \\
\hline$C-100$ & & $\begin{array}{l}\text { How the shaft-liner design was selected should be } \\
\text { explained. A reference would be helpful. }\end{array}$ \\
\hline C-104 & & $\begin{array}{l}\text { The various instruments should be made of corrosion- } \\
\text { resistant material. Salt is an extremely corrosive } \\
\text { material and readily attacks less chemically active } \\
\text { metals. }\end{array}$ \\
\hline$-108-C-109$ & $25-30 ; 1-3$ & $\begin{array}{l}\text { The meaning of "layout and maximum power of waste } \\
\text { packages" is unclear. If the phrase refers to waste- } \\
\text { package spacing and heat load, which together result in } \\
\text { an areal thermal load, the subject of the phrase is a } \\
\text { cause rather than an effect. }\end{array}$ \\
\hline
\end{tabular}




\begin{tabular}{|c|c|c|}
\hline Dage(s) & $\underline{\text { Line(s) }}$ & Comment \\
\hline$C-116$ & $1 ; 4 \mathrm{ff}$ & $\begin{array}{l}\text { The word "canister" should be replaced by "container.' } \\
\text { See comment for page } 46 \text {, lines } 10-15 \text {. }\end{array}$ \\
\hline$C-123$ & $27-29$ & $\begin{array}{l}\text { The thermomechanical models to be used should be } \\
\text { specified. Since there is no generally accepted } \\
\text { constitutive relationship for creep, numerical simulations } \\
\text { of thermomechanical behavior may not be accepted in all } \\
\text { quarters as correct. }\end{array}$ \\
\hline$C-133$ & $11-19$ & $\begin{array}{l}\text { Although existing thermomechanicel models may have } \\
\text { been validated for elastic materials, it is unlikely that } \\
\text { they have been validated for salt; hence, the results } \\
\text { should be considered tenuous. }\end{array}$ \\
\hline$C-135$ & $13-17$ & $\begin{array}{l}\text { The time needed to achieve recrystallization is a } \\
\text { contentious issue and depends on the structure of the } \\
\text { salt. See comments and suggestions for improving the } \\
\text { test's effectiveness in Sec. } 3.3 .3 \text { of this report. }\end{array}$ \\
\hline$C-144$ & $18-22$ & $\begin{array}{l}\text { Measurements of the surface roughness should be } \\
\text { included. }\end{array}$ \\
\hline$C-148$ & $22-27$ & $\begin{array}{l}\text { The test should explain how these models apply to salt. } \\
\text { Neither approach seems relevant for domal salt, since it } \\
\text { does not contain throughgoing discontinuities and is not } \\
\text { porous. In bedded salt, one might be able to model salt } \\
\text { through a discontinuum approach by assuming that } \\
\text { interbeds act as discontinuities. }\end{array}$ \\
\hline$C-149$ & 24-25 & $\begin{array}{l}\text { "Through-going rock discontinuities" do not generally } \\
\text { exist in salt. }\end{array}$ \\
\hline C-156 & 1 & $\begin{array}{l}\text { In a medium as highiy impermeable as salt, it is } \\
\text { optimistic to expect many data from a cross-hole } \\
\text { hydraulic conductivity test. }\end{array}$ \\
\hline C-157 & $16-20$ & $\begin{array}{l}\text { Both approaches seem inapplicable for salt. See } \\
\text { comment for page } \mathrm{C}-148 \text {, lines } 22-28 \text {. }\end{array}$ \\
\hline C-158 & & $\begin{array}{l}\text { Figure C-16 appears to have been copied directly from } \\
\text { another source without citing a reference. It shows no } \\
\text { transducers outside the packed-off intervals. Pressures } \\
\text { must be monitored above the top packer and below the } \\
\text { bottom packer to detect leakage past the packers (i.e., } \\
\text { along the wall of the borehole or along fractures } \\
\text { extending into the rock). }\end{array}$ \\
\hline
\end{tabular}




\begin{tabular}{|c|c|c|}
\hline$\underline{\text { Page(s) }}$ & Line & Comment \\
\hline C-161 & $5-7$ & $\begin{array}{l}\text { The authors mention "the groundwater flow equation." } \\
\text { Several equations could be applied, depending on } \\
\text { assumptions made about the type of aquifer, among other } \\
\text { things. The text should indicate which of these equations } \\
\text { is to be used. }\end{array}$ \\
\hline$C-161$ & $7-13$ & $\begin{array}{l}\text { It is wrong to assume that a discontinuity is necessarily a } \\
\text { confined system. Prudence suggests that pressure- } \\
\text { monitoring devices be placed on either side of the } \\
\text { discontinuity during such tests to determine whether this } \\
\text { assumption is valid. }\end{array}$ \\
\hline
\end{tabular}

C-161

$12-13$

Darcy's law may not apply in low-permeability materials. Using Darcy's law requires one to assume (1) a measurable flow potential (or gradient) and hence a flow direction and (2) a known hydraulic conductivity.

C-161

29-33

C-163-C-169

C-165

C-168-C-169

$5-33 ; 1-3$

The last two sentences are unclear. Graphical procedures or methods include "type curve methods."

See comments in Sec. 3.4.3 of this report.

An arrow is needed to "tracer measuring instrument" in the upper borehole. Also, the figure shows no transducers for monitoring leakage past the packers. The methods of sampling for tracer concentrations within the injection and monitoring intervals -- a most important aspect of the test -- are not specified.

The authors should reassess the applicability of these analytical methods to salt.

C-169

C-170

4-13

1

C-174-C-175 22-24;1-26

C-175

19
See comments in Sec. 3.4.3 of this report.

Diffusion is not a realistic transport mechanism because the diffusion length of radionuclides in rock is only a few feet. Thus, the activity of radioactive species will have attenuated to satisfactory levels long before they reach the accessible environment (if they reach it at all).

Salt may not act as a saturated porous medium. See comment for page C-148, lines 22-27.

Mechanical dispersion should be defined as "aṽ." 
Page(s)

C-175

21-25

C-176

C-177

6-7

C-177

25

C179-C-180

$17-30 ; 1-30$

C-180

23-30

C-183

1

C-184

3-15

C-184

4-6

C-185

7-16

\section{Comment}

It is important to demonstrate by calculation that the pressure gradient imposed during the matrix diffusion test will not affect the calculation of the matrix diffusion coefficient. It seems doubtful that a significant pressure effect could be corrected for by theoretical means.

It is not clear how effective porosity can be determined from a diffusion test. The matrix diffusion coefficient depends not only on effective porosity, but also on tortuosity. It will be virtually impossible to isolate these two factors from each other, unless one of them is determined by independent means.

Revise the sentence to read: "horizontal to vertical. Horizontal holes. ..." The "but" in the existing sentence does not express a valid contrast.

For clarity, revise to read: "around a natural bridge of salt. ..."

See comments in Sec. 3.4.5 of this report.

Brine flow will probably alter the salt as noted. Such alteration may make comparison of tests at different times at the same location difficult.

The term "equivalent seal permeability" should be clearly defined.

The test design should also emphasize obtaining data on the structural interaction of the seal and host formation.

The stated objective of room sealing is "to inhibit the passage of groundwater or gas. ..., yet gas is not part of the test. This comment also applies to the borehole-seal and room-backfill performance tests.

A single test cannot evaluate the three fundamental types of proposed seals. Also, the seal types to be tested are not specified. This apparent lack of test definition is serious because such things as appropriate test techniques and durations depend on the seal material and design. The adequacy of the test cannot be determined from the material provided. See Sec. 3.4.6 of this report for further comments. 
Page(s)

C-185

C-192

C-195

C-194

C-194

12-15

C-194

C-194

20-23

C-195

22-25

C-197

C-197

C-198

28-31

\section{Comment}

For a detailed critique of D'Appolonia's seal design, see Hambley et al. (1984).

The term "effective hydraulic conductivity" should be clearly defined.

The phrase "confirmation of satisfactory performance [of the seal]" needs explanation.

For a detailed critique of D'Appolonia's seal design, see Hambley et al. (1984).

Change the word "volume" to "arrival rates" or "release rates" because the volume is time-dependent.

The citation of "Gnirk et al. (1981)" in the list of references on page 116 is incorrect; the correct report number is SAND 81-7054. Also, the reference "Pigford (1982)" should be included.

17-18 What is implied or anticipated by ". . potentially complex synergistic effects relevant to actual repository conditions. .." should be explained.

Gamma radiation had substantial effects on brine migration in the tests at the Asse mine, and it should not be ignored here.

To improve the simulation values, the "nonreactive porous backfill" should perhaps be crushed salt. The same comment applies to page C-198, lines 1-2.

Change "redundacy" to "redundancy."

Section C.4.7.2.3 refers to "Sec. 2.4.4.4.2," which does not exist.

The fluid surge following heater shutdown is not yet understood; it cannot be explained simply as a function of "microcracking during cooling." Some researchers (Pigford, 1985) consider it an important phenomenon to examine, both in situ and in modeling.

The equipment/instrumentation/services list should include stress-meters that are carefully calibrated before installation. 
$\underline{\text { Page(s) }}$

Line(s)

C-203

18-28

C-209

C-213

5-6

C-213

12-14

C-219

1-2

C-221

8-10

C-221

18-21

$C-223$

11-12

C-224

18-26

The rate-of-moisture-release equation needs to be clarified. Furthermore, " $\mathrm{K}$ " is used to represent two parameters -- Boltzmann's constant and permeability. The units for vapor pressure and permeability should be dyne/cm ${ }^{2}$ and $\mathrm{cm}^{2}$, respectively. The superseript "2" seems to have been inadvertently omitted in both cases.

6-8 Grout must be chemically compatible with surrounding rocks, a fact not mentioned here. See comments in Sec. 3.4.8 of this report.

It is not clear how pressure data collected in the vicinity of the repository will "establis" or confirm the boundary conditions for the site geohydrological model." The boundaries of such a model will be far removed from the repository. The near-field model may be intended. The scale of the assumed model should be clarified.

This last bulleted objective is nebulous. The answer will be obtained from all of the test and monitoring data at the site, not merely from the pressure data. The data obtained may or may not be sufficient to characterize this impact with absolute confidence.

Because salt is such a low-permeability material, it will be difficult to assess the travel pathways taken and hence the lag time.

The drifts are not adits. An adit is a horizontal entry driven into the side of a hill from the surface.

Pore fluids are only one of several possible types of fluids present in a salt formation. As a result, the net water content at an engineered barrier could exceed the level indicated by pore fluids alone.

Add "such as interbeds" after the word "discontinuities."

This equipment is very reminiscent of brine-sampling equipment/instrumentation at the brine migration testing facility at the Asse mine, where severe problems with brine contamination exist. The problem of contamination should be addressed.

C-226 2-4

It is very difficult to "quantify reaction rates for dissolution" of a fluid, in which the dissolution of the solute has already occurred. 


\section{REFERENCES}

Baar, C.A., 1977, Applied Salt Rock Mechanics - I, Elsevier Scientific Publishing Co., Amsterdam.

Blake, W., and F. Leighton, 1970, Recent Developments and Applications of the Microseismic Method in Deep Mines, in Rock Mechanics -- Theory and Practice, Society of Mining Engineers, New York, pp. 429-444.

Blake, W., Nov. 1979, self-employed consultant, Hayden Lake, Idaho, unpublished information.

Cook, J.C., 1972, Seeing through Rock with Radar, Proc. 1972 Rapid Excavation and Tunneling Conf., Society of Mining Engineers, New York, 1:89-101.

Hambley, D.F., et al., Sept. 1984, Radioactive Waste Isolation in Salt: Peer Review of the D'Appolonia Report on Schematic Designs for Penetration Seals for a Repository in the Permian Basin, Texas, Argonne National Laboratory Report ANL/EES-TM-262.

Halbouty, M.T., 1979, Salt Domes: Gulf Region, United States and Mexico, Gulf Publishing Co., Houston.

Hohlfelder, J.J., June 1980, Salt Block II: Description and Results, Sandia National Laboratories Report SAND 79-2226.

Kelsall, P.C., et al., Nov. 1982, Schematic Designs for Penetration Seals for a Reference Repository in Bedded Salt, ONWI-405, prepared by D'Appolonia Consulting Engineers, Inc., for the Office of Nuclear Waste Isolation, Battelle Memorial Institute, Columbus, Ohio.

Mraz, D.Z., and M.B. Dusseault, 1985, Method of Correlation of Laboratory Tests with In Situ Conditions, Proc. Sixth International Symp. on Salt, The Salt Institute, Alexandria, Va., 2:259-268.

Nickel, H., 1980, Absorption Measurements with Radio Waves in Salt Mines, Its Passibilities and Limitations, Proc. Fifth Symp. on Selt, Northern Ohio Geological Society, Inc., Cleveland, 1:305-308.

Pigford, T.H., 1982, Migration of Brine Inclusions in Salt, Nuclear Technology, 56:93.

Pigford, T.H., April 1985, Lawrence Berkeley Laboratory, unpublished information.

Rote, D.M., et al., Oct. 1985, Radioactive Waste Isolation in Salt: Peer Review of Westinghouse Electric Corporation's Report on Reference Conceptual Designs for $a$ Repository Waste Package, Argonne National Laboratory Report ANL/EES-TM-292. 
Sellers, J.B., 1974, Measurement of In Situ Shear Strength Using the Torsional Shear Method, in Field Testing and Instrumentation of Rock, American Society on Testing and Materials, STP 554, Philadelphia, pp. 147-155.

Stein, R., 1985, Acting Head, Engineering and Licensing Division, Office of Civilian and Radioactive Waste Management, U.S. Department of Energy, personal communication to J. Neff et al., Salt Repository Project Office, Columbus, Ohio.

Stormont, J.C., R.V. Matalucci, and H.S. Morgan, April 1984, Field Tests of Stress Measurement Techniques in Rock Salt, Sandia National Laboratories Report SAND 83-2507.

Thierbach, R., and H. Mayrhofer, 1980, Electromagnetische Reflexionsmessungen in Saltzlagerstatten, Proc. Fif th Symp. on Salt, Northern Ohio Geological Society, Inc., Cleveland, 1:393-403.

Unterberger, R.R., 1974, Electromagnetic Wave Propagation in Salt -- Probing into Salt with Radar, Fourth Symp. on Salt, Northern Ohio Geological Society, Inc., Cleveland, 2:11-26.

Unterberger, R.R., 1980, Radar and Sonar Probing of Salt, Fif th Symp. on Salt, Northern Ohio Geological Society, Inc., Cleveland, 1:423-438.

Unterberger, R.R., April 12, 1985, personal communication to W. Harrison, ANL QA No. ASI-72.

U.S. Department of Energy, Feb. 1985, Annotated Outline for Site Characterization Plans, Office of Civilian Radioactive Waste Management.

U.S. Department of Energy, 1984, Draft Environmental Assessment, Deaf Smith County Site, Texas, Vol. 1, Office of Civilian Radioactive Waste Management, DOE/RW-0014.

Zeuch, D.H., D.J. Holcomb, and H.S. Lauson, Jan. 1985, Analysis of Consolidation of Granulated Rocksalt Using a Plastic Flow Model for Isostatic Hot-Pressing, Sandia National Laboratories Report SAND 84-1106. 


$$
65 / 66
$$

APPENDIX A

U.S. DEPARTMENT OF ENERGY LETTER REQUESTING PEER REVIEW 
Department of Energy

Chicago Operations Office

Salt Repository Project Office

505 King Avenue

Columbus, Ohio 43201-2693

Commercial (614) 424-5916

F.T.S. 976-5916

March 19, 1985

\begin{abstract}
Wyman Harrison
EES-362

Argonne National Laboratory

9700 South Cass Avenue

Argonne, IL 60439

Dear Dr. Harrison:

SUBJECT: REQUEST FOR PEER REVIEW OF SRP'S IN-SITU TEST PLAN

SRPO requests that ANL conduct a Peer Review of the subject $p 1$ an by ANL's established procedures. SRPO also requests that ANL provide us with a detailed schedule of the review process and a complete list of the personnel involved, including their specific responsibilities by March 31, 1985. The latter request is made to provide SRPO with assurance that an appropriate review will be performed within a time frame consistent with SRPO schedule for publication of the document.
\end{abstract}

The document presenting the results of the review should specifically address at least the following items.

The general technical adequacy of both the document and the activities described within it.

The interrial consistency of the plan.

The consistency of the plan with general programatic goals such as those stated in the NWPA, 10 CFR 60, 40 CFR 100, and the Mission Plan.

The ability of the plan to provide information indicated in the SCP Annotated Dutline, Sections 8.3.1 and 8.3.2. That is:

- Why the test, study, or analysis is planned and what data or information will be obtained

How the results will be used to help resolve specific information needs

- What methods, techniques, and data analysis will be used

Limitations and uncertainties of test methods and data analysis are discussed 
Representativeness, precision, and accuracy of proposed test methods and data analysis are addressed

Significant options or al ternative test methods and data analysis to those proposed are discussed

In addition, you should also review tile test plan to see if it provides:

A description of tests that could use radioactive materials

A description of tests that might affect the capability of the site to isolate waste

- A discussion of instrumentation and monitoring requirements

- The application of expected test results to the development of follow-up testing

You snould also compare the plan with the most recent Issues Hierarcy and data needs with regard to at least the following:
a) Issues or data needs not identified in the plan, which could be addressed by in-situ testing;
i) The likelinood that tests described in tile plan will satisfy the identified data needs.

The preceeding items represent aspects of the docunent that SRPO expects to be addiressed in Aill's response and are not intended to restrict the usual scope of your peer review.

SRPO requests that ANL provide the formal written review results by Hay 19 , 1985. Questions regarding this letter should be addressed to Ram Lahoti of my staff.

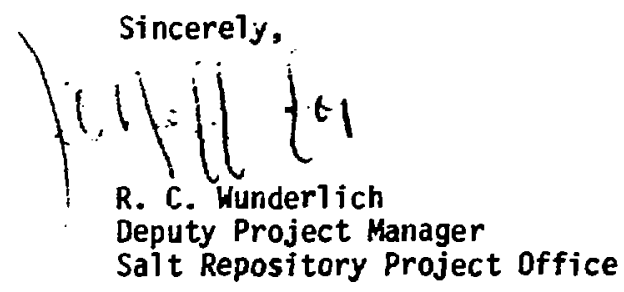

SRPO:RBL : $\max :$ 6434B

\author{
CC: J. Neff, SRPO \\ J. Sherwin, SRPO \\ G. Appe 1, SRPO \\ T. Baillieul, SRPO \\ R. Wu, SRPO \\ L. Casey, SRPO \\ K. Robinette, SRPO \\ B. kiaters, SRPO \\ S. Weuster, SRPO
}


$69 / 70$

APPENDIX B

CONCURRENCE SHEET 
71172

APPENDIX B

CONCURRENCE SHEET

I concur that the Argonne National Laboratory review of the Colder Associates, Inc., Draft Test Plan for In Situ Testing in an Exploratory Shaft in Salt fairly represents my comments, where incorporated, to the peer review panel.

Apery wrecker Gregory $\beta$. Beecher EA. Satin. Richard $M$. Bateman
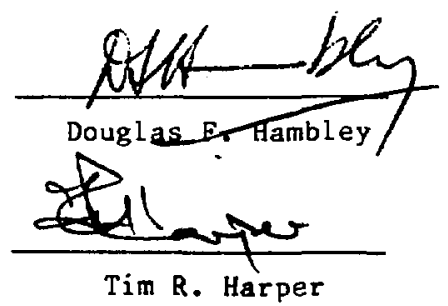

$\frac{\text { Shbow Near }}{\text { shoo P. Newman }}$

Robert a. Parlors Robert A. Paddock

Doualomirete Donald $M$. Rote
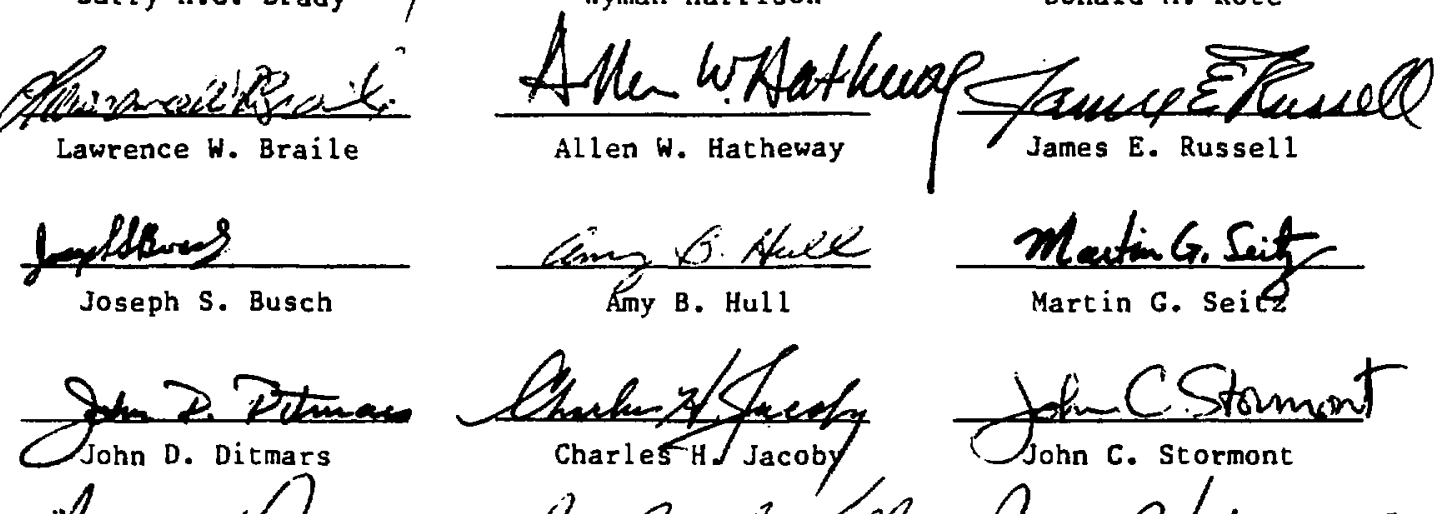

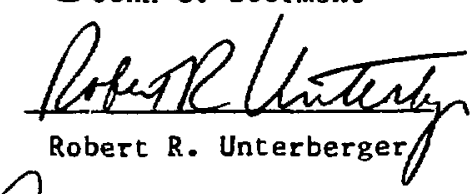
C. Randy Keller Charles H. Downing
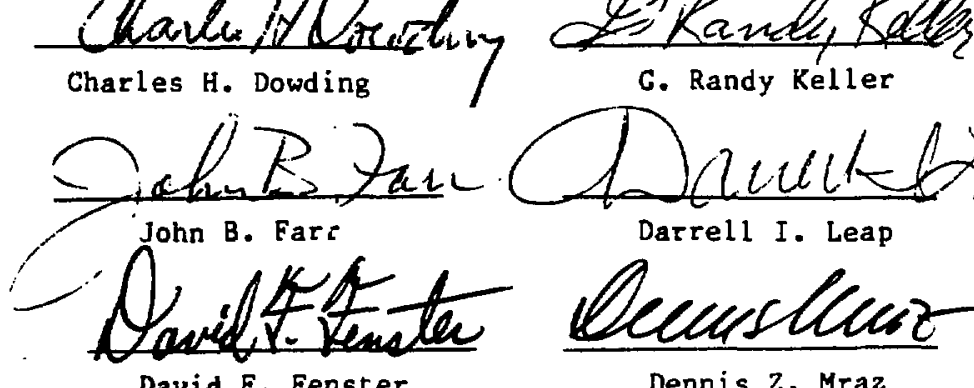

David F. Fenster

Dennis Z. Mra

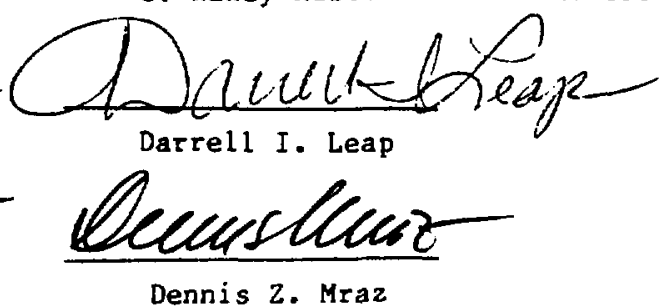


APPENDIX C

ACTION TO BE TAKEN ON THE ARGONNE PEER REVIEW PANEL COMMENTS 


\section{APPENDIX C}

\section{ACTION TO BE TAKEN ON THE ARGONNE PEER REVIEW PANEL COMMENTS}

Responses to the Argonne National Laboratory (ANL) comments were received in December 1985. The apparent differences of opinion between Golder Associates, Inc. (Golder), and ANL on several issues necessitated a meeting to resolve them. The meeting was held at ANL on February 4-5, 1986, and was attended by representatives of ANL, ONWI, SRPO, and Golder. The action statements in this appendix reflect the agreements reached at that meeting and in subsequent telephone conversations. Argonne assumes that subsequent versions of the reviewed plan will incorporate the suggested revisions.

\section{ACTION ON ARGONNE RECOMMENDATIONS}

\section{General Comments}

Recom$\underline{\text { mendation }}$

\section{Action Statement}

The document's title will be changed to Draft Underground Test Plan for Site Characterization and Testing in an Exploratory Shaft Facility in Salt (hereafter referred to as UTP). Also, the term "in situ" will be replaced throughout the UTP by "underground."

The unique mechanical and thermomechanical behaviors and properties of salt were considered as information needs were developed and tests were evaluated, selected, and described. When the tests are described more completely in the detailed test plans, the creep behavior of salt will be considered to the extent required. The abbreviated test descriptions in Sec. 5 of the UTP will be deleted, and readers will be referred to the descriptions in App. $C$ of that document. With regaro to fluid migration mechanisms, see the action statement for recommendation 17.

The discussion of test selection methodology, as well as the discussion of why the specific suite of tests was selected, will be included in Sec. 4.2 of the UTP. Specifically:

- The first sentence in Sec. 4.2 will be replaced with the following paragraph:

The approach used to derive the program of underground testing from the identified information needs is shown in Fig. 4-2. Essentially, once information needs have been developed, the tests available for 


\section{Action Statement}

addressing each information need are identified, and each test is evaluated with respect to its ability to satisfy that information need. After this evaluation, the suite of tests (type and number) necessary and sufficient to satisfy the information needs is then selected. A smaller program would be insufficient, resulting in project delays, while a larger program would be unnecessary, resulting in excessive costs. In selecting the suite of tests, interactive effects are considered, that is, the efficacy of a combination of tests in satisfying an information need and the satisfaction of different information needs by a single test, as well as the efficacy of single and multiple tests in satisfying an information need. Because the current information needs are qualitative in nature, the evaluations have been qualitative and the tests have had to be selected based on subjective assessments. Once the information needs have been quantified, tests can be selected in a more objective manner.

- The last paragraph in Sec. 4.2 will be replaced with the following paragraphs:

The integrated test program, to include surface-based, surfaceborehole, laboratory, and underground testing, can be derived by considering the information needs to be satisfied by testing and the efficacy, cost, and duration of available test methods. Because of the qualitative nature of the analysis and the current emphasis on underground testing, the following approach was used to formulate the program of underground testing, after considering available underground tests.

Underground tests fall essentially into two major categories: (1) those concerned primarily with site characterization and (2) those concerned with evaluating the interactions between the engineered systems and the site. The types of tests that fall into the former category are generally of low cost and short duration; however, a large number of repetitions is usually required to have good confidence in the data. Those in the latter category are generaily of intermediate to high cost and of relatively long duration; however, only a small number of tests of each type is usually necessary. The cost of testing also depends on when and where the tests are performed, which is implicitly factored into the analysis. For example, activities performed within the shafts will generally be much more costly than the corresponding activities performed within the test rooms. 
In general, geologic site characterization activities are included in the UTP, even when the individual activities are by themselves only moderately effective in addressing information needs, because of the moderate cost of these activities and the of ten considerable benefit obtained by overlaying the results of the individual efforts (e.g., geophysical surveys). However, if a specific method is considered to have very little relevance (e.g., radar surveys in an argillaceous salt environment), it is not included. Other geologic site characterization methods, such as geologic mapping in the shafts, are included, notwithstanding the significant costs, because of the importance of gathering this information.

Geomechanical, thermomechanical, and geohydrological site characterization testing is generally limited to relatively simple and cost-effective tests. In general, it is preferable to obtain statistically significant test data representative of the entire facility, rather than detailed information at a single location. Hence, tests such as the torsional shear test for assessing discontinuity/shale-interbed shear strength are included and tests such as the direct shear test are not. Similarly, relatively expensive in situ material-property tests such as heated or unheated block tests (to study medium-scale deformational and thermomechanical behavior) and cross-hole heater tests (to determine thermal conductivity and specific heat) are not included because (1) information of adequate quality was judged to be available from either laboratory testing or simpler underground testing and (2) confirmatory data, which can be used to calibrate the results of simpler tests, will be available from some of the complex engineeredsystem/site tests being conducted prinarily for other purposes, as noted below.

Almost invariably, testing associated with assessing the interactions between engineered systems (e.g., rooms, waste packages, backfill, and plugs and seals) and the host rock consists of large-scale and relatively expensive tests. Because it is difficult to predict the esponse of such complex systems, high priority is given to tests considered to be relatively good in situ demonstrations of the repository systerns (e.g., mine-by and room heater tests, facility response monitoring, waste package tests, and room seal tests), notwithstanding the costs of such lesting. In those cases where significant modifications to the current exploratory shaft facility concept would be required before the testing; could be undertaken (e.g., shaft decommissioning seal), such lesting is deferred on logistical grounds. Large-scale tests for model validation purposes (e.g., pillar and chamber tests of various configurations), rather than for both model validation and repository system demonstration purposes, were considered less cost effective and are not included in the UTP. 
Recom-

mendation

\section{Action Statement}

The selected underground test methods from Table B-2, together with the underground tests specifically required by the regulations (see the regulatory testing requirements in Table $A-1$ ), are presented and discussed in Sec. 5 .

Factors such as costs and the efficacy of different test methods are qualitatively evaluated in Table B-2 of the UTP. Quantitative specification of the information needs will define the confidence with which performance must be predicted. A defensible determination of the number of tests required must await such definition of the information needs. Also see action statement for recommendation 3 .

5 Long horizontal exploration holes will not be a significant element in the revised UTP, which will be specific for the Deaf Smith County site, that is, for bedded salt. (Horizontal holes would be of considerable potential value in domal salt, provided care were taken not to penetrate the flanks of the dome.) The UTP will not be changed.

No resolution is required. The revised UTP will be specific for the Deaf Smith County site, that is, for bedded salt.

The words "validating models" will be changed to "assist in validating models."

\section{Technical Comments}

Tables $\mathrm{C}-1$ and $\mathrm{C}-2$ of the UTP will be revised as shown in Tables $\mathrm{C.} 1$ and C.2.

Radar has limited application for site characterization in wet or argillaceous salts, such as those typical of bedded salt sites. However, radar may have considerable application in dry and clean salts, such as those typical of domal salt sites. The revised UTP will discuss radar probing with respect to the type of salt found at the Deaf Smith County site.

10 The application of sonar will be reviewed; if appropriate, this technique will be incorporated into the revised UTP.

11 The amount of information on in situ stresses that can be deduced from hydrofracturing tests will be limited because salt does not exhibit the classical hydrofracturing response. However, hydrofracturing will continue to be considered in the revised UTP. 
TABLE C.1 Information to Be Interpreted from Individual Logging Methods

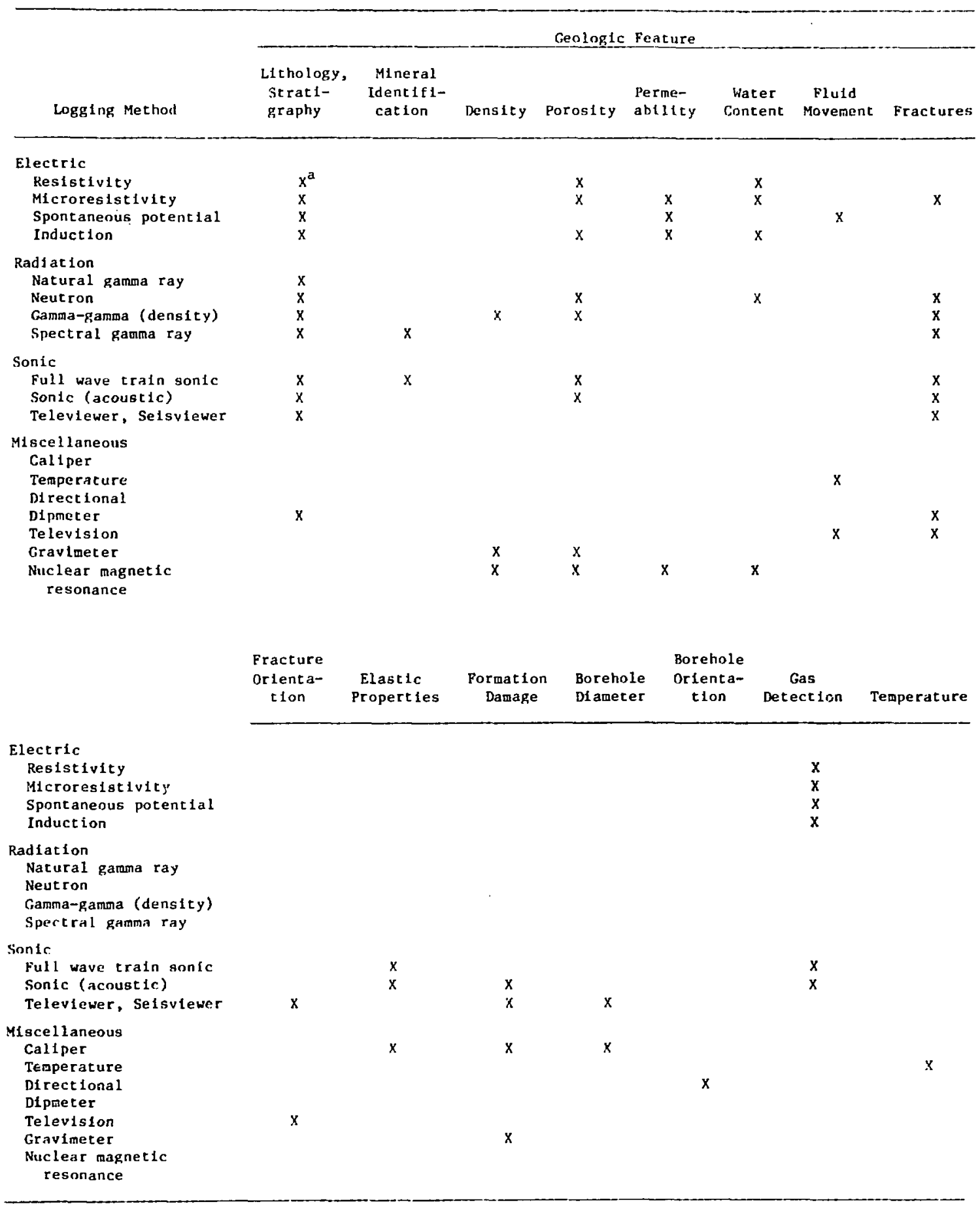

$a^{X}=a p p l i c a b i l i t y$ for spectfic purpose. 
TABLE C.2 Borehole Conditions Appropriate for Individual Logging Methods

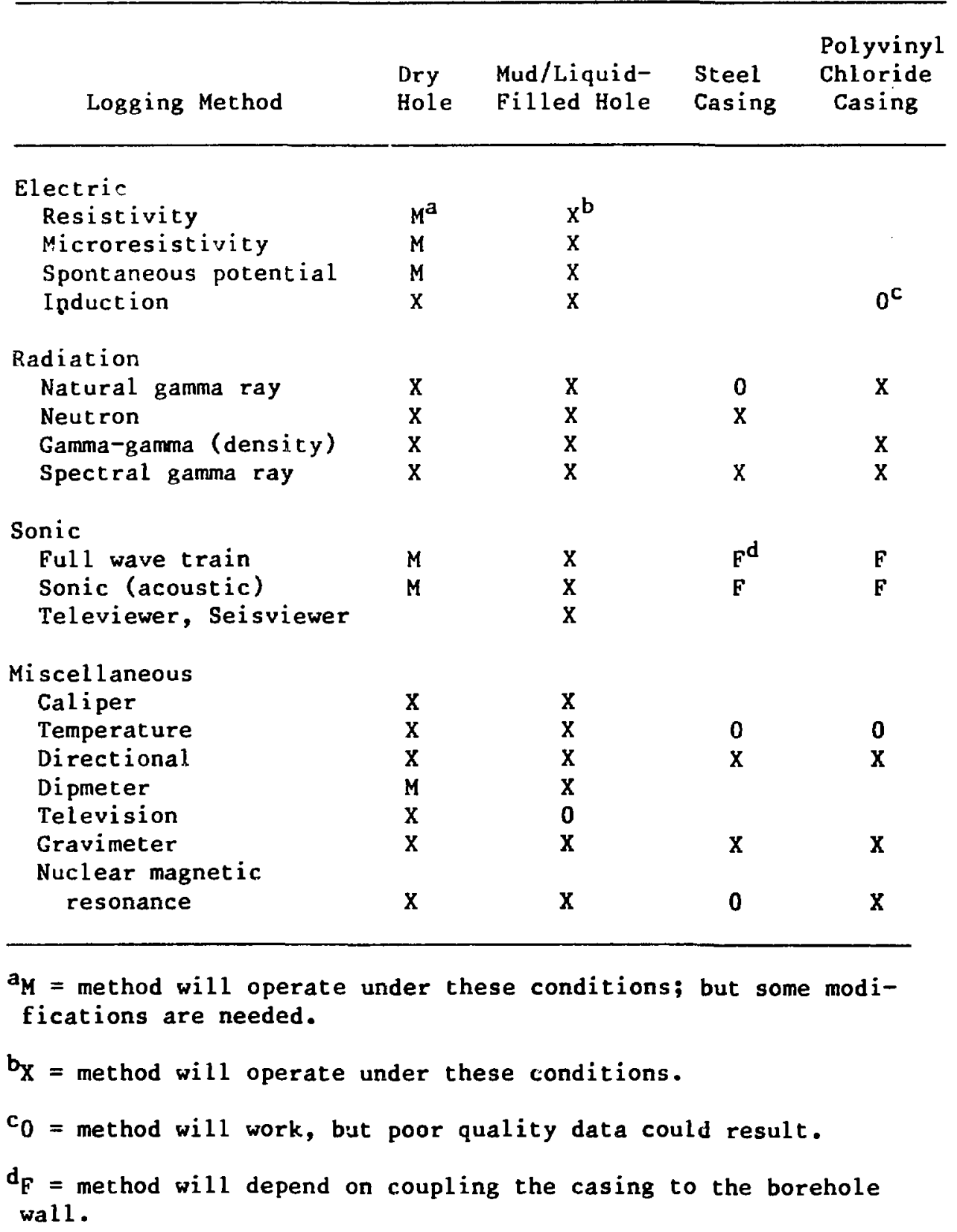


Recom-

mendation

12

13

14

15

16

17

18

\section{Action Statement}

Many of the major tests will not have been completed by the time of the license application, and testing will continue during the license application process. A concurrent mine-by and room-scale heater test would be desirable; however, Golder does not consider such testing to be necessary and claims that monitoring data from other rooms will provide long-term information on ambient temperature behavior. The UTP will not be changed.

The block test proposed by ANL is inappropriate. The UTP will not be changed.

The revised UTP will state that a variety of bolts will be tested, including any that might be used within the repository. The test description will be modified to indicate the limitations of such testing in salt formations.

The conceptual design of the room backfill test in the UTP is considered adequate at this stage, although detailed test design may result in significant modifications. (Such modifications will be a function of room backfill design, which is currently unspecified.) The UTP will not be changed.

The revised UTP will provide additional descriptive material concerning the borehole and room-seal performance tests. See action statements for Secs. 3.4.5, ๆ 1 , and 3.4.6, ข 1 , for related commentary concerning these tests.

The revised UTP will provide for single-borehole hydraulic conductivity tests as a reconnaissance tool to identify zones of relatively high permeability and to demonstrate the low permealility of intact salt or other materials. The specific hydrogeologic tests will be conducted only in zones identified as being sufficiently perineable to obtain meaningful data. See action statement for Sec. 3.4.4 for comments regarding the applicability of tracer diffusion tests.

The revised UTP will incorporate the changes concerning the fluidsampling system that are outlined in the action statement for Sec. 3.5.1.

The revised UTP will state that laboratory chemical analyses are not within its scope. 


\section{ACTION ON ARGONNE COMMENTS IN THE MAIN TEXT}

\section{General Comments}

Section Paragraph(s)

2.1

2

2.2

2

3

2.3

\section{Action Statement}

See action statement for recommendation 1.

The Nuclear Waste Policy Act of 1982 does not permit radioactive sources during site characterization testing prior to license application unless analysis demonstrates the need and NRC approves. In addition, the UTP is not an appropriate place to review laboratory studies. The UTP will not be changed.

Waste package corrosion testing will be incorporated into the canister-scale heater tests. Information relevant to waste package corrosion as derived from brine migration tests and chemical characterization of in situ materials and fluids will be considered.

Inconsistencies will be resolved by removing the short test descriptions in Sec. 5 of the IJTP and by referring directly to . the descriptions in App. $C$ of that document. The rationale for selecting the tests (App. C) from those available (App. B) is described briefly in Sec. 4 of the UTP. Essentially, the tests chosen were those considered after evaluation to be both necessary and sufficient in satisfying the information needs. However, the current set of information needs is not only preliminary but also qualitative in nature. As a consequence, any evaluation of the tests with respect to their ability to satisfy information needs must also be qualitative (and even subjective).

Once the information needs are finalized and quantified by ONWI, the tests can be more rigorously evaluated with respect to the degree to which the information needs are satisfied and a clear basis for test selection can be established. In other words, the set of tests selected must satisfy the information needs (i.e., must reduce the parametric and modeling uncertainties to the required levels) within budget and schedule restraints. It must also be remembered in this context that each test typically addresses more than one information need and that a suite of independent tests addressing one information need typically has a cumulative effect larger than that of any one of the tests. This rationale will be clarified in the revised UTP. Also see action statement for recommendation 3 . 
Section Paragraph(s)

2.4

2.5.1

2.5.2

2.5 .3

2.6

2.7

2.8
Action Statement

See action statement for recommendation 12 .

See action statement for Sec. 2.2, ॥ 2 .

The ANL comments regarding hydraulic fracturing were inappropriate in this context. The need for developing a technology for sealing horizontal holes is recognized. Also see action statement for recommendation 5 .

The revised UTP will indicate that much of the test instrumentation for site characterization will require development. This consideration will be addressed in the detailed test plans and procedures that will be developed. However, the basis for this concern will be summarized in the introduction to the revised UTP. Follow-up testing will receive further consideration. Also see action statement for Sec. 2.2, If 3 .

Section 2.2 of the UTP was meant to provide only a brief review of previous in situ testing programs. All available WIPP published data up to mid-1984, which date was essentially the cutoff for inclusion in the reviewed version of the UTP, were examined. Section 2.2 is not the place to discuss unresolved issues for other test programs. Such unresolved issues are of direct interest only to the extent that they relate to SRP needs. Section 4 and supporting material in App. A of the UTP identify in a qualitative manner the unresolved issues and information needs for the SRP, taking into account available information from other programs. This type of material will be presented more completely and quantitatively in the SCP and other documents. No further action will be taken.

Golder is aware of the many models proposed for salt behavior. The detailed test plans to be developed will reflect the models of mechanical behavior available at that time.

See action statement for recommendation 6 . 
Section Paragraph(s)

2.9

2.10

2.11

2.12

\section{Action Statement}

Laboratory testing will be valuable in studying backfill consolidation. However, field demonstrations will also be required to evaluate backfill/surrounding-rock interface effects and to provide data from larger-scale tests to assist in model validation.

Tests that depend on backfill consolidation for their effectiveness might not be effective if the expected consolidation does not occur. In fact, a major purpose of such testing is to demonstrate that such consolidation does occur. If it does not, the potentially significant impacts would be for repository design rather than for test effectiveness. This reasoning will be incorporated into the revised UTP.

See action statement for recommendation 3 .

See action statement for recommendation 7 .

The concept for the data acquisition system planned for the exploratory shaft facility will be briefly described in the revised UTP. A detailed planning document for the data acquisition system and a data management plan are being prepared.

The discussion of the available underground tests (App. B) explicitly acknowledges the surface-based and laboratory test programs and their roles in satisfying information needs. In fact, the reason that these other test programs were considered in the UTP was to clarify the overall approach to resolving information needs and to demonstrate that the program of underground testing must consider more than underground test methods. Indeed, it is generally more cost effective to resolve issues and satisfy information needs by surface-based methods where possible and have exploratory shaft facility test activities address only those items that cannot be resolved by other means.

Since the revised UTP will address methods of data acquisition, but not predictions or data specifications, the UTP may not be the place for detailed discussion of this issue. How'ever, feedback between the test programs and the information needs will be added to the figures in Sec. 4 of the UTP that outline the methods for developing information needs and test programs. 
Technical Problems
3.1 .1
See action statement for recommendation 8.
3.1 .1
Such testing will be addressed in the surface-based test plan.
3.1 .2
The section will be retitled as suggested. Methods for reducing gravity data will be presented in the detailed procedures to be developed later. With regard to borehole gravity measurement, see action statement for Sec. 3.1.2, ข 4.

\section{1 .2}

Microgravity surveys may prove useful and will remain as an option in the revised UTP.

Gravity surveys may provide useful information if the conditions are right. However, since the maximum contrast will be between rock and an air-filled cavity, it may be difficult to identify anomalies located more than several times their size from the measurement traverse.

The revised UTP will not recommend gravity surveys in boreholes drilled from within the exploratory shaft facility; therefore, further discussion of borehole gravity measurement is unwarranted.

See action statement for recommendation 9.

The UTP will be revised to indicate that multichannel seismic surveys may use hammer-type as well as explosivetype sources.

The revised UTP will state that surface-based seismic work will be discussed in the surface-based test plan.

See action statement for Sec. 3.1.4, 2. The revised UTP will state that the plan addresses only the seismic testing to be performed from within the exploratory shaft facility.

The discussion of seismicity monitoring will be revised to cover monitoring of all natural and man-made seismic activity (i.e., large, distant earthquakes to near-field earthquakes [microseismics], noise [acoustic emissions], and construction [blast vibrations]). 
Section Paragraph(s)
3.1.5
2,3

3.1.6

3.1.7

3.2

1

3.2

2

3.2 .1

1

3.2 .1

3.2 .1

2

3

\section{Action Statement}

The locations and layouts of the various seismic sensor arrays (geophones and accelerometers) will be given.

The revised UTP will state that large-diameter coring is a preferred method of obtaining large block samples.

See action statement for recommendation 10 .

Details regarding test procedures and methods for analyzing data will be provided in the detailed test procedures. No change will be made to the UTP.

The ANL comment about stress gradients relates to far-field models on a subregional scale. Such considerations are beyond the scope of the UTP. In addition, the reference to inclinometers relates to a grid of instruments in surface boreholes away from the shaft. Such instrumentation is more properly considered in the surface-based test plan. The possibility that differences in underground stress measurements in different locations could to some extent reflect regional stress gradients will be mentioned in the revised UTP. Discussion of the volume of rock to be measured is beyond the scope of the UTP; therefore, no change will be made.

Although Golder was aware of state-of-the-art measurement techniques, the information could not be referenced at the time the UTP was drafted. This problem will be resolved in the revised UTP.

See action statement for recommendation 11.

The ANL comment concerning grouted flatjacks actually refers to borehole pressure cells. The revised UTP will refer to such cells as one of the methods that has been and will be applied in attempting to measure stress change. Stresschange monitoring will be used to assist in model validation and, when necessary, model development.

The ANL comments will be incorporated into the revised UTP, along with the reference.

See action statement for recommendation 12 . The revised UTP will clarify that data from the mine-by test will be one means of confirming the validity of the geomechanical model. 
Section Paragraph(s)

3.3.3

3.3.3
See action statement for recommendation 14.

ANL concerns under this heading are covered in Sec. 5.1.2.3 (Borehole Condition/Convergence Monitoring) of the UTP. Also see action statement for recommendation 13.

The canister-scale heater test offers no opportunity for obtaining quantitative information on thermally induced brine migration (see Sec. C.4.7 [Brine Migration Test] of the UTP). The revised UTP will state that underground geochemical and corrosion testing will be coordinated with the Waste Package Management Design Group.

See action statement for recommendation 12. The revised UTP will clarify ANL concerns.

See action statement for recommendation 15 .

Preliminary calculations indicate that accelerated testing is required. The revised UTP will emphasize that this position must be quantitatively verified.

A test can provide a useful demonstration of a phenomenon even though test conditions are different from those in a repository. Accelerated testing may indeed emphasize unimportant processes. However, if the test were well designed, this difficulty could be avoided.

The room-backfill performance test was designed as an accelerated test because it would take too long to obtain meaningful data in real time. This test as designed represents a compromise in that more useful information will be gained than lost. However, this proposal will be evaluated in more detail at a later date. No additional action will be taken.

The short test descriptions in Sec. 5 of the UTP wiil be deleted, triereby eliminating the sentence referring to "appropriately validated thermomechanical models." The relationship between model validation and data is explained in Sec. C.3.4.4.2 of the UTP. ANL withdraws its comment about salt being lithified at temperatures higher than those occurring in the repository. 
$\underline{\text { Section }}$

3.3.3

3.3.3

3.3.3

3.4 .1
Paragraph(s)

5

6

7

1

\section{Action Statement}

The revised UTP will state that increasing the initial inplace density of the backfill relative to that anticipated in the repository may prove desirable as an approach. Supporting information to justify this approach will be developed through laboratory testing.

Stressing or destressing of the intervening plug is a function of a variety of factors, including excavation sequence and geometry, including pillar size. The detailed test plans will address such variables as the excavation sequence, pillar size, and sequence of instrumentation for the thermomechanical models available at that time. The test diagram will be redrawn so that the length of the pillar will considerably exceed its height.

It is not now possible to make "wholly convincing" arguments justifying accelerated tests. The detailed test plans will address to the extent possible these difficulties in interpreting data.

The revised UTP will state the need to develop a guarded (double) straddle packer test tool for hydrologic testing. With such a tool, fluid pressures could be monitored within the test interval (between the guarded packers) and possibly outside the packers (in the remaining portions of the borehole).

Fluid injection pressures that are not excessively greater than ambient formation pressures will be used to ensure that hydrofracturing does not occur. Hydrofracturing would probably not occur at ambient or lower pressures, unless the total stress had changed (e.g., as a result of excavation). An appropriate test stretegy might be to conduct a series of tests at successively higher pressures to establish the permeabiiity/pressure relationship before the conditions conducive to hydrofracturing are approached. It might then be possible to extrapolate hydraulic-conductivity/pressure data and predict hydrologic properties at ambient pressure conditions. If credible breach scenarios are expected to occur at formation pressures different from ambient, consideration will be given to conducting tests at these pressures. These suggestions will be incorporated into the revised UTP. 
Section Paragraph(s)

3.4.1

\section{Action Statement}

To minimize wellbore storage and skin effects, the most reliable single-borehole testing method is an injection (withdrawal)/recovery test in which hydraulic recovery is measured in a shut-in borehole. Test results can be analyzed using the Theis (1935) semilog recovery method and the Gringarten et al. (1979) type-curve method, as discussed in Marinelli and Rowe (1985). These analytical techniques either account for or do not require consideration of the borehole skin effect. Hence, difficulties in interpretation caused by the skin effect are minimized. In applying these methods, a greater proportion of shut-in data will be usable for analysis if the shut-in borehole is hydraulically "stiff" (i.e., has minimal wellbore compressibility). This condition implies that "afterflow" into the borehole during recovery will rapidly approach a very small value.

There are two main disadvantages to using gas as the injection fluid as suggested by ANL. First, since gas represents a highly compressible fluid, wellbore compressibility during shut-in will be extreme, leading to a situation where afterflow essentially dominates the entire recovery period. Data obtained from such a situation cannot be analyzed by the methods mentioned above. Available techniques for analyzing injection-period and recovery data for a condition dominated by afterflow do not account for the skin effect. If the borehole skin effect is significant, these solutions will lead to erroneous values of hydraulic conductivity. Second, injecting gas into a saturated medium will result in multiphase flow. The analysis of test results will be much more complicated, leading to greater uncertainty.

Gas permeability testing might be more appropriate for the construction-affected zone adjacent to excavations, particularly if such zones have dilated by grain loosening and are unsaturated. The revised UTP will incorporate the above points. 


\section{4 .1}

\section{4 .1}

\section{Action Statement}

The proposed single-borehole hydraulic conductivity tests have two primary purposes: (1) to verify that lowpermeability conditions exist within intact salt (i.e., hydraulic conductivities falling below a critical value) and (2) to obtain order-of-magnitude hydraulic conductivity measurements for strata and rock discontinuities identified as being relatively permeable. For these purposes, a test duration of one or two days should be adequate. Multipleborehole hydraulic conductivity and tracer tests will be conducted to characterize relatively permeable features in much more detail.

The revised UTP will discuss the potential for hydrofracturing and the possibility of developing guidelines for predicting the conditions under which hydrofracturing will occur and for identifying such fracturing if it has occurred.

The standard Hvorslev, or gravity, tests described in U.S. Bureau of Reclamation (1981) and mentioned by. ANL are inappropriate because of the excessive time required to conduct them in low-permeability materials and their inapplicability to upward-angle holes.

Analysis of steady-state constant-head injection (packer) tests is based on the following equation:

$\mathrm{K}=\frac{\mathrm{QC}}{2(\pi) \mathrm{Ls}}$

where:

$\mathbf{K}=$ hydraulic conductivity,

$Q=$ steady-state injection flow rate,

C = "shape factor,"

$\mathrm{L}=$ length of test interval, and

$s$ = excess hydraulic head in borehole. 
The shape factor $\mathrm{C}$ is a dimensionless parameter related to the assumed geometry of the flow system near the borehole. Steady-state equations presented in Theim (1906), Hvorslev (1951), U.S. Bureau of Reclamation (1981), and Marinelli (1984) are similar to the above equation, except that they have different expressions to evaluate the shape factor. Regardless of the shape factor expression used, its value generally ranges from four to seven in most applications. Since these tests are considered to provide order-of-magnitude estimates of hydraulic conductivity, the differences between the above-mentioned methods are insignificant.

Golder has reviewed the proceedings volumes of the International Association of Hydrogeologists (1985) conference. Suitable test methods will be incorporated into the revised UTP where appropriate. Table C-5 will not appear in the revised UTP.

$3.4 .2 \quad 1$

ANL retracts the first sentence of this paragraph as lacking specificity. The revised UTP will reference solutions to the appropriate groundwater flow equations.

The revised UTP will state that it is not prudent to assume that a discontinuity will behave as a confined system and that it would be advisable to locate pressure-monitoring devices on either side of the discontinuity to test the validity of this assumption. If significant hydraulic responses are measured in these installations, other analytical methods (e.g., leaky aquifer solutions) may be applied to analyze the test. In addition, data obtained from the installations can be used under appropriate conditions to determine the hydraulic properties of rocks adjacent to the discontinuity. Such considerations will be incorporated into the revised UTP.

The analysis method should depend on the physical nature of the rock and not on the desire to simplify the test. Moreover, more sophisticated analytical/numerical solutions should be used only if it can be demonstrated that they lead to a reduction in overall uncertainty. To present a list of all possible well hydraulics solutions would be exceedingly tedious and would reduce the usefulness of the UTP, which is essentially a preliminary document. This point will be addressed in the revised UTP. 
Section Paragraph(s)

\subsection{2}

\section{Action Statement}

See action statement for Sec. 3.4.1, थ 1 .

Cross-hole tracer tests to evaluate both construction and longer-term hydrogeologic conditions will be included in the detailed test plans. These tests may include radial divergent tests, radial convergent tests, and two-well (doublet) tests. The analytical models to be considered include those for equivalent porous media, single/multiple fracture systems, and fracture systems with matrix diffusion. Many of these items, including a more detailed discussion regarding temperature and matrix diffusion effects, are more appropriate for the detailed test plans but will be mentioned in the revised UTP. Specific tracer and sensing systems will be discussed in the detailed test plans and will not be mentioned in the revised UTP.

The quoted sentence will be changed to: "The cross-hole tracer test. . .provides a method for measuring in situ kinematic porosity at a scale larger than that of singleborehole and laboratory tests." The references to geophysical logging and other nontracer test methods will be deleted.

As stated in the UTP, the cross-hole tracer test measures effective Forosity of materials within a rock discontinuity or stratum. The test does not provide a value for the rock mass as a whole. This aspect of the test will be explained more clearly in the revised UTP.

The revised UTP will use the term "quasi-steady-state" conditions. This term implies that hydraulic gradients have stabilized in the area of the test, even though the magnitudes of the hydraulic heads are still transient. In a confined aquifer, quasi-steady-state conditions will exist within the region for which Jacob's approximation is valid.

See action statement for Sec. 3.4.1, il 1. Also, fluid sampling is not considered to be the preferred method for measuring tracer concentrations. In low-permeability media, withdrawal of fluid from an observation borehole may result in significant perturbation of the flow system, a condition that is not accounted for in theoretical solutions. 
In-hole instrumentation is the preferred method for measuring tracer concentrations in an observation borehole. Although scintillometers and conductivity sensors have been used successfully to monitor radioactive and chloride tracers, respectively, the latter type of tracer is not suitable in a bedded salt environment. If other potential tracers and monitoring instrumentation prove feasible, they will be mentioned in the revised UTP.

The prime purpose of the tracer diffusion test is to evaluate the rock matrix diffusion coefficient, which is a function of the connected porosity and pore space tortuosity of the matrix. The cross-hole tracer test, which studies advective transport in relatively more permeable materials (e.g., permeable interbeds), will provide no information on the rock matrix diffusion coefficient, except by inference from matrix-diffusion-related retardation of the tracer. Over the relatively short path lengths and for the relatively short durations of the cross-hole tracer tests, this retardation effect will probably be negligible. The reference to determining pore space connectivity will be deleted, and the need for the test will be more clearly explained. The details of overpressuring and overcoring will be treated in the detailed test plans.

The revised UTP will state that choosing a proper test fluid is an important part of test development and that trial tests in the laboratory with different brines, as well as with petroleum-based fluids and inert gases, may be required.

Drilling coaxial boreholes toward each other from opposite ends of a pillar may be difficult. Developing such techniques will be an important part of test development. Alternative configurations will be considered if it is not practical to drill such boreholes with the accuracy required. Comparing flow through a borehole seal with that through intact salt of the same configuration will provide one of the best measures of seal performance. An a'ternative would be to simply seal a borehole and measure the amount of flow over time. However, this second approach will not provide a good estimate of how much flow is occurring through the seal and along the seal-salt interface as compared with how much is flowing through the surrounding salt. These considerations will be discussed in the revised UTP. 
Section Paragraph(s)

3.4 .5

3.4 .5

3

3.4 .6

1

\section{Action Statement}

The three parameters mentioned -- borehole diameter, seal material, and seal length -- are important, as is the method of seal emplacement. However, neither the selection of the method of emplacement nor of the seal material is properly within the scope of the borehole-seal performance test. This point will be clarified in the revised UTP, as will the rationale for conducting multiple tests.

Porosity and specific storage are different quantities, and the text will be modified accordingly.

It may not be possible to validate codes and models with laboratory tests and one in situ room-seal performance test. The adequacy of a single test will be evaluated when additional information on seal design becomes available. Aspects such as changing seal performance associated with room closure may be partially evaluated by in situ testing and partially determined by modeling and laboratory testing.

The room-seal performance test will evaluate the construction and performance of a seal that generally incorporates the major elements of the planned room-seals/bulkheads. Although different types of room seals may eventually be constructed (e.g., repository panel bulkheads, repository boundary bulkheads, and tunnel bulkheads), it is not clear at this stage that such seals will be of fundamentally different design. Golder will review this issue when more information is available and the adequacy of a single test has been reevaluated. These comments will be incorporated into the revised UTP.

Whether the difficulty of the problem has been underestimated will depend largely on precise definition of the information required from testing, which definition will be formally developed by ONWI.

Since seal design for salt will be oriented toward minimizing the flow of groundwater, the reference to inhibiting the passage of gas will be deleted in the revised UTP. 
Section Paragraph(s)

\section{4 .6}

2

3.4 .6

3

3.4 .6

4

3.4.6

5

\section{Action Statement}

The test proposed by ANL (i.e., removal of a full-sized pillar) would be complicated to perform. In addition, it is not clear how effective test bulkheads equivalent to the packers in the borehole seal test would be constructed, removed to permit excavation of the salt bridge and construction of the seal, and then replaced before testing the seal. Leakage past these bulkheads would probably be significant and of different magnitude for the salt plug and seal configurations, making even relative comparisons difficult. No change will be made in the revised UTP.

The revised UTP will state that small-scale tests may be necessary to provide valuable design data for the full-sized tests. The UTP as presently envisaged does not have to address every test that might be required during the performance confirmation period, which follows the license application process.

With regard to the interaction between the seal and the host formation, see action statement for Sec. 3.4.6, * 4 .

The revised UTP will state that instrumentation will be incorporated to monitor buildup of radial stress. The importance of this phenomenon to seal performance will depend on the detailed approach to seal design, which is yet to be determined.

The revised UTP will include additional information outlinirg alternative strategies in terms of continuing or discontinuing the test.

The revised UTP will acknowledge that the room-seal performance test does not address the issue of closure before seal emplacement. One alternative is to evaluate this problem within the exploratory shaft facility after substantial room closure has occurred; however, this type of performance confirmation testing is not addressed in the UTP. A second alternative is to concuct tests at another facility where substantial room closure has already occurred. 
The extent of the disturbed zone surrounding the seal is likely to be limited, and the design could compensate for the existence of such a zone. For example, the affected zone could be grouted. Although these issues need to be addressed, they cannot be dealt with effectively within the exploratory shaft facility and within the time frame of this testing program.

$\begin{array}{ll}3.4 .6 & 6\end{array}$

3.4 .6

3.4 .6

8

3.4 .7
The revised UTP will state that such contamination will be removed before sealing.

These suggestions will be incorporated into the revised UTP.

The revised UTP will eliminate this type of downstream psychrometry.

It is uncertain at this stage what conclusions can be drawn from the Asse test results about the effects of gamma radiation because of problems with leaks experienced in several of the tests. The Asse data will be reanalyzed once testing there has been completed. No change will be made in the UTP unless the results of the reanalysis are available and show a need for changes.

The revised UTP will state that computer codes must be reviewed for applicability and accuracy before their use. Specific computer codes are not referenced anywhere in the UTP; instead, conceptual models are discussed.

The proposed salt-block-type test is a scaled-down laboratory version of the in situ brine migration test. Such laboratory testing is not properly part of the UTP; therefore, no change will be made in the revised UTP.

Posttest profiling of moisture conditions around the heaters will be incorporated into the revised UTP. Pretest moisture conditions, which must also be known, can be measured from within the perimeter of the heater hole and from outside the direct influence of the test. (Taking test samples from the immediate test area could adversely affect test performance.) These points will be included in the revised UTP. 
Borehole-to-borehole radar may not give useful data. Measurements would yield a gross average, whereas the principal interest is in the moisture content profile. Furthermore, using the heater borehole for radar testing implies that measurements would be made following cooldown and removal of the heater. At this stage, the test area may be so disrupted as a result of cool-down and microfracturing as to limit the value of the radar test results. The revised UTP will incorporate this discussion of posttest activities.

$3.4 .7 \quad 5$

5 The brine migration tests will not significantly reduce uncertainties about the fundamental transport processes at work. A degree of residual uncertainty may be acceptable, providing its effects are properly recognized and accounted for. A major reason for these tests is the difference in lithology between the Deaf Smith County site and sites previously studied. For example, the effects of clay interbeds may prove to be important. These corisiderations will be discussed in the revised UTP.

Radiation effects are being studied at the Asse and WIPP sites and will eventually be studied in the exploratory shaft facility, although not, as of now, before the license application stage.

Detailed discussion of brine chemistry is inappropriate for the UTP; however, the revised version will briefly discuss brine chemistry as it affects such things as corrosion, as a justification for the brine migration testing. The test descriptions are at a conceptual level, and the tests wili be more completely described in the detailed test plans. No other changes regarding brine chemistry will be made in the revised UTP.

Although details are still to be determined, the present description includes tests that progressively remove vapor during testing and tests that do not remove vapor and allow pressure to build up. The Asse test results may throw some light on the influence of the different boundary conditions and on the mechanisms of migration. Such information will be considered in the design of detailed tests. 
Present and future tests at other facilities are briefly discussed in Sec. 2 and noted in App. A of the UTP. These tests are important in terms of the information they will provide to the SRP. When the SCP is prepared, the information needs and the extent to which existing information has helped to define those information needs will be presented more formally. In any case, these other tests do not need to be discussed in the individual conceptual-level test descriptions in App. C. No change will be made to the UTP.

3.4 .8

The revised UTP will incorporate the ANL comments.

The revised UTP will incorporate geochemical characteristics of in situ fluid samples (e.g., Eh and pH).

The revised UTP will incorporate the following points.

- The proposed formation-fluid sampling system allows the borehole to be oriented in any direction. (The upward angle of approximately $45^{\circ}$ in Fig. C-24 of the UTP is arbitrary.) The diameter and length of the borehole in the drawing are not to scale and will be determined based on the expected locations of zones sufficiently permeable to permit such sampling.

- Packers may be used (instead of clay or grout) to isolate the test interval. The Asse brine migration test may provide data on the best type of seals for this application.

- Nitrogen is not used to induce flow from the formation to the sampling ports, but to establish a system pressure slightly less than the existing formation fluid pore pressure as the fluid flows into the sampling ports and fills the system.

- Filtering of the samples is important, and it is anticipated that the sampling system will have an in-line filter located between the double valves immediately ahead of the sample collection vessel. A revised Fig. C-24 will illustrate the filter location. 
- Certain instrumentation problems (e.g., clogging and corrosion) must be resolved, as must the long-term accuracy of any instrumentation that cannot be removed during the test.

- Materials in the sampling apparatus that will be in contact with the samples should be tested for long-term compatibility with the fluids expected to be in the samples. Such data are necessary for minimizing sample contamination. The nitrogen will be doped with a stable isotope to determine whether formation fluids have been contaminated by nitrogen.

- The fluid release rate will be quantified.

- The dissolution reaction rates will be quantified in the laboratory; hence, they are beyond the scope of the UTP. The revised UTP will clarify this point.

\section{5 .2}

Regulatory Considerations

4

4
3

4

As previously indicated, the revised UTP will state that laboratory chemical analyses are not within its scope. However, the ANL points will be briefly discussed in the revised UTP.

The reference to $30 \mathrm{CFR} 57$ will be changed to $30 \mathrm{CFR}$ Chapter 1 (subchapters $\mathrm{N}, \mathrm{E}$, and $\mathrm{N}$ ).

The revised UTP will incorporate the following points in clarifying the distinctions between performance, information, testing, and other requirements specified in the regulations:

- A performance requirement is a quantitative limit specified for the performance of an element of the overall repository system (i.e., a performance criterion). The value cannot be measured a priori, but must be predicted. In this way, a performance issue arises -- does the predicted value for a given parameter satisfy the performance requirement? In many cases, performance issues are identified at several levels of detail, resulting in an internally consistent hierarchy. 
- An information requirement is the need for a specific piece of information. Such information can be the result of measurement or inference. Typically, such information provides the input for predicting performance. However, in some cases, the reason or procedure for obtaining the information is not explicitly discussed in the regulations. In other words, certain pieces of information must be obtained, regardless of the performance issues.

- A testing requirement is the need for a specific testing activity. Although such tests typically provide data to satisfy an information requirement, thereby contributing to resolution of a performance issue, the reason for performing the test may not be explicitly discussed in the regulations. In other words, this type of test must be performed, regardless of the performance issues and information needs.

- Other requirements include design requirements (e.g., waste storage capacity) and documentation or licensing procedures (e.g., submittals and hearings). Such requirements are not expected to influence the technical design of the UTP.

- The formulation of the performance issues will be clerified in the revised UTP.

Some interpretation of the regulations was required to differentiate the requirements as presented above. However, interpretation was minimal and did not significantly affect the proposed UTP. Regardless of whether a requirement was considered to be a performance, information, or testing requirement, it was considered. The result is that the proposed test program, in conjunction with other test programs, satisfies all the regulatory requirements.

Although explicit cross-referencing between the issues currently identified in the UTP and those identified elsewhere was not done, a cursory comparison did not reveal significant differences. The comparisons showed that the issues and information needs may be on different hierarchical levels, but are generally consistent. The foregoing discussion will be incorporated into the revised UTP. 


\section{$\underline{\text { Section }}$}

4

5,6

\section{Action Statement}

The performance issues identified in the UTP were developed by Golder in the absence of a defensible set of performance issues from ONWI. As noted in Table A-2 of the UTP, the issues were developed as a hierarchy to ensure comprehensiveness and mutual exclusivity. The hierarchy was developed so that the performance issues were never broader than any performance requirement.

An issues hierarchy tree will be inco:porated into the revised UTP. Also, some of the issues and information needs are too broadly defined. The current configuration has helped in deriving a preliminary UTP, and the SCP will address the whole question of issues and information needs in appropriate detail.

In general, only those portions of the regulations that were considered to have some relevance to underground testing were considered in the development of the UTP. Some portions were included that, although possibly not directly related, provide perspective on the entire program. An alternative would have been to include the entire set of regulations, which would not have been useful for preliminary development of requirements for the UTP and which would have obscured the message. The UTP will be reviewed to ensure that all relevant regulatory citations having a direct bearing on in situ testing have been included.

Golder attempted to be rigorous in interpreting the regulations and associated issues. In this respect, the wording of each regulation is important. For example, if the prime emphasis of a regulation is "geohydrology," vut the regulation is phrased such that an assessment of overall performance is required, then many other factors must be addressed in addition to geohydrologic factors. The resulting list of issues may be very broad. The table will be reexaminead and this section redone using a newly developed list of performance issues whose interrelationships are indicated in an issues hierarchy.

The term "hydrogeology" will be replaced by "geohydrology."

The following numbers correspond to numbered comments in the ANL review report.

1. The regulatory citations will be checked and corrected in the revised UTP. Both errors noted will be corrected. 
2. See action statement for Sec. 4, ๆs 5 and 6.

3. Although hydraulic conductivity and effective porosity are specified in 10 CFR 960.4-2(b)(4)(iv) to be determined only along likely travel paths, these paths are not known a priori. Therefore, determining these variables for likely travel paths will be an aspect of performance rather than an information requirement, and it will be necessary to assess the distribution of hydrologic parameters. Thisis distribution, together with the hydraulic gradients, would then determine the likely travel paths as well as satisfy the specific information requirement. The point is that more information is required because the locations of the travel paths are unknown. This point will be clarified in the revised UTP.

4. See action statement for Sec. 4, If 4. In addition, 10 CFR 960.4-2-2(b)(2) simply specifies the requirements for particular characteristics in a qualitative manner, whereas items (3) and (4) specify requirements in terms of a performance measure.

5. Performance issues are at a higher hierarchical level than information requirements; that is, information requirements derive from performance issues. Hence, the information requirements to be identified are included by implication in the performance issues and will subsequently be derived as the issues are broken down into information needs (e.g., see Table 4-1 of the UTP). However, in some cases (e.g., 10 CFR 960.4-24[a]), more than one thought is presented. If the thoughts are at different levels and the subordinate one is not implicitly included in the other, then two different requirements have been explicitly identified. Implied information needs will be explicitly incorporated into the revised UT'P.

6. See action statement for Sec. 4 , IIs 5 and 6.

7. See action statement for Sec. 4, $1 / 5$ and 6. 
8. Tectonics can affect repository performance in two main ways -- directly, by causing a loading on the waste package (e.g., seismic events, faulting, or regional stress or temperature changes), and indirectly, by changing the groundwater flow regime (e.g., creation of preferential pathways as a result of faulting or changes in the hydraulic gradients through uplift or other surface displacements). Hence, if the requirement is stated in terms of performance (i.e., the site characteristics shall be such that the performance will be acceptable), both issues are pertinent. This clarification will be incorporated into the revised UTP.

9. A redefined issue that is more appropriate to the citation will be substituted.

10. For the purposes of the UTP, natural resource concerns are related to the geochemistry and hydrochemistry of the site. The presence of economic quantities of minerals would have automatically disqualified the site; that is, it could not have been selected as a candidate for a repository. No change will be made in the revised UTP.

11. The costs associated with such activities as repository siting and construction can be considered as an issue, just as any other. Because costs cannot be measured a priori, they must be estimated. As is true for other issues, costs will depend on site characteristics and design variables, that is, on information requirements. Costs can be considered to include the aspect of technical feasibility based on reasonably available technology (10 CFR 960.5-1[a][3]); in that infeasible or unavailable methods are extremely costly. This clarification will be incorporated into the revised UTP.

12. The UTP addresses only those aspects of the regulations relevant to underground testing. In the case of surface characteristics, costs (see 10 CFR 960.51[a][3]) and preclosure water inflow are the only relevant issues. No changr will be made in the revised UTP.

13. See action statement for Sec. 4 , श/ 7 . 
14. See action statement for Sec. 4 , If 7 .

15. Most documentation requirements (e.g., $10 \mathrm{CFR}$ 60.11) are not considered relevant to the development of the UTP, as they do not result in performance issues, information needs, or testing requirements, nor do they provide liseful perspective. No change will be made in the revised UTP.

16. 10 CFR 60.21, Subpart $B$, which pertains to the content of a license application and especially to the safety analysis report, was included because it specifies information requirements that must be addressed at least in part by the UTP. Simply because the information requirements and performance issues are also referenced in other sections of the regulations does not mean that they should not be referenced here. Rather, the intent is to eventually identify the information needed to adequately respond to each and every regulation that is to be addressed by underground testing, as summarized in Table 4-1. No chsinge will be made in the UTP.

17. Procedural requirements (e.g., Secs. 60.22, 60.23, and 60.24 of 10 CFR 60) are not relevant to development of the UTP, as they do not result in performance issues, information needs, or testing requirements, nor do they provide useful perspective. Also see action statement for Sec. 4, if 7 .

18. See action statement for Sec. 4 , ฯ 7 .

19. Sections $60.71,60.73$, and 60.75 of 10 CFR 60 are documentation and procedural requirements and are not considered relevant to development of the UTP, as they do not result in performance issues, information needs, or testing requirements, nor do they provide useful perspective. Also see action statement for Sec. 4 , ๆ 7 .

20. As Secs. 191.03(a) of 40 CFR 191 and 60.111(a) of $10 \mathrm{CFR} 60$ are essentially the same requirement, the identified performance issues should be the same. Hence, the omission of two issues relating to $10 \mathrm{CFR}$ 60.111(a) will be corrected in the revised UTP. 
21. The performance issues that are applicable to the regulation and relevant to underground testing have been listed. However, regulations are of ten stated in the following terms: the site characteristics shall be such that performance will be acceptable. In such cases, a broad list of issues may have to be addressed, although the intended focus may be on the specific site characteristic.

Section $60.122(\mathrm{c})(3)$ of $10 \mathrm{CFR} 60$ addresses the potential for surface disruptions (e.g., landslides) that could affect the geohydrology. The only aspect of surface disruptions relevant to underground testing is their possible effect on geohydrology. It is true, however, that the performance issue is broader than the regulation. Nonetheless, further detail on those aspects of the issue unrelated to underground testing is unwarranted.

Section 60.122(c)(5) of 10 CFR 60 addresses changes in hydrologic conditions that may affect isolation of waste. The performance issues related to changes in geohydrology must first be addressed to identify what type of effects such changes might have. The potential for change can then be assessed. Hence, performance issues are listed rather than information requirements, simply because the former include the latter. No change will be made in the UTP.

Section 60.122(c)(16) of 10 CFR 60 addresses erosion during the Quaternary Period. See resolution statement for Sec. 4, If 5 and 6 . The information requirements have been specified to a specific level of detail. It is intended that they include aspects such as inferring geologic and other processes during the Quaternary Period primarily from present stratigraphy (including lithology) and structure. Also see action statement for Sec. 4, If 4.

22. In general, only those sections of the regulations relevant to underground testing were cited in the UTP. However, some sections that provide useful perspective on the entire program, but that may otherwise be unrelated to underground testing, were occasionally cited. The intent was to be comprehensive; if a section was questionable, it was cited. Also see action statement for Sec. 4, If 7 . 
23. The intent in the UTP was to identify the repository regulations that require demonstration of compliance as part of the license application process and that can be addressed by underground testing. For brevity, potentially relevant portions of the regulations were listed; for comprehensiveness and perspective, some portions that might be considered by some to be only very marginally relevant were also included.

The following paragraph will be inserted between the first and second paragraphs of Sec. 4.0 in the revised UTP:

Underground testing is only one component of the site characterization and repository design program and is not intended, by itself, to demonstrate compliance with all of the regulations governing repository development. Rather, underground testing will provide information that addresses various portions of the regulations to different degrees. This information will be combined with that from other components of the program to demonstrate regulatory compliance.

The third paragraph of Sec. 4.1 will read as follows in the revised UTP:

Those sections of the regulations that could possibly be addressed by underground testing are presented in Table A-1. Not all portions of the regulations are presented. Some cannot be addressed by underground testing; others have been included to improve comprehension. Underground testing is not intended, by itself, to demonstrate compliance with all the regulations. However, as one component of the site characterization and repository design program, it can address various aspects of the regulations to different degrees.

Regarding 10 CFR 20, see the paragraphs concerning page 3 in the action statements for the page-by-page comments. 
24. 30 CFR, Chapter 1, contains repository regulatory requirements relating to repository operating procedures that must be addressed in the license application process (e.g., 10 CFR 60.131[b][9]). It will be relatively easy to demonstrate compliance with most of these regulatory requirements, as they are of a procedural or design character and do not lend themselves to testing; footnote "d" applies to these citations. These sections, especially those that describe the regulatory purpose, are included to provide perspective and show that some of the regulations do not lead to testing. As few citations as possible were included. These points will be clarified in the revised UTP.

The "safety and health inspections" category relates to "tests" to evaluate the adequacy of proposed safety and health procedures during operation of the repository (Table $5-1$ of the UTP). In some cases, such testing is specified in the regulation; that is, it must be carried out, regardless of why. However, such operations-type testing, although conducted within the exploratory shaft facility, is outside the scope of the UTP, as noted in Table 5-1. A footnote will be added to Table A-1, indicating that, although such operations testing is outside the scope of the UTP, it has been cited for completeness.

\section{ACTION STATEMENTS FOR PAGE-BY-PAGE COMMENTS}

Main Body of Underground Test Plan

$\underline{\text { Page(s) } \quad \underline{\text { Line(s) }} \quad \text { Action Statement }}$

Figure ES-1 will be edited for consistency. 


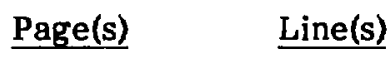

It would be desirable to demonstrate prior to license application (i.e., during exploratory shaft facility activities) that the repository will comply with 10 CFR 20, among other regulations. However, because Sec. 113(b)(2) of NWPA effectively prohibits use of radioactive material in the exploratory shaft facility, the ability to demonstrate compliance with 10 CFR 20 will be extremely limited. Compliance with 10 CFR 20 in exploratory shaft facility activities is intrinsically triviai in the absence of radioactive sources. The UTP will not be changed. See item 23 in the action statements for Sec. 4.

Brief descriptions of the regulations cited in Fig. ES-2 are unnecessary. However, Fig. 4-1, the corresponding figure in the main text, will refer to Table A-1 in App. A; a reference of this type is not appropriate in the executive summary.

In Fig. ES-3, "in situ" will be replaced by "underground." See action statement for recommendation 1.

See action statement for page 4.

Hydrofracturing is a method of stress measurement. Although hydrofracturing is less applicable in salt than in elastic rocks, it has some application for measuring the minimum principal stress and perhaps for confirming isotropic virgin stress states if the fracture patterns can be observed. The UTP will not be changed, except that the acronym "DEIS" will be defined. Also see action statement for recommendation 1, which pertains to changes in terminology.

"National Waste Terminal Storage (NWTS)" will be replaced by "Office of Civilian Radioactive Waste Management (OCRWM)."

The UTP will be amended to read: "Submission to iNRC of a site characterization plan (SCP), as required by NWPA and 10 CFR 60, with...." [Revised portions of 10 CFR 60 were published in the Federal Register on July $30,1986$. 


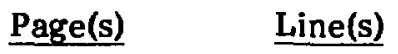

14

14

17

17

18
1-8

20-21

2-6

7-20

25-30

3

5

8-12

13-15

26-30

\section{$\underline{\text { Action Statement }}$}

Terms will generally be defined in the glossary. However, "underground testing" will also be defined here to aid comprehension.

This sentence will be deleted, as the revised UTP is to be site specific.

This introductory paragraph will be expanded.

Section 3 of the UTP summarizes the work accomplished for the respective environmental assessments. However, the data reported for Deaf Smith County are not from the site selected for the repository (i.e., they are not site specific), but are from several locations within the county. This point will be clarified in the revised UTP.

The reference to observations of multiphase flow referred to laboratory investigations and not to observations at Project Salt Vault. However, the ANL points will be incorporated into the revised UTP. Also, "constitutive relationship" will be replaced by "empirical creep law" in the revised UTP.

The revised UTP will include the observations from Project Salt Vault that pillar shortening in salt is temperature sensitive and that emplacement and retrieval of spent fuel rods in salt are practical.

The revised UTP will include information concerning when and by whom the Avery Island tests were conducted.

The wording will be changed to: "Longer-duration laboratory creep tests using different load paths are required to establish a reliable constitutive law, associated parameters, etc."

See action statement for recommendation 9.

Sealing tests are being conducted in the Federal Republic of Germany, but documentation of these tests is difficult to obtain. No change in the UTP will be made.

13-34 See action statement for Sec. 2.6.

22 "Pierced" and "non-pierced" will be replaced with "piercement" and "nonpiercement," respectively. 


\begin{tabular}{|c|c|c|}
\hline Page(s) & Line(s) & Action Statement \\
\hline 24 & $27-28$ & $\begin{array}{l}\text { The wording will be changed to: "bordered by areas that } \\
\text { are structurally more complex." }\end{array}$ \\
\hline 25 & $12-16$ & $\begin{array}{l}\text { The revised UTP will be site specific for the Deaf Smith } \\
\text { County site; hence, all material related to the Paradox } \\
\text { Basin will be removed. }\end{array}$ \\
\hline 25 & $21-25$ & $\begin{array}{l}\text { The word "hydraulic" will be inserted before all references } \\
\text { to "conductivity." The revised UTP will be site specific } \\
\text { for the Deaf Smith County site; hence, all material } \\
\text { related to the Paradox Basin will be removed. }\end{array}$ \\
\hline 25 & $30-33$ & See action statement for page 25 , lines $12-16$. \\
\hline 25 & 34-35 & See action statement for page 25 , lines $12-16$. \\
\hline $26 ; 28$ & & $\begin{array}{l}\text { Depths and thicknesses will be added to the stratigraphic } \\
\text { column in Fig. } 3-2 \text { of the UTP. Figure } 3-1 \text {, which gives } \\
\text { the stratigraphic column for the Paradox Basin, will not } \\
\text { appear in the revised UTP. }\end{array}$ \\
\hline $27-30$ & & $\begin{array}{l}\text { The revised site description will include a figure showing } \\
\text { simplified regional geological and tectonic relationships. }\end{array}$ \\
\hline 27 & 32 & $\begin{array}{l}\text { The revised UTP will use terminology consistent with the } \\
\text { SRP environmental assessments. }\end{array}$ \\
\hline $27 ; 29$ & $34 ; 1-2$ & $\begin{array}{l}\text { This sentence will be replaced with: "The lower high- } \\
\text { conductivity unit comprises carbonates and arkosic } \\
\text { sandstones that range in age from lower Permian } \\
\text { (Wolfcamp Series) to Pennsylvanian." }\end{array}$ \\
\hline 29 & 12 & $\begin{array}{l}\text { The word "slake" will be inserted between "Low" and } \\
\text { "durability." }\end{array}$ \\
\hline 32 & 6-8 & The words "faulting has" will be replaced by "faults have." \\
\hline 32 & 17-18 & $\begin{array}{l}\text { The sentence in line } 19 \text { will be deleted and replaced by: } \\
\text { "Although the reason for this anomaly is unknown, the } \\
\text { waters are of a } \mathrm{NaCl} \text { type, which may indicate salt } \\
\text { dissolution." }\end{array}$ \\
\hline 33 & 2 & $\begin{array}{l}\text { A definition of "internal sheath" will be added to the } \\
\text { glossary. }\end{array}$ \\
\hline
\end{tabular}


Page(s)
Line(s)

$2-5$

33-34

$16-18$

6-10

24-27

$6-8$

10-15

\section{Action Statement}

The term "sheath materials" refers to lithologic materials. The last sentence in the paragraph will be reworded to make this clear.$$
\text { The verb "has" will be replaced by "have." }
$$

The cited report has been noted. No change in the UTP will be made.

The cited reference will be reviewed. If the SRP takes the position that waste removal from the waste container is not a feasible waste recovery method, the text will be changed accordingly.

Section 3.3.1 of the UTP will be revised to indicate that preliminary site-specific designs have been developed.

"Leaching/dissolution of the waste form" will be added. Corrosion should apply only to metals.

Section 3.3.2 of the UTP will be modified so that the primary and secondary functions of the container are adequately specified and that the terminology preferred by DOE will be used.

The words "remote handling" will be changed to "identification and remote handling."

The acronym "NWTS" will be replaced by "CRWM."

See action statement for recommendation 1.

See action statement for recommendation 1.

In the revised UTP, "for a considerable time" will be replaced by "for several years." The details of monitoring are test specific and will be considered in the detailed test descriptions.

The revised UTP will be site specific; therefore, it will not be necessary to contrast bedded and domal features.

The words "brine pockets" will be used instead of "brine inclusions." 
$\underline{\text { Page(s) }}$

73

$73-74$

74

75

75

76

76-77

77

77

1

$31-34 ; 1-3$

4-24
Action Statement

See action statements for recommendations 9 and $\mathbf{1 0 .}$

17-32;1-17 See action statement for Sec. 3.1.4, Is 2 and 3.

18-30 The revised UTP will distinguish between microseismi monitoring, which is concerned with seismic signals of lov amplitude and duration (detected by low-frequenc geophones typically having a response range of $1-100 \mathrm{~Hz}$ ) and acoustic emission monitoring, which is concerned witl monitoring higher-frequency rock noise (detected b: accelerometers typically having a response range 0 $10,000 \mathrm{~Hz}$ and above, depending on the volume of rocl being monitored). Microseismic monitoring is planned to be part of the site microearthquake monitoring, a: indicated in the environmental assessment for the Dea: Smith County site (U.S. Department of Energy, 1986 Sec. 4.1.1.1.9, page 4-14). The revised UTP will discus: the problems that could arise during such monitoring caused by outside noise from other site activities. It wil also discuss the successes achieved with seismic monitoring at other sites.

14-16 Salt masses fail in flow-type deformations, but may als fail in brittle-type modes; hence, strength is of concern However, it is acknowledged that the flow behavior of sal 1 is generally of predominant interest. No change will be made in the revised UTP. See action statement for Sec. 2.7.

17-20 Salt masses tend to fracture only relatively near underground openings. The effects of such behavior on hydraulic conductivity in the affected areas are poorly understood. The UTP will not be revised.

See action statement for page 75 , lines 14-16.

See action statements for Sec. 3.2.1, Is 1 and 2.

The revised UTP will mention the difficulties experienced at the WIPP site with stress measurement using inclusion cells (Stormont et al., 1984).

15-24 The revised UTP will state that knowledge of the material properties of salt is required to calibrate the gages. 


\section{$\underline{\text { Page(s) }}$}

80

80

83

83

83

84

\section{Action Statement}

The revised UTP will state that modeling of the mine-by test will require knowledge of the in situ stresses.

See action statement for Sec. 3.2.4.

The revised UTP will incorporate the suggested wording.

See action statement for Sec. 3.3.1.

Because the intent of the entire paragraph is unclear, misunderstandings along the lines of ANL's comments are possible. The meaning will be clarified in the revised UTP.

The test description in Sec. 5 of the UTP will be removed. The test description in App. $\mathrm{C}$, which contains a suitable drawing, will be substituted.

See action statement for Sec. 3.3.2.

See action statement for recommendation 15. The revised UTP will clarify that the models will be validated on the basis of the results of the entire testing program.

See action statement for page 84, lines 25-29.

See action statement for Sec. 3.4.3, ๆ 4 .

Matrix diffusion is not a realistic mechanism for transport of radionuclides from the engineered barrier to the accessible environment, through the geosphere. The importance of matrix diffusion lies in its ability to retard migration of solutes by fracture-type flow. Diffusion may also be a significant transport mechanism near the waste package, where solute concentration gradients are high and groundwater flow might be limited; that is, diffusion provides a potential mechanism for moving solute to a relatively more permeable interbed. See action statement for Sec. 3.4.4. These ideas will be clarified in the revised UTP.

A diagram is included in App. $\mathrm{C}$ of the UTP. The test description in Sec. 5 will be deleted.

The name "room-seal performance test" will be maintained in the revised UTP. 


\begin{abstract}
$\underline{\text { Page(s) } \quad \text { Line(s) }}$
95

98

106

121

\section{Action Statement}

See action statement for Sec. 3.4.8.

Certain in situ conditions will not be preserved. The requirements of the laboratory program will be clearly defined in the revised UTP, so that detailed sampling procedures will be designed to ensure that samples are as representative as practicable.

The assumed advance rates in Fig. 5-1 of the UTP were provided by the exploratory shaft facility designer, Parsons Brinckerhoff/PB KBB, Inc. The UTP will not be revised.

The sentence will be changed to: "A project management plan for the exploratory shaft facility is being prepared by ONWI."

These terms are defined in appropriate sections of the UTP. These definitions will be added to the glossary of the revised UTP.
\end{abstract}

Appendix A

A-4

$14-15$

A-103-A-108

A-104

A-105
"([S]ee Appendix I of this Part)" is a direct quotation from the regulations and therefore does not need to be deleted.

The title of Table A-2 in the UTP will be changed to

Postclosure thermomechanical loading of the waste package can be predicted by numerical modeling. The confidence in the prediction will depend on the extent to which the model is able to predict the short-term behavior demonstrated in the exploratory shaft facility. This point will be clarified in the revised UTP.

The issue of groundwater flow through the constructionaffected zone can be resolved to a certain degree by demonstration, that is, by monitoring the hydrologic response of the underground facility. This point will be clarified in the revised UTP. "Potential Performance Issue Resolution Methodologies." 
$\underline{\text { Page(s) }}$

$\underline{\text { Line(s) }}$

A-109-A-130

\section{Action Statement}

The descriptions of the conceptual models (second column) are very brief. Although they expand somewhat on the identified performance issue, they do not provide an adequate framework for mathematical modeling. The descriptions of the numerical models are similarly very brief and nonspecific. Although these models are to be the basis for the information needs, most of them have not yet been identified or described by ONWI. Since development of both information needs and models is generally outside the scope of the UTP, more thorough treatment is not warranted. Instead, App. A of the UTP will be replaced when the information needs have been definitively established by ONWI (e. .., in the SCP).

In keeping with the above discussion, Table A-3 of the UTP will be revised as follows:

- The new title will be: "Types of Information Required to Resolve Performance Issues by Numerical Analysis."

- The heading "Information Required for Relevant Numerical Analysis" will be deleted.

- The following footnotes will be added for the headings of the second and third columns.

Column 2. Conceptual models have not yet been formally defined for each performance issue to the level required to provide a framework for mathematical modeling. Instead, the scenarios are briefly described and will be replaced by more detailed descriptions of the conceptual models, including all relevant processes.

Column 3. Specific numerical models have not yet been identified for the conceptual models. Instead, the type of model (e.g., mechanical response of the waste package) is denoted, to be replaced by the specific model(s).

Similar changes will be made in Tables A-4 and A-5. The text in Sec. 4.1 of the UTP will be modified to reflect the above changes. 
$\underline{\text { Page(s) } \quad \text { Line(s) }}$

A-113

A-118

A-121

A-122

A-131-A-140

\section{Action Statement}

If best available proven technology is used and specified acceptance standards are met, then "poor construction techniques" are precluded from being the cause of failure. "Proven technology and standards" are specified for seals for this reason. However, proven technology is unavailable, and standards have not been specified. Hence, poor (or inadequate) construction techniques could conceivably lead to seal failure, even though the seal design may otherwise be adequate. Design confirmation testing in the at-depth test facility should lead to the proving of suitable technology and the development of standards that will eliminate "poor construction techniques" as a potential cause of seal failure, but only if both are properly applied in repository development. Until these advances take place, poor construction techniques cannot be ignored. No change will be made to the UTP.

Although response models are referred to in the UTP as if decoupled, coupled analyses will be conducted as appropriate. The following footnote will be added to the third column of Table A-3: When more than one numerical model is involved, they must coupled. The text in Sec. 4.1 will also be modified to reflect this approach.

The revised UTP will note that thermomechanical loading of the waste package may be affected by corrosion.

The revised UTP will clarify that the chemical composition of the brine in the vicinity of the waste package may be affected by radiation.

The revised UTP will state that pressure and density distributions must be assessed to predict nonhomogeneous brine movement through a nonisothermal field.

As was true in Table A-3 of the UTP, appropriate empirical equations have not yet been identified by ONWI. Since development of the equations and of information needs in general is outside the scope of the UTP, more thorough treatment is unwarranted. Instead, App. A of the UTP will likely be replaced when the information needs have been definitively established by ONWI (e.g., in the SCP). 
In keeping with the above discussion, Table A-4 will be revised as follows (changes are parallel to those for Table A-3 in the action statement for pages A-109A-130):

- The new title will be: Types of Information Required to Resolve Performance Issues by Empirical Analysis.

- The heading "Information Required for Relevant Empirical Analysis" will be deleted.

- The following footnotes will be added for the headings of the second and third columns.

Column 2. Conceptual models have not yet been formally defined for each performance issue to the level required to provide a framework for empirical equations. Instead, the scenarios are briefly described and will be replaced by more detailed descriptions of the conceptual models, including all relevant processes.

Column 3. Specific empirical equations have not yet been identified for the conceptual models. Instead, the type of equation (e.g., mechanical response of the tunnel) is denoted, to be replaced by the specific equations.

Similar changes will be made in Tables A-3 and A-5 of the UTP. The text in Sec. 4.1 of that document will be modified to reflect these changes.

Some numerical models use empirically derived parameters, such as those derived for brine migration. However, these models were never intended to be included under empirical analysis. This distinction will be clarified by adding the following footnotes:

- Table A-3. Numerical analysis consists of developing conceptual and then numerical models to theoretically represent the process, and then assessing and using the appropriate model input (e.g., data from physical simulation tests or empirical relationships) to calculate performance. 
$\underline{\text { Page(s) } \quad \text { Line(s) }}$

Action Statement

- Table A-4. Empirical analysis consists of quantifying past experience under similar conditions and extrapolating to develop nontheoretical equations that relate performance to some (but not necessarily all) relevant characteristics, and then assessing and using these characteristics to predict performance. This method does not include empirical derivation of parameters for input to numerical models, which is considered to be part of numerical modeling.

The text in Sec. 4.1 of the UTP will be modified to reflect these changes.

A-132

The UTP will be revised so that standard mine ventilation formulas fall under the heading "ventilation/cooling" and that "safety and health" is included in the list under "air content."

A-144 Discussion of surface boreholes is beyond the scope of the UTP. The UTP will not be revised.

A-155-A-182

No further action is necessary.

A-155

It is inappropriate to add an introduction to Table A-6 of the UTP stating that sufficient information is available to support a very conservative repository design. Also, prediction of performance will be briefly discussed in Sec. 4 of that document. Finally, if the stratigraphy is sufficiently detailed, structural domains having essentially uniform response can be identified.

A-156

Stress measurement techniques for salt require development. Regarding rock strength, the comments in Sec. 2.7 of this report have been noted. The UTP will not be revised.

A-157

Deformation moduli are required for modeling purposes. The revised UTP will note that adequate constitutive relationships are unavailable but are needed for many aspects of salt behavior, including stress and flow. See action statement for Sec. 2.7 .

A-158

The revised UTP will state that density is an information requirement for transient thermal analysis and that it will be measured. 


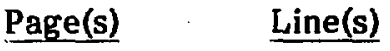

A-159

A-161

A-163

A-165

A-166

A-167

A-168

A-171

A-172

A-176

\section{Action Statement}

See action statement for Sec. 3.4.3, $\| \mathrm{s} 2$ and 3 . The term "effective porosity" was intended to mean "kinematic porosity"; the latter term will be used in the revised UTP. Also, specific storage has no meaning in the case of dewatering and resaturating the rock mass. What was meant here was dewatering and resaturating of the repository openings themselves, which is not inconsistent with a saturated rock mass. This point will be clarified in the revised UTP.

The revised UTP will use the term "adsorption/retardation coefficient." Also, the methods of measurement are discussed in App. B of the UTP.

Specific heat is dependent on water content. However, for an in situ measurement, this dependeney is automatically included. Thus, no change will be made in the revised UTP.

The revised UTP will clarify that the mechanical response of the shaft includes the response of the support system, including any liner.

A combination of coupled models may be sufficient in the absence of a fully coupled system model. The UTP will not be revised.

The revised UTP will state that extrapolating to full scale from laboratory tests is not straightforward because the effects of load paths and strain rates on salt creep are not well understood.

See action statement for page A-158.

See action statement for page A-158.

There is considerable uncertainty in modeling salt behavior because an acceptable model for the deformational behavior of salt is lacking. This point will be included in the revised UTP.

See action statement for page A-158. 
$\underline{\text { Page(s) }}$

$\underline{\text { Line(s) }}$

\section{Action Statement}

\section{Appendix B}

B-2-B-18

B-3

B-4

B-4-B-6

B-7

B-8
See action statement for recommendation 1 . Also, the revised UTP will explicitly state that creep tests will not be restricted to constant-stress tests and that other types, such as stress-path-control and constant-strain-rate tests, may also be performed.

Pumping tests to detect abandoned boreholes will be considered.

Strength in its conventional sense has less meaning for salt than for other rock types because deformations tend to control salt behavior. No change will be made in the UTP.

Although uniaxial creep tests are commonly performed, care must be taken in interpreting the results because loading conditions are not the same as those underground. Hydrofracturing is a method for measuring stresses, but its applicability in salt is more limited than in elastic-type rocks. See action statement for page 9. No change will be made in the UTP.

References to "geophysical well logging" and "tracer diffusion test" under "effective porosity" will be deleted. See action statement for page A-159.

Specific storage is important only during the transient phase of the test, that is, before establishment of quasisteady-state conditions and injection of the tracer. The revised UTP will clarify this point.

Under the headings "Surface Borehole Testing" and "Underground Testing," single-hole and cross-hole tests will be added to allow the computation/prediction of large-scale dispersivity after the method of Gelhar and Axness (1983). However, the applicability of this method to solute transport in discretely fractured media has not yet been demonstrated.

See action statement for page A-121. 
$\underline{\text { Page(s) } \quad \underline{\text { Line }}(\mathrm{s})}$

B-9

B-10

B-11;B-14

B-17

B-19

B-21

\section{Action Statement}

Laboratory testing of samples from near the surface of underground openings can provide data on material properties in the disturbed zone for comparison with those of samples from the undisturbed zone. However, laboratory-determined values may only furnish indices relating the relative rock mass properties of the disturbed and undisturbed materials.

If a sample ruptures during a creep test (i.e., after tertiary creep), some inferences can be made regarding sample strength. No change will be made in the UTP.

Although laboratory-derived strengths have little meaning for salt, comparing the values for disturbed and undisturbed salt samples gives an indication of the effect of the disturbance. This level of detail is beyond that required for the table; hence, no change will be made in the UTP.

Kinematic porosity can only be measured using tracer tests. Since confusion arose from the use of the term "effective porosity," this term will be replaced by "kinematic porosity" in the revised UTP.

See previous action statements relating to the strength of salt (e.g., those for pages 75, B-4, and B-9).

The revised UTP will clarify that compressive strength is not a meaningful parameter for backfill materials, but that it is meaningful in the case of seals made of nonsalt materials.

Relative humidity will be monitored and hygroscopic water will be measured; however, this level of detail is beyond that required for the table. No change will be made in the UTP.

Considerable controversy exists as to whether solutioning can be discerned in drill cores, especially in the case of the Deaf Smith County site. Hence, this issue cannot be completely resolved by drilling. This point will be made in the revised UTP.

Analysis of gamma-radiation damage is a detail beyond the scope of Table B-2; therefore, no change will be made in the UTP. 


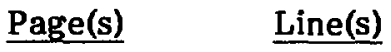

B-22

B-23

B-24

B-24-B-25

\section{Action Statement}

Wawersik and Stone (1986) report an experience with hydrofracturing in salt that indicates that the method does have some promise. Also see action statement for page 9. No change will be made in the UTP.

At least minor development and demonstration are needed to establish a credible and reasonably effective procedure for overcoring from surface boreholes. A note to this effect will be added in the revised UTP.

The revised UTP will indicate that geophysical well logging can provide information about total, but not kinematic, porosity. Also, Table B-2 will be modified to indicate that more test development is required to obtain geochemical and hydrochemical information from geophysical well logging.

Experience with head monitoring, hydraulic tests, and tracer tests in very-low-permeability formations is quite limited. However, it is necessary to show that measured conductivities are less than the critical values identified through performance assessment modeling. The revised UTP will incorporate these points.

The revised UTP will downgrade the effectiveness of the cross-hole tracer test for measuring adsorption/ retardation, but will state that kinematic porosity can be determined well by this test.

The revised UTP will indicate that major test development is required before hydrochemical parameters can be well resolved by downhole probing in a salt environment.

See previous action statements relating to the streng th of salt (e.g., those for pages 75, B-4, B-9, and A-156). Results from uniaxial creep testing should be used with care because loading conditions are different from those encountered underground. Because discussion of this point represents a level of detail not appropriate for Table B-2, no change will be made in the UTP.

If failure occurs during a creep test (i.e., during tertiary creep), some inferences can be made about the "strength" of the salt. Also see previous action statements relating to the strength of salt. Deformation moduli are required for modeling purposes. 
$\underline{\text { Page(s) } \quad \text { Line(s) }}$

B-25

B-27

B-28

B-29

B-36

B-38-B-39

The level of gamma radiation should be a test variable; however, test variables have not been specified at this stage. No change will be made in the UTP.

See $\|$ i 3 of action statement for page B-22.

See action statements regarding hydrofracturing (e.g., those for pages 9 and B-22). With regard to radar, see action statement for Sec. 3.1.3.

Regarding the torsional shear test, see action statement for Sec. 3.2.2. Regarding failure during creep testing, see action statement for pages B-24 and B-25. Finally, regarding plate jacking, its effectiveness in salt is low. Therefore, the bar for effectiveness in determining deformation moduli will be corrected in the revised UTP.

See II 2 of action statement for page B-21.

In the revised UTP, the key to Table B-2 will precede the table.

\section{Appendix C}

C- $\mathbf{4}$

3

C-6

C-6

C-7

1-16

C-7

$7-11$
Details such as those suggested by ANL belong in the detailed test plans and not in the UTP. No change will be made in the UTP.

4-8 The suggested modification is unnecessary; therefore, no change will be made in the UTP.

4-16 The section on geologic mapping in the revised UTP will explicitly discuss determination of structural domains.

Geophysical logging cannot replace visual logging and, without calibrations, geophysical logs do not have a definite meaning. No change will be made in the UTP.

The revised UTP will be site specific; hence, distinguishing between bedded and domal sites will be unnecessary. However, the revised UTP will make clear that only underground testing and development are being considered. 


\begin{tabular}{ccl} 
Page(s) & Line(s) & \multicolumn{1}{c}{ Action Statement } \\
C-7-C-8 & $17-31 ; 1-4$ & $\begin{array}{l}\text { This level of detail is outside the scope of the UTP. No } \\
\text { change will be made in the UTP. }\end{array}$ \\
C-8 & $27-28$ & $\begin{array}{l}\text { See action statement for page C-7, lines 17-31, and page } \\
\text { C-8, lines 1-4. }\end{array}$ \\
C-9 & $11-13$ & $\begin{array}{l}\text { Petrographic analyses are outside the scope of the UTP. } \\
\text { No change will be made in the UTP. }\end{array}$ \\
C-9 & 16 & $\begin{array}{l}\text { See action statement for recommendation 1. } \\
\text { C-10 }\end{array}$ \\
The title will be changed to "Geophysical Borehole \\
L-14
\end{tabular}




\begin{tabular}{|c|c|c|}
\hline Pageis & $\underline{\text { Line(s) }}$ & Action Statement \\
\hline$C-15-C-16$ & $16-26 ; 1-7$ & $\begin{array}{l}\text { Borehole orientation will be important for reduction of } \\
\text { some of the logging data. For this reason, directional } \\
\text { surveys are indicated in Table C-1 of the UTP. No change } \\
\text { will be made in the UTP. }\end{array}$ \\
\hline $\mathrm{C}-16$ & $9-20$ & See action statement for Sec. 3.1.1, I 1 . \\
\hline $\mathrm{C}-17$ & $10-15$ & $\begin{array}{l}\text { The revised discussion of resolution of anomalous features } \\
\text { will mention the independent variables upon which } \\
\text { resolution depends. The words "(factor of 10)" will not } \\
\text { appear in the revised UTP. }\end{array}$ \\
\hline$C-18$ & $9-14$ & $\begin{array}{l}\text { The revised UTP will clarify the use of the term } \\
\text { "breakouts." Discussion of surface boreholes is outside } \\
\text { the document's scope. No change will be made in the } \\
\text { UTP. }\end{array}$ \\
\hline $\mathrm{C}-19$ & & Table C-3 will not be included in the revised UTP. \\
\hline$C-20$ & $22-28$ & ANL retracts this comment. \\
\hline$C-21$ & $2-7$ & $\begin{array}{l}\text { The level of detail represented by the ANL suggestion is } \\
\text { inappropriate for the UTP. No change will be made in the } \\
\text { UTP. }\end{array}$ \\
\hline C-22 & $2-5$ & $\begin{array}{l}\text { The revised UTP will show the interrelationships between } \\
\text { different geophysical methods. Radar will be deleted } \\
\text { from the UTP. }\end{array}$ \\
\hline C-23 & 1 & $\begin{array}{l}\text { The word "underground" will be deleted because the } \\
\text { subject test plan is understood to cover underground } \\
\text { testing. }\end{array}$ \\
\hline C-23 & $2-16$ & See action statement for Sec. 3.1.2, I 2 . \\
\hline $\mathrm{C}-24$ & $6-8$ & $\begin{array}{l}\text { The revised UTP will mention the need for base-station } \\
\text { calibration. }\end{array}$ \\
\hline C-24 & $17-18$ & $\begin{array}{l}\text { The words "and earth tides" will be added to the end of } \\
\text { the sentence. }\end{array}$ \\
\hline C-24 & 26-27 & See action statement for page $C-24$, lines $17-18$. \\
\hline C-25 & $6-7$ & $\begin{array}{l}\text { This section will be modified in the revised UTP to } \\
\text { eliminate the use of a tower. }\end{array}$ \\
\hline
\end{tabular}




\begin{tabular}{|c|c|c|}
\hline$\underline{\text { Page(s) }}$ & $\underline{\text { Line(s) }}$ & Action Statement \\
\hline $\mathrm{C}-26$ & $11-20$ & $\begin{array}{l}\text { Borehole gravimetry can provide estimates of rock mass } \\
\text { density; however, this method will not be referred to in } \\
\text { the revised UTP. }\end{array}$ \\
\hline$C-27$ & $19-22$ & $\begin{array}{l}\text { The section on radar probing will not be included in the } \\
\text { revised UTP, as radar is not applicable in a "wet" salt such } \\
\text { as that found at the Deaf Smith County site. Thus, all } \\
\text { references to "collapse features" will be deleted from the } \\
\text { UTP. }\end{array}$ \\
\hline $\mathrm{C}-30$ & $7-15$ & See action statement for page $\mathrm{C}-27$, lines $19-22$. \\
\hline C-30 & $13-15$ & See action statement for page C-27, lines $19-22$. \\
\hline$C-32$ & $26-30$ & $\begin{array}{l}\text { The depth to which a seismic wave penetrates will depend } \\
\text { on the rate of attenuation caused by the subsurface } \\
\text { medium and the charge size, rather than on geophone } \\
\text { spacing. This point will be clarified in the revised UTP. } \\
\text { The revised UTP will also state that reflections may be } \\
\text { received from depths greater than the geophone spread. }\end{array}$ \\
\hline $\mathrm{C}-\mathbf{3 3}$ & & $\begin{array}{l}\text { In shallow refraction surveying, the tendency is to have } \\
\text { the first-geophone-to-shot distance shorter than } \\
\text { subseguent geophone spacings. A reference will be } \\
\text { provided in the revised UTP. }\end{array}$ \\
\hline $\mathrm{C}-34$ & $1-5$ & $\begin{array}{l}\text { This topic belongs in the surface-based test plan. No } \\
\text { change will be made to the UTP. }\end{array}$ \\
\hline C- 34 & $29-33$ & $\begin{array}{l}S \text { and } P \text { waves can be distinguished over short distances. } \\
\text { However, to accomplish this would require state-of-the- } \\
\text { art equipment and a competent geophysical company with } \\
\text { experience outside the petroleum field. The revised UTP } \\
\text { will clarify these points. }\end{array}$ \\
\hline$-C-37$ & & $\begin{array}{l}\text { These conceptual-level descriptions will be modified in } \\
\text { the revised UTP. More detailed information will be } \\
\text { provided in the subsequent detailed test plans. }\end{array}$ \\
\hline $\mathrm{C}-35$ & $6-33$ & See action statements for Sec. 3.1.4. \\
\hline-36 & 1-33 & ion statements for Sec. 3.1.4. \\
\hline
\end{tabular}




\begin{tabular}{|c|c|c|}
\hline Page(s) & $\underline{\text { Line(s) }}$ & Action Statement \\
\hline $\mathrm{C}-36$ & $8-13$ & $\begin{array}{l}\mathrm{S} \text { waves are required so that dynamic moduli can be } \\
\text { determined. In elastic rocks, the ratio of the in situ } \\
\text { dynamic moduli to the laboratory value provides a } \\
\text { qualitative measure of the amount of fracturing. No } \\
\text { change will be made in the UTP. }\end{array}$ \\
\hline$C-36$ & 22 & "Wave forms" will be replaced by "waveforms." \\
\hline C-37 & $3-5$ & $\begin{array}{l}\text { The text implies that only statistical methods can be used } \\
\text { to improve the signal-to-noise ratio. The revised UTP will } \\
\text { indicate that methods to improve the signal-to-noise ratio } \\
\text { include the commonly used common-depth-point shooting, } \\
\text { which is not a statistical method. }\end{array}$ \\
\hline $\mathrm{C}-38$ & $2-22$ & $\begin{array}{l}\text { Section C.1.8.1 of the UTP will be rewritten to indicate } \\
\text { monitoring of all natural and induced vibrations. Various } \\
\text { types of sensors will be specified according to the } \\
\text { frequency range of interest. }\end{array}$ \\
\hline $\mathrm{C}-38$ & 25 & See action statement for page 74 , lines $18-30$. \\
\hline $\mathrm{C}-39$ & $7-9$ & $\begin{array}{l}\text { The instruments are accelerographs; the revised UTP will } \\
\text { clarify their operation and their function. }\end{array}$ \\
\hline$C-39$ & 16 & $\begin{array}{l}\text { The spelling of "propagation" will be corrected in the } \\
\text { revised UTP. }\end{array}$ \\
\hline C-39 & $27-29$ & $\begin{array}{l}\text { The revised UTP will state that calibration is carried out } \\
\text { using a calibration coil installed in each geophone and that } \\
\text { geophones can be calibrated in an environment free of } \\
\text { acoustic noise prior to installation. }\end{array}$ \\
\hline$C-40$ & 18 & $\begin{array}{l}\text { The spelling will be corrected in the revised UTP as } \\
\text { suggested. }\end{array}$ \\
\hline$C-42$ & $1-9$ & $\begin{array}{l}\text { The revised UTP will indicate that precharacterization of } \\
\text { the sample location is warranted and that large-diameter } \\
\text { coring is the preferred sampling method. }\end{array}$ \\
\hline $\mathrm{C}-42$ & 24 & The abbreviation will be corrected as suggested. \\
\hline$C-43$ & 11 & The spellings will be changed as noted. \\
\hline$C-43$ & 16 & added. \\
\hline
\end{tabular}




\begin{tabular}{cll} 
Page(s) & Line(s) & \multicolumn{1}{c}{ Action Statement } \\
C-43 & $31-33$ & $\begin{array}{l}\text { The sentence will be reworded to read: "Specially } \\
\text { designed nondestructive tests, including..." }\end{array}$ \\
C-45 & $8-13$ & $\begin{array}{l}\text { The revised UTP will indicate that velocities measured at } \\
\text { ultrasonic frequencies can be compared with low- } \\
\text { frequency velocities from seismics to check on } \\
\text { dispersion. }\end{array}$ \\
C-47 & $20-26$ & $\begin{array}{l}\text { The revised UTP will note that vibrating wire } \\
\text { stressmeters of the IRAD type have not performed well in } \\
\text { salt. }\end{array}$ \\
C-48 & $\begin{array}{l}\text { The revised UTP will explicitly state the reason for } \\
\text { choosing an adjacent elastic bed. }\end{array}$ \\
C-48 & $\begin{array}{l}\text { In general, stress measurements do not provide ambiguous } \\
\text { results. Since measurement techniques for elastic rocks } \\
\text { are well developed, as complete a picture as possible } \\
\text { should be compiled of the in situ conditions in the elastic } \\
\text { rocks, so that the total stress picture can be elucidated } \\
\text { and confidence developed in the results. In addition, the } \\
\text { stress state in the nonsalt rocks is of importance to far- } \\
\text { field geohydrological modeling and to shaft design. These } \\
\text { points will be clarified in the revised UTP. }\end{array}$
\end{tabular}
C-49-C-50 8-32;1-11 See action statements for Secs. 2.5.2 and 3.2.1. .
C-51-C-52 20-34;1-11 The comment concerning the experience at WIPP with stiff inclusion devices has been noted; "Stormont et al., 1984" will be referenced in the revised UTP. Also see action statements for Sec. 3.2.1.

C-57 27-29 The cited reference does not discuss overcoring. The revised UTP will clarify that overcoring will be used in nonsalt rocks only.

C-63 16-21 The methodology proposed by Heuzé and Amadei (1985), which seems to result in realistic modulus values, will be referenced in the revised UTP. See previous action statements relating to deformability (e.g., that for page A-157).

C-66 11-16 The detailed test plans will state that the borehole calipers for closure monitoring should be permanently installed. No change will be made in the UTP. 


\begin{tabular}{|c|c|c|}
\hline$\underline{\text { Page(s) }}$ & $\underline{\text { Line(s) }}$ & Action Statement \\
\hline$C-69$ & $4-25$ & $\begin{array}{l}\text { The revised UTP will provide a reference for this test, } \\
\text { that is, "Sellers (1974)." }\end{array}$ \\
\hline$C-74 ; C-75$ & $25 ; 7$ & $\begin{array}{l}\text { The source "Sellers, 1974" will be referenced in the } \\
\text { revised UTP. The digits in the second equation are } \\
\text { reversed in Sellers (1974); the equation provided is a } \\
\text { corrected version. }\end{array}$ \\
\hline$C-76$ & 22 & $\begin{array}{l}\text { The transducers will likely be accelerometers; however, } \\
\text { such details should be specified in the detailed test } \\
\text { plans. No change will be made in the UTP. }\end{array}$ \\
\hline $\mathrm{C}-83$ & $4-6$ & $\begin{array}{l}\text { In situ stresses and properties such as deformability and } \\
\text { creep are measured; a conceptual mechanical model with } \\
\text { incorporated constitutive laws is developed, for example, } \\
\text { into a computer code; and the model is then applied to a } \\
\text { problem with known boundary conditions. The predictions } \\
\text { of stress and deformation are then compared with } \\
\text { observations to evaluate the applicability of the model to } \\
\text { the problem of interest, thus contributing to validation of } \\
\text { the model. The original intent was to indicate that the } \\
\text { mine-by test is only part of the model validation process. } \\
\text { The sentence eliciting the ANL comment is unclear and } \\
\text { will be modified in the revised UTP. }\end{array}$ \\
\hline$C-84$ & $16-19$ & $\begin{array}{l}\text { Under many circumstances, exact geometric similitude is } \\
\text { unnecessary. However, to extrapolate from a test } \\
\text { geometry, it is necessary to have a satisfactory } \\
\text { constitutive model. Since satisfactory constitutive } \\
\text { models do not as yet exist for salt, geometric similitude } \\
\text { and real-time testing should be adopted wherever possible } \\
\text { in the exploratory shaft facility. No change will be made } \\
\text { in the UTP. Also see action statement for Sec. } 3.2 .3 \text {. }\end{array}$ \\
\hline $\mathrm{C}-87$ & $27-30$ & $\begin{array}{l}\text { It will be desirable to excavate the exploratory shaft } \\
\text { facility with the same type of equipment to be used in the } \\
\text { repository. Although it is likely that a roadheader will be } \\
\text { used, as was the case at WIPP, the method of excavation } \\
\text { in the exploratory shaft facility is outside the scope of the } \\
\text { UTP. This fact highlights the importance of close } \\
\text { coordination between ONWI and its various subcontrac- } \\
\text { tors. No change will be made in the UTP. }\end{array}$ \\
\hline
\end{tabular}




\begin{tabular}{|c|c|c|}
\hline Pageis) & $\underline{\text { Line(s) }}$ & Action Statement \\
\hline $\mathrm{C}-88$ & $25-29$ & $\begin{array}{l}\text { The use of rock bolts in the roofs of both salt and potash } \\
\text { mines depends on the nature of the immediately overlying } \\
\text { strata. The various types of rock bolts have different } \\
\text { useful lives and also different effects on the response of } \\
\text { the roof. No change will be made in the UTP. Also see } \\
\text { action statement for Sec. 3.2.4. }\end{array}$ \\
\hline C-89 & $12-14$ & $\begin{array}{l}\text { Long horizontal holes can be drilled, provided sufficient } \\
\text { care is taken. Also, } 200 \mathrm{ft} \text { is not a particularly long hole; } \\
\text { however, wandering may still occur during drilling. This } \\
\text { point will be noted in the revised UTP. }\end{array}$ \\
\hline C-90 & $5-10$ & $\begin{array}{l}\text { Selection of numerical codes is outside the scope of the } \\
\text { UTP; however, it might be wise to design tests with } \\
\text { particular codes in mind for the analysis phase. The } \\
\text { revised UTP will mention this point. }\end{array}$ \\
\hline C-91 & 1 & $\begin{array}{l}\text { The revised UTP will clarify that the rock bolts used in } \\
\text { the repository might not have mechanical or friction } \\
\text { anchors, but might be grouted instead. Also see action } \\
\text { statement for page C-88, lines } 25-29 \text {. }\end{array}$ \\
\hline C-91 & $17-21$ & $\begin{array}{l}\text { See action statement for Sec. 3.2.4. It is anticipated that } \\
\text { rock bolts will be required for support, particularly at the } \\
\text { Deaf Smith County site. See action statement for page } \\
\text { C-88, lines } 25-29 \text {. }\end{array}$ \\
\hline $\mathrm{C}-92$ & & Part "b" of Fig. C-6 will be relabeled. \\
\hline$C-100$ & & $\begin{array}{l}\text { The shaft liner designs will be referenced in the revised } \\
\text { UTP. }\end{array}$ \\
\hline C-104 & & $\begin{array}{l}\text { Instruments will be made of corrosion-resistant material. } \\
\text { Because this level of detail is more appropriate for the } \\
\text { detailed test plans, no change will be made in the UTP. }\end{array}$ \\
\hline$-108-C-109$ & $25-30 ; 1-3$ & $\begin{array}{l}\text { The revised UTP will clarify that, because of allowable } \\
\text { threshold temperature values, there will be a minimum } \\
\text { waste package spacing for each type and age of waste, } \\
\text { that is, for each particular waste package thermal power. }\end{array}$ \\
\hline$C-116$ & $1 ; 4 \mathrm{ff}$ & $\begin{array}{l}\text { This test will be called the "waste-package heater test" in } \\
\text { the revised UTP. }\end{array}$ \\
\hline $\mathrm{C}-123$ & $27-29$ & statement for page $\mathrm{C}-90$, lines $5-10$. \\
\hline
\end{tabular}




\begin{tabular}{|c|c|c|}
\hline$\underline{\text { Page(s) }}$ & $\underline{\text { Line(s) }}$ & Action Statement \\
\hline C-133 & $11-19$ & See action statement for page C-90, lines 5-10. \\
\hline C-135 & $13-17$ & See action statement for Sec. 3.3 .3 , I 1 . \\
\hline C-144 & $18-22$ & $\begin{array}{l}\text { The surface roughness of excavated openings will affect } \\
\text { the rate of convective heat transfer. If a roadheader is } \\
\text { used to drive the rooms, the resulting smooth profile will } \\
\text { make this comment trivial. No change will be made in the } \\
\text { UTP. }\end{array}$ \\
\hline$C-148$ & $22-27$ & $\begin{array}{l}\text { Significant permeability (if any) in bedded salt is related } \\
\text { to the presence of fractures or strata of impure salt or } \\
\text { other sedimentary materials. Hence, the purpose of the } \\
\text { single-borehole hydraulic conductivity test is to measure } \\
\text { the in situ hydraulic parameters related to flow in such } \\
\text { features. It is probably not feasible to measure the } \\
\text { hydraulic parameters within pure intact salt, although } \\
\text { verification of its low-permeability characteristics is } \\
\text { required. These ideas will be clarified in the revised UTP. }\end{array}$ \\
\hline$C-149$ & $24-25$ & $\begin{array}{l}\text { On a repository scale, sedimentary interbeds can be } \\
\text { thought of as discontinuities. Other possible } \\
\text { discontinuities are shear zones that have incorporated } \\
\text { nonsalt impurities so that "healing" of the fractures by } \\
\text { plastic flow does not occur. These ideas will be clarified } \\
\text { in the revised UTP. }\end{array}$ \\
\hline$C-156$ & 1 & $\begin{array}{l}\text { The revised UTP will state that the cross-hole hydraulic } \\
\text { conductivity tests will be performed in rock } \\
\text { discontinuities or sedimentary interbeds that have been } \\
\text { identified as having sufficiently high hydraulic } \\
\text { conductivity to make the test feasible. }\end{array}$ \\
\hline$C-157$ & $16-20$ & See action statement for page C-148, lines 22-27. \\
\hline C-158 & & $\begin{array}{l}\text { This drawing was not copied from another source. No } \\
\text { change will be made in the UTP. With regard to } \\
\text { transducers outside the packers, see action statement for } \\
\text { Sec. 3.4.1, I } 1 \text {. }\end{array}$ \\
\hline C-161 & $5-7$ & See action statement for Sec. 3.4.2, $\uparrow 2$. \\
\hline C-161 & $7-13$ & ts for Sec. 3.4.2, Iा 1 . \\
\hline
\end{tabular}


$\underline{\text { Page(s) Line(s) }}$

C-161

C-161

C-163-C-169

C-165

C-168-C-169

C-169

C-170

C-174-C-175

C-175

C-175

C-176

C-177

C-177
21-25

12-13

29-33

$5-33 ; 1-3$

4-13

1

$22-24 ; 1-26$

3-5

6-7

25

\section{$\underline{\text { Action Statement }}$}

Darcy's law may not apply to extremely low permeability materials such as intact salt. However, the testing strategy does not call for actually measuring hydraulic conductivities in such tight materials. It will suffice to verify the low permeability characteristics of the salt by determining an upper bound. These points will be incorporated into the revised UTP.

The terms "graphical" and "type-curve" will be changed to "semilog" and "curve-matching," respectively.

See action statements for Sec. 3.4.3.

The labeling of the instrumentation will be corrected in the revised UTP. With regard to the use of guarded packers, see action statement for Sec. 3.4.1, I 1. With regard to methods of monitoring tracer concentrations, see action statement for Sec. 3.4.3, II 5 .

The revised UTP will clarify that tracer tests (if any) will be conducted within features wiih relatively high permeabilities, such as rock discontinuities or sedimeritary interbeds.

See action statement for Sec. 3.4 .3 , is 2 and 3.

See action statement for page 91, lines 1-24.

See action statement for Sec. 3.4.4.

The revised UTP will define mechanical dispersion as "av."

The revised UT' will indicate that sensitivity analyses will be performed to determine whether the pressure gradient imposed during the test affects calculation of the matrix diffusion coefficient.

It is unclear how effective porosity can be determined from a diffusion test. The text of the UTP will be modified accordingly.

The UTP will be revised to read: "horizontal to vertical. Horizontal holes. ..."

The sentence will be revised to read: "around a natural bridge of salt. .. ." at the first reference to the bridge. 


\begin{tabular}{|c|c|c|}
\hline$\underline{\text { Page(s) }}$ & $\underline{\text { Line(s) }}$ & Action Statement \\
\hline$-179-C-180$ & $17-30 ; 1-30$ & See action statement for Sec. 3.4 .5 , ๆ 1 . \\
\hline$C-180$ & 23-30 & See action statement for Sec. 3.4.5, ๆ 1 . \\
\hline$C-183$ & 1 & $\begin{array}{l}\text { The term "equivalent seal permeability" will be clearly } \\
\text { defined in the revised UTP. }\end{array}$ \\
\hline $\mathrm{C}-184$ & 3-15 & See action statement for Sec. 3.4.6, $\| \mathrm{s} 3$ and 4 . \\
\hline$C-184$ & $4-6$ & See action statement for Sec. 3.4.6, $₫ 1$. \\
\hline $\mathrm{C}-185$ & $7-16$ & See action statement for Sec. 3.4.6, ๆ 1 . \\
\hline C-185 & $8-10$ & $\begin{array}{l}\text { The eited reference has been noted; no additional action } \\
\text { will be taken. }\end{array}$ \\
\hline C-192 & 28 & $\begin{array}{l}\text { The revised UTP will clearly define the term "effective } \\
\text { hydraulic conductivity." }\end{array}$ \\
\hline$C-193$ & 8-10 & $\begin{array}{l}\text { The aim of this test is to ensure that performance } \\
\text { requirements can be achieved. In that sense, this test } \\
\text { constitutes a demonstration of seal performance. This } \\
\text { point will be clarified in the revised UTP. With regard to } \\
\text { the cited reference, see action statement for page C-185, } \\
\text { lines } 8-10 \text {. }\end{array}$ \\
\hline C-194 & $7-8$ & ANL retracts its comment, as it is trivial. \\
\hline C-194 & $12-15$ & $\begin{array}{l}\text { The citation for "Gnirk et al. (1981)" in the list of } \\
\text { references will be corrected. }\end{array}$ \\
\hline C-194 & $17-18$ & $\begin{array}{l}\text { Uncertainty exists concerning the mode of fluid transport } \\
\text { in response to a thermal gradient. In all likelihood, } \\
\text { several mechanisms are both operative and interactive. } \\
\text { Furthermore, thermomechanical effects may affect the } \\
\text { fluid migration process by creating zones of increaser } \\
\text { permeability. These points will be clarified in the revised } \\
\text { UTP. }\end{array}$ \\
\hline
\end{tabular}

C-194 20-23 The revised UTP will add a sentence on radiation effects. 


\begin{tabular}{|c|c|c|}
\hline Page(s) & $\underline{\text { Line(s) }}$ & Action Statement \\
\hline $\mathrm{C}-195$ & $22-25$ & $\begin{array}{l}\text { Although repository conditions would be exactly simulated } \\
\text { with a backfill of crushed salt, it would be difficult to } \\
\text { monitor any brine migration taking place. For this reason, } \\
\text { a "porous, nonreactive backfill" is satisfactory within the } \\
\text { context of this test. In addition, this type of backfill will } \\
\text { result in a worst case because mole migration will occur } \\
\text { in the vicinity of the waste package than would if salt } \\
\text { were used for backfill. No change will be made in the } \\
\text { UTP. }\end{array}$ \\
\hline$C-197$ & 7 & "Redudacy" will be changed to "redundancy." \\
\hline $\mathrm{C}-197$ & 21-22 & The revised UTP will refer to Sec. C.4.7.4.2. \\
\hline$C-198$ & 28-31 & $\begin{array}{l}\text { The revised UTP will clarify that a fluid surge may occur } \\
\text { following heater shutdown, but that the mechanism } \\
\text { causing this surge is not well understood. }\end{array}$ \\
\hline
\end{tabular}

C-199-C-201

Stress meters are unnecessary in this test because they will be used in the waste package heater test. Load cells could be attached to the simulated waste package to measure loads developed on the container. This possibility will be mentioned in the revised UTP.

C-203

18-28 The rate-of-moisture-release equation will be clarified. Furthermore, "K" will not be used to represent two parameters -- Boltzmann's constant and permeability. The units for vapor pressure and permeability will be changed to dyne $/ \mathrm{cm}^{2}$ and $\mathrm{cm}^{2}$, respectively.

C-209 6-8 See action s'atement for Sec. 3.4.8.

C-213 5-6

The assimed hydrogeological model is intended for the near field. In this case, the potential hydrogeologic boundaries near the underground facility include the first dolomite interbeds above and below the repository horizon as well as any shear or fault zones present. These features may not be far removed from the repository. The revised UTP will clarify these points.

C-213

12-14 The revised UTP will indicate that determining whether excavation interferes with the ability of the site to isolate waste will be based on the results of all tests, not just this one. 


\begin{tabular}{|c|c|c|}
\hline Page(s) & Line(s) & Action Statement \\
\hline C-219 & $1-2$ & $\begin{array}{l}\text { If pressure lines were to extend from the piezometers to } \\
\text { the access room, it would be possible to perform pressure- } \\
\text { pulse tests to directly measure effective hydraulic } \\
\text { conductivity. The values would reflect the properties of } \\
\text { both the undisturbed formation and the disturbed zone } \\
\text { adjacent to the borehole. This information could be used } \\
\text { to calculate the time lag for a particular piezometer } \\
\text { installation. These points will be clarified in the revised } \\
\text { UTP. }\end{array}$ \\
\hline$C-221$ & $8-10$ & $\begin{array}{l}\text { The term "adit" will be replaced by "drift," "entry," or } \\
\text { other appropriate term. }\end{array}$ \\
\hline $\mathrm{C}-221$ & $18-21$ & $\begin{array}{l}\text { ANL's comment is inappropriate and is therefore } \\
\text { retracted. }\end{array}$ \\
\hline $\mathrm{C}-223$ & $11-12$ & $\begin{array}{l}\text { The words "such as interbeds" will be added after } \\
\text { "discontinuities." }\end{array}$ \\
\hline $\mathrm{C}-224$ & $18-26$ & $\begin{array}{l}\text { ANL's comment is retracted because the contamination } \\
\text { experienced in the German tests will not be a problem } \\
\text { with the proposed test because of different test } \\
\text { conditions. }\end{array}$ \\
\hline $\mathrm{C}-226$ & $2-4$ & This sentence will be deleted in the revised UTP. \\
\hline
\end{tabular}




\section{REFERENCES FOR APPENDIX C}

Gelhar, L.W., and C.L. Axness, 1983, Three-Dimensional Stochastic Analysis of Macrodispersion in Aquifers, Water Resources Research, 19(1):161-180.

Gringarten, A.C., et al., 1979, A Comparison between Different Skin and Wellbore Storage Type Curves for Early-Time Transient Analysis, presented at the SPE-AIME 54th Annual Technical Conference and Exhibition, Las Vegas, Nev., Sept. 23-26, Society of Petroleum Engineers Reprint SPE-8205.

Heuzé, F.E., and B. Amadei, 1985, The NX Borehole Jack: A Lesson in Trials and Errors, International J. Rock Mechanics and Mining Sciences and Geomechanics Abstracts, 22(2): 105-112.

Hvorslev, J.M.J., 1951, Time Lag and Soil Permeability in Ground-Water Observations, Waterways Experiment Station, U.S. Army Corp of Engineers, Bulletin No. 36.

International Association of Hydrogeologists, 1985, Hydrogeology of Rocks of Low

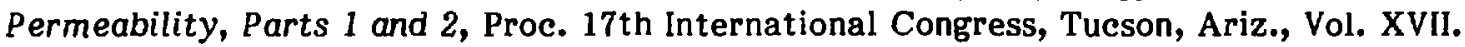

Marinelli, F., 1984, Analysis of Constant Head Injection Tests in Single, Partially Penetrating Boreholes, M.S. thesis, University of Arizona, Tucson.

Marinelli, F., and J.W. Rowe, 1985, Performance and Analysis of Drill-Stem Tests in Small-Diameter Boreholes, Groundwater, 23(3):367-376.

Sellers, J.B., 1974, Measurement of In Situ Shear Strength Using the Torsional Shear Method, in Field Testing and Instrumentation of Rock, American Society of Testing and Materials, STP 554, Philadelphia.

Stormont, J.C., et al, 1984, Field Tests of Stress Measurement Techniques in Rock Salt, Sandia National Laboratories Report SAND83-2507.

Theim, G., 1906, Hydrologische Methodes, Gebhardt, Leipzig.

Theis, C.V., 1935, The Relation between the Lowering of the Piezometric Surface and the Rate of Duration of Discharge of a Well Using Groundwater Storage, Transactions American Geophysical Union, 16th Annual Meeting, pt. 2, pp. 519-524.

U.S. Bureau of Reclamation, 1981, Ground Water Manual: A Guide for the Investigation, Development, and Management of Ground Water Resources U.S. Department of the Interior.

U.S. Department of Energy, 1986, Environmental Assessment, Deaf Smith County Site, Texas, DOE/RW-0069, Office of Civilian Radioactive Waste Management, 3 vols.

Wawersik, W.R., and C.M. Stone, 1986, Experience with Hydraulic Fracturing Tests for Stress Measurements in the WIPP, in Rock Mechanics: Key to Energy Production, H.L. Hartman, ed., Society of Mining Engineers, Littleton, Colo., pp. 940-947. 


\section{CONCURRENCE}

I concur with the responses, as presented in App. $C$, to the recommendations and comments of Argonne's review report entitled Radioactive Waste Isolation in Salt: Peer Review of the Golder Associates Draft Test Plan for In Situ Testing in an Exploratory Shaft in Salt.

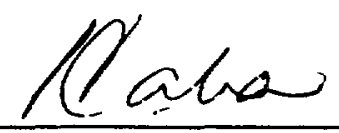

H.N. Kalia, Office of Nuclear Waste Isolation

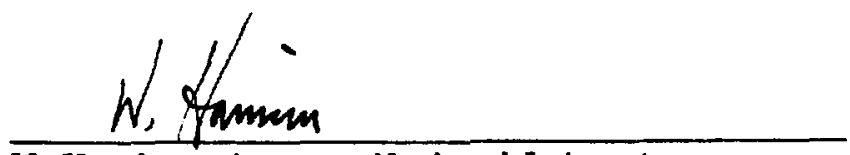

W. Harrison, Argonne National Laboratory



J. Poyrell, Salt Repository Project Office

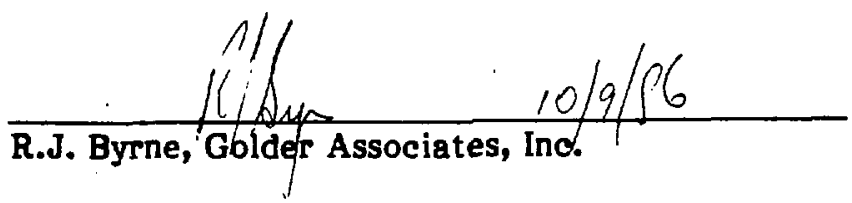




\section{APPENDIX D}

CREDENTIALS OF PEER REVIEW PANEL MEMBERS 


\section{Gregory B. Baecher}

University of California, Berkeley: B.S.C.E., Civil Engineering (1968) Massachusetts Institute of Technology, S.M., Civil Engineering (1970) Massachusetts Institute of Technology, Ph.D., Civil Engineering (1972)

Dr. Baecher is Associate Professor of Civil Engineering and Head of the Construction Facilities Division at the Massachusetts Institute of Technology. His principal field of interest is engineering geology and rock mechanics, with emphasis on statistical site characterization and engineering risk assessment. Since 1974, he has served as a consultant for numerous geotechnical engineering firms and U.S. government agencies. In 1978-1979, he served on an independent review panel concerning nuclear waste disposal for the Office of Science and Technology Policy and has since been an expert consultant to other U.S. government committees. Before 1974, Dr. Baecher worked at the International Institute for Applied Systems Analysis and served with the U.S. Army Corps of Engineers.

Dr. Baecher has taught numerous courses in geotechnical engineering and reliability, soil mechanies, and prediction and risk in rock engineering. He has published more than 65 papers on such topics as safety and uncertainty in soil engineering, methods of estimating soil properties, and statistical methods in engineering geology.

As an invited lecturer at several American and European universities, Dr. Baecher has spoken on the uncertainty of models in geotechnical prediction and on the probabilistic geotechnical analysis of waste repositories. Dr. Baecher is a member of seven civil engineering and mathematical societies. 


\section{Richard M. Bateman}

Oxford University (Lincoln College): B.A., Physics (1962)

Oxford University (Lincoln College): M.A., Physics (1967)

Since 1982, Mr. Bateman has been President of Vizilog, Inc., a consulting service to major oil companies in the fields of petrophysics and formation evaluation. As President of Petrophysical Data Consultants from 1980 to 1983, he directed a team of engineers and geologists that was writing log analysis software and installing log analysis systems for oil companies. Mr. Bateman spent five years at Amoco International (19751980), where his expertise was established in reserve estimation, equity negotiation, quality control of field logging, log interpretation, and formation evaluation by computer. As an engineer for Schlumberger (1964-1975), Mr. Bateman worked in both South and North America on logging projects and carried out research projects at the Schlumberger Doll Research Center in Ridgefield, Conn. His work included interpretation of well logs using statistical methods, permafrost studies, design and programming of well-log interpretation routines, dipmeter studies, nuclear tool responses, and accuracy studies for quality control. Mr. Bateman has been actively engaged in teaching formation evaluation to engineers and geologists, both domestically and overseas, through his association with the International Human Resource Development Corporation.

Mr. Bateman acquired a patent on a neutron well-logging technique for gas detection in 1977. Since then he has published many papers on log analysis and formation evaluation, and has written books on control of $\log$ quality and monitoring of reservoir performance. He is a member of four professional societies. 


\section{Barry H.G. Brady}

University of Queensland: B.Sc. (1963)

University of Queensland: M.Sc. (1967)

University of London (Imperial College): M.Sc., Engineering and Rock Mechanics (1977)

University of London (Imperial College): Ph.D., Mining and Geo-Engineering (1979)

As Chief of CSIRO's Division of Geomechanics in Melbourne, Australia, Dr. Brady directs a group of 80 scientists, engineers, and support staff in basic and applied research in geomechanics. From 1979 to 1983, he was a professor at the University of Minnesota, where his research focused on numerical methods of stress analysis and their application to design of radioactive waste repositories and mining excavations. While at the Royal School of Mines, Imperial College, London (1975-1979), he researched boundary element methods of stress analysis and their application to mine design and underground excavation. Before that time, he acquired experience in rock mechanics at Mount Isa Mines, Ltd. (1967-1975).

Over the last six years, Dr. Brady has been a principal investigator supported by research grants from the Australian Mineral Industries Research Association, Ltd., Battelle's Office of Nuclear Waste Isolation, Rockwell International, and the National Science Foundation. He is principal author of a book on rock mechanics for underground mining and has authored or coauthored more than $\mathbf{5 0}$ journal articles, conference and symposium papers, keynote addresses, and major consulting reports for corporations and government agencies in Australia, the United Kingdom, the United States, Canada, and Finland.

Dr. Brady was a member of the DOE Research Assistance Task Force in 1981, which was a group of 30 specialists who were to advise on research needs in radioactive waste isolation. He is an active member of 10 international professional societies and has been an invited speaker at several international symposia. Dr. Brady received the U.S. National Rock Mechanics Committee Award in 1980 for significant original contributions to research in rock mechanics. 


\section{Lawrence W. Braile}

University of Washington: B.S., Geology (1969)

University of Washington: M.S., Geology (1970)

University of Utah: Ph.D., Geology (1973)

Dr. Braile has been a professor in the Department of Geosciences at Purdue University since 1973. His research interests include crustal seismic studies, applications of quantitative analysis methods in geology and geophysics, and seismotectonics of midcontinental North America. In 1978, Dr. Braile was codirector of an international cooperative seismic profiling experiment in the Yellowstone-Snake River Plain. As part of a research team from Purdue University, the University of Texas at El Paso, and the University of Pittsburgh, Dr. Braile has been actively involved for the past six years in geological and geophysical studies of the midcontinent area of eastern North America. These studies have been aimed at evaluating earthquake hazards and understanding midcontinent seismicity.

Additional research interests of Dr. Braile include developing quantitative linear inversion methods for modeling geophysical data and applying digital processing techniques to one- and two-dimensional filtering of gravity, magnetic, and seismic data. Since 1976, Dr. Braile has served as a consultant to petroleum companies on geophysical methods of exploration and to several of the national laboratories.

Dr. Braile has published more than 60 papers on seismic research and the application of analytical methods in geophysical studies. He has presented approximately 80 papers at national and international meetings over the past 10 years. $\mathrm{He}$ is a member of four professional geological societies and is an associate editor of the Journal of Geophysical Research. In 1983 he was appointed to the Committee on Seismology of the National Research Council, National Academy of Sciences. 


\section{Joseph S. Busch}

Northwestern University: B.S., Chemical Engineering (1949)

Johns Hopkins University: M.S., Chemical Engineering (1953)

Carnegie Mellon University: Ph.D., Chemical Engineering (1960)

Dr. Busch is Principal Engineer with Raymond Kaiser Engineers, Oakland, Calif. He has 32 years experience working on nuclear and chemical engineering projects for both government and industry. He has supervisory and design experience with solid-, liquid-, and gas-processing systems for nuclear and nonnuclear facilities. His nuclear experience includes work on both fast reactors and light-water reactors.

Dr. Busch participated in the National Waste Terminal Storage Program by working on a conceptual design for a mined repository in salt for highly radioactive waste. He was assistant project manager in charge of underground technology and also served as head of the thermal analysis group. As such he directed the work of mining, rock mechanics, heat transfer, and ventilation engineers and consultants, and coordinated the design of subsurface systems with that of surface facilities. Dr. Busch also served as manager of a preconceptual design of an incinerator facility to be constructed at Idaho National Engineering Laboratory. He has also participated in the Basalt Waste Isolation Project and the Nevada Nuclear Waste Storage Investigation.

A registered chemical engineer in Pennsylvania, Michigan, Mississippi, and New York, Dr. Blisch has published numerous papers on heat transfer, nuclear systems, and pollution abatement. 


\section{John D. Ditmars}

Princeton University: B.S.E., Civil Engineering (1965)

California Institute of Technology: M.S., Civil Engineering (1966)

California Institute of Technology: Ph.D., Civil Engineering (1971)

Dr. Ditmars is Senior Engineer and leader of the Hydrologic and Geologic Engineering Section of the Engineering Geosciences Group of the Energy and Environmental Systems Division at Argonne National Laboratory. Measuring and modeling portions of the hydrosphere affected by energy technologies and natural resource development has been the main research area of this section. Particular attention has been given to evaluations of model performance and to experimental designs for the acquisition of data at prototype scales for performance evaluation. Dr. Ditmars has extensive experience in measuring and modeling transport and mixing processes in the hydrologic environment. He was for several years responsible for the annual literature review in the area of "Mixing and Transport" for the Journal of the Water Pollution Controi Federation and is Vice Chairman of the Executive Committee of the Hydraulics Division of the American Society of Civil Engineers. He is also Chairman of the Task Committee on Verification of Models of Hydrologic Transport and Dispersion for the Hydraulies Division of the same society and, as such, has been concerned with the generic aspects of verification and validation as well as with those aspects of particular models.

Before joining Argonne in 1977, Dr. Ditmars was Assistant Professor of Civil Engineering at the University of Delaware. From 1970 to 1972 he was Visiting Assistant Professor in the Water Resources and Hydrodynamics Division of the Civil Engineering Department at the Massachusetts Institute of Technology. His teaching and research activities at those institutions focused on hydraulic engineering and fluid mechanical processes in the natural hydrologic environment and involved analytical and numerical modeling as well as laboratory and field experiments. He is author of more than 45 technical publications in these areas. 


\section{Charles H. Dowding}

University of Colorado at Boulder: B.S., Civil Engineering (1967)

University of Illinois at Urbana: M.S., Civil Engineering (1968)

University of Illinois at Urbana: Ph.D., Civil Engineering (1971)

Dr. Dowding is Associate Professor of Civil Engineering at Northwestern University, where he has taught since 1976. From 1972 to 1976, he was an Assistant Professor at the Massachuset ts Institute of Technology. His principal field of research is in rock and soil mechanics, with special emphasis on blasting, dynamic response, jointed media, exploration decisions, and foundation engineering.

Dr. Dowding has been a consultant to numerous national engineering companies on projects related to nuclear power plant design, rock mechanies testing, earthquakes, blasting, and subsidence. He has been Cochairman of the National Research Council Committee for Rock Mechanics Research Requirements and is Chairman of the Rock Mechanics Committee of the Geotechnical Division of the American Society of Civil Engineers. Over the past 10 years, he has received numerous research grants, one of which was for calculating and characterizing the behavior of rocks under unusual conditions such as blasts and earthquakes.

In 1981, Dr. Dowding received the Outstanding Applied Research Award in Rock Mechanics from the U.S. National Committee for Rock Mechanics. He has published more than 40 papers and books, has edited proceedings on rock mechanics, and has presented more than 30 public talks on his research. 


\section{John B. Fart}

University of California, Berkeley: A.B., Geophysies (1951)

University of California, Berkeley: M.A., Geophysics (1953)

University of California, Berkeley: Ph.D., Geophysics (1957)

University of Tulsa: J.D. (1971)

Dr. Farr is Chief Geophysicist at Western Geophysical Company, Litton Industries, where he is responsible for design and implementation of extensive seismic programs throughout the world. As Manager of Special Projects (1975-1979), Dr. Farr directed nuelear power plant siting programs in the United States and Puerto Rieo, using high resolution seismic methods. He was responsible for developing a high-frequency seismic method having a resolution one order of magnitude greater than existing systems.

From 1957 to 1975, Dr. Farr worked for A MOCO, where he directed geophysical research on the seismic responses of various geological rock suites and on matrix and pore materials. He also developed new methods of subsurface imaging. During this period, he received 10 U.S. patents related to novel methods of acquiring and processing seismic data. His work from 1957 to 1965 was mainly related to geophysical exploration. During this period, he held positions as Seismograph Party Chief, District Geophysicist (Texas), Senior Staff Geologist (Oklahoma), and Supervisor of Geophysical Operations (Alaska).

Dr. Farr has written more than 16 publications on his work in resolution of seismic profiling, including earth holography as a seismic method. He is a member of eight professional societies, including two bar associations. 


\section{David F. Fenster}

City College of the City University of New York: B.A., History (1967)

University of Illinois: M.A., History (1968)

Queens College of the City University of New York: M.S., Geology (1975)

Certified Professional Geologist, No. 4668, American Institute of

Professional Geologists

Certified Professional Geologist, No. 85, State of Indiana

Mr. Fenster joined Roy F. Weston, Inc., in May 1985 as a Senior Geologist. Since that time, he has worked on U.S. Department of Energy (DOE) environmental assessments and has been managing DOE headquarters' oversight of the Crystalline Repository Project Office (currently the Repository Technology Program) and the site characterization plan effort of the Salt Repository Project Office.

From 1982 to 1985 , Mr. Fenster was a staff member of the Geoscience and Engineering Group of the Energy and Environmental Systems Division of Argonne National Laboratory. He was Technical Project Manager and member of the multidisciplinary core peer review staff, which reviews technical and programmatic documents for the Salt Repository Project Office of the Civilian Radioactive Waste Management Program. He also served as a technical reviewer for parts of Argonne's Lake Superior regional report related to siting a repository for high-level radioactive waste in crystalline rocks.

Before his employment with Argonne, Mr. Fenster was Project Geologist with Dames \& Moore, Park Ridge, Ill. He had been with Dames \& Moore since joining the staff of the Cranford, N.J., office in 1974. During his tenure with Dames \& Moore, Mr. Fenster acquired extensive experience in seismotectonics, structural geology, radioactive and hazardous waste disposal, regional geology, engineering geology, hydrogeology, and general geologic field mapping. For example, Mr. Fenster was Principal Investigator for Stratigraphy for the Generic Environmental Impact Statement concerning disposal of radioactive waste in bedded salt, granitic rocks, and argillaceous formations for Oak Ridge National Laboratory. He also worked on a revised draft (unpublished) of a national screening document concerning selecting sites for repositories in crystalline rocks for isolating high-level radioactive waste.

Mr. Fenster also worked on geologic investigations related to nuclear power plant siting and licensing. He is familiar with U.S. Nuclear Regulatory Commission review and licensing procedures, having worked on early site reviews, preliminary safety analysis reports, final safety analysis reports, and detailed fault investigations.

Mr. Fenster has published on the siting of repositories for high-level radioactive waste, midcontinent tectonics, and structural geology in the Northeast, and has worked on more than 30 consulting reports. He is a member of five professional societies, including the Association of Engineering Geologists.

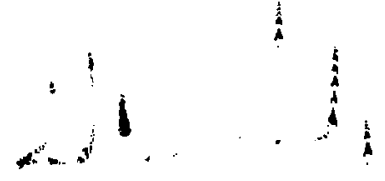




\section{Douglas F. Hambley}

Queen's University at Kingston: B.Sc., Mining Engineering (1972)

Lewis University: MBA, Finance and Operations Management (1986)

Registered Professional Engineer, No. 18026014, Province of Ontario

Registered Professional Engineer, No. 062-039201, State of Illinois

Mr. Hambley has extensive experience in mining, tunneling, and underground construction. He has been a member of the Engineering Geosciences Group of the Energy and Environmental Systems Division at Argonne National Laboratory since 1984. In addition to his duties as the core peer review panelist responsible for mining engineering and rock mechanics, he has been a consultant to Fermi National Accelerator Laboratory on tunneling and siting considerations for the proposed Superconducting Supercollider Accelerator and has participated in an Argonne Environmental Research Division study on Greater Confinement Disposal for low-level nuclear waste.

From 1980 to 1984 he was Senior Mining Engineer with Engineers International, Inc., a mining/tunneling consulting firm. He was Project Engineer on several major projects, including U.S. Nuclear Regulatory Commission contracts to assess retrievability from high-level radioactive waste repositories and to provide technical assistance for repository design reviews.

Between 1972 and 1980, Mr. Hambley held operating and staff-engineering positions with major Canadian mining companies and consulting firms. During his employment at Denison Mines Ltd. (1977-1980), he was responsible for several major projects in addition to his duties as the mine's Rock Mechanics Engineer.

Mr. Hambley is author and coauthor of journal articles, conference presentations, and government agency contract reports on retrievability of high-level radicactive wastes, computer modeling of mine openings, repository ventilation, design of shafts and tunnels, and raise-boring cost estimation, in addition to the technical memoranda generated as a result of peer review activities. He is a member of the national Rock Mechanics Committee of the Association of Engineering Geologists and is chairman of the Chicago Section of the Society of Mining Engineers. 


\section{Timothy R. Harper}

University of Southampton, B.Sc., Geology (1965)

University of London (Imperial College): M.Sc., D.I.C.,

Structural Geology and Rock Mechanics (1970)

University of London (Imperial College): Ph.D.,

Engineering, Rock Mechanics (1973)

Dr. Harper is a research associate concerned with hydraulic fracturing and fluidrock interactive processes. Fifteen of his 20 years of experience have been primarily devoted to geomechanical problems. In many cases, the projects have related to the safety of nuclear installations and to waste disposal. His experience encompasses both surface workings and deep exploration.

From 1975 to 1981 , he was with Dames \& Moore, where his consulting work included evaluation of fault stability, development of potential movement criteria for nuclear power plant design, evaluation of the mechanical aspects of the genesis of a series of geological structural episodes, and evaluation of rock mechanics. Clients included power companies, oil companies, and governments. Before 1975, Dr. Harper taught geotechnics in the Department of Engineering at the University of Aberdeen, Scotland.

Consulting services relating to nuclear facility safety have been provided by Dr. Harper to a variety of organizations, including British Nuclear Fuels Limited, the governments of the United Kingdom and Sweden, and to a major utility in the United States. These services, ranged from the site specific (e.g., the Windscale reprocessing plant in the United Kingdom and the Nine Mile Point plant in New York State) to the generic (e.g., shaft sealing and backfilling, and overall research requirements for intermediate-level waste disposal). A significant percentage of his consulting work has involved evaluation of stress state and the implications for engineering projects. Approaches used have included numerical modeling and laboratory and field testing of the mechanical response of both porous and fractured media to fluid injection and withdrawal.

Dr. Harper has published more than 15 papers dealing with mechanical aspects of geological materials, the mechanics of geological processes, and nuclear waste disposal. He is a member of six professional societies. 


\section{Wyman Harrison}

University of Chicago: S.B., Geology (1953), after three years of undergraduate work at Stanford University

University of Chicago: S.M., Geology (1954)

University of Chicago: Ph.D., Geology (1956)

Registered Geologist, No. 2476, State of California

Certified Professional Geologist, No. 134, American Institute of

Professional Geologists, and No. 487, State of Virginia

Dr. Harrison is Associate Director of the Engineering Geosciences Group for Argonne National Laboratory's Energy and Environmental Systems Division. He directs a 25-person group that performs analytical and experimental studies related to management of energy and mineral resources and to development and deployment of related technologies. Major activities of the group include (1) acquisition of geophysical and geotechnical data bases, (2) analysis of the data of geoscience to support design and deployment of energy technologies, and (3) development of physical and mathematical models of geophysical and geotechnical systems.

Dr. Harrison's group recently completed comprehensive surveys of geoscience data pertaining to crystalline rock complexes in the northeastern and Lake Superior regions of the United States to help assess their potential as possible sites for repositories for high-level radioactive waste. He and his group were the first to apply formal decision analysis for determining the relative favorability of specific crystalline rock areas for such repositories. Dr. Harrison has conducted numerous other geotechnical projects at Argonne, ranging from field studies of the feasibility of using dredged material to reclaim abandoned mined lands to projecting future Soviet oil output by assessing the development of its giant fields.

From 1971 to 1975, Dr. Harrison was Professor of Geography (Associate Department Chairman) at the University of Toronto, where he specialized in studies of slope stability in sedimentary terrains and the siting of supertanker ports. Before that, he was Associate Director for Physical, Chemical, and Geological Oceanography at the Virginia Institute of Marine Science and a Professor of Marine Science at the College of William and Mary. Dr. Harrison was Director of Environmental/Science Services Administration's (now National Oceanic and Atmospheric Administration's) Land and Sea Interaction Laboratory from 1964 to 1968. Earlier he was on the faculty of Dartmouth College's Department of Geology and geologist with the Indiana Geological Survey.

An author of more than 125 papers, reports, reviews, and books, Dr. Harrison was made Senior Scientist at Argonne in 1976. 


\begin{abstract}
Allen W. Hatheway
University of California at Los Angeles: A.B., Geology (1961)

University of Arizona: M.S., Geological Engineering (1966)

University of Arizona: Ph.D., Geological Engineering (1971)

University of Arizona: Professional Degree, Geological Engineering (1982)

Professional Registration:

Geological Engineer, No. 9025, State of Arizona

Geologist, No. 1439, State of California, and No. 153, State of Maine

Engineering Geologist, No. 941, State of California

Civil Engineer, No. C-22654, State of California, and No. 28417, State of

Massachusetts
\end{abstract}

Presently a Professor of Geological Engineering at the University of Missouri at Rolla, Dr. Hatheway specializes in waste management, seismic risk assessment, hazards mitigation, rock engineering and underground construcî́ion, and critical facility siting. From 1976 to 1981, he was Vice President and Chief Geologist of Haley and Aldrich, Inc., where he directed a professional geologic staff in waste disposal siting, rock structure evaluation, and seismic risk assessment. From 1961 to 1976, he worked for geological and geotechnical consulting firms in California and as an exploration geologist in Arizona and $W$ ashington.

As a member of the U.S. Army Reserve, Colonel Hatheway is Mobilization Designee, and Deputy Division Engineer, U.S. Army Engineer Division, Missouri River, Omaha. He was Adjunct Assistant Professor of Civil Engineering at the University of Southern California from 1971 to 1974 and Adjunct Associate Professor of Geology at Boston University from 1979 to 1981 .

Dr. Hatheway's main field of interest and experience has been the development of site- and area-specific geologic assessments in terms of hydrogeology, engineering properties, rock structure, and hazards. He has applied his expertise to a wide variety of projects, including solid, special, and hazardous waste disposal.

Dr. Hatheway is author of more than $\mathbf{5 0}$ technical papers and editor of three books encompassing material on engineering geology, environmental geology, hydrogeology, geotechnical engineering, rock mechanics, seismic risk, nuclear facility siting, and professional practice. He belongs to 12 professional societies and is active on several committees. For example, he is a member of the Environmental Concerns Committee and serves as the elected secretary (1984-1989) of the Management of Hazardous Waste Committee of the American Society of Civil Engineers. 


\section{Amy B. Hull}

Iowa State University, B.S., Biochemistry/Chemistry (1980)

Northwestern University, M.S., Geology (1984)

Northwestern University, Ph.D., Geochemistry (1987)

Ms. Hull is a Geochemist in Argonne National Laboratory's Energy and Environmental Systems Division. Her research focuses on theoretical and experimental analysis of the geochemistry of brines in rock salt as a function of the thermal profile and gamma radiation field. She is modeling the dissolution behavior of rock salt by studying a multicomponent electrolyte system $\left(\mathrm{Na}-\mathrm{K}-\mathrm{Mg}-\mathrm{Ca}-\mathrm{SO}_{4}-\mathrm{Cl}-\mathrm{H}_{2} \mathrm{O}\right)$ at elevated temperatures and varying gamma radiation exposures. The purpose of these studies is to illuminate the phenomena that could accelerate brine migration in a repository environment.

Since 1983, as a graduate research assistant, Ms. Hull has been studying the problems of toxic versus essential environmental concentrations of micronutrients and has been modeling the geochemical cycles of these trace elements. In 1982 she conducted experimental studies on the high-temperature solubilities of clay minerals. Before attending Northwestern University, Ms. Hull worked for Nalco Chemical Company (1981) as a Chemist and Project Leader, researching the formation and removal of sulfur oxides from [lue gases. From 1979 to 1981 , she was a research associate in chemical sedimentology at lowa State University.

Ms. Hull is author and coauthor of numerous publications dealing with (1) the morphology, growth, thermodynamic stability, and dissolution of evaporitic minerals under various sedimentological conditions; (2) the global geochemical cycles of micronutrients; and (3) her studies of $\mathrm{SO}_{2} / \mathrm{SO}_{3}$ at Nalco. She is a member of four professional and honorary chemical and geological societies. 


\section{Charles H. Jacoby}

Missouri School of Mines and Metallurgy: B.S., Mining Engineering (1941)

Mr. Jacoby has extensive experience in conducting exploration and feasibility studies related to salt domes. He is presently Consulting Engineer for Jacoby and Company Inc., and consults on various problems related to salt exploration, evaluation, recovery, and storage capacity. From 1953 to 1977 , he was Director of Development for International Salt Company, where he gained extensive experience in the directed development of salt mines all over the world. His work included evaluating and studying the emplacement of hazardous and toxic materials in salt deposits. Before 1953, $\mathrm{Mr}$. Jacoby worked in manganese exploration and evaluation for several corporations and U.S. government offices.

Some of Mr. Jacoby's recent consulting activities have included (1) economic evaluation of salt reserves, (2) creation of propane storage cavities in bedded salt, (3) design of deep well disposal systems in salt to combat and prevent pollution, and (4) establishment of design criteria for creating cavities in salt for Battelle's Office of Nuclear Waste Isolation.

Mr. Jacoby holds 22 U.S. patents dealing with salt mining, brine field revival, hydraulic fracturing, and geothermal systems. He has published more than 30 papers in his areas of expertise and is a member of 12 professional societies. 


\section{G. Randy Keller}

Texas Tech University: B.S., Mathematics (1968)

Texas Tech University: M.S., Geophysics (1969)

Texas Tech University: Ph.D., Geophysics (1973)

Dr. Keller is Chairman and Professor of Geophysics at the University of Texas at El Paso. He is also Directcr of the J.W. Miller Memorial Geophysical Laboratory and consultant to Los Alamos National Laboratory. From 1976 to 1982 , Dr. Keller was Director of the University of Texas at El Paso Seismological Observatory. He was Assistant Professor at the University of Kentucky from 1973 to 1976 and at the University of Utah for the academic year 1972-1973.

Dr. Keller's research interests include seismic studies of crustal structure and plate tectonics. Some of his most recent work involves the seismicity of the midcontinental United States, specifically the Mississippi embayment and New Madrid fault zone.

Dr. Keller has been professionally active as Associate Editor for the Journal of the Society of Exploration Geophysicists, the Geological Society of America Bulletin, and a special volume on rifting published by Tectonophysics. He is a member of 12 professional societies and has served on four committees. He has authored and coauthored more than 70 papers, maps, and reports on seismology, regional geophysics, and tectonics. 


\section{Darrell I. Leap}

Marshall University: B.S., Geology (1960)

Indiana University: M.A., Geology (1966)

The Pennsylvania State University: Ph.D., Geology (1974)

Certified Professional Geologist, No. 518, State of Indiana

Registered Professional Hydrogeologist, American Institute of Hydrology

Dr. Leap has been Associate Professor of hydrogeology at Purdue University since 1980, teaching courses in general hydrogeology, groundwater modeling, and welltesting methods. From 1974 to 1980, Dr. Leap was employed as a hydrologist with the U.S. Geological Survey, serving as Project Chief of a groundwater tracer project and as Principal Investigator for Hydrology for the Nevada Nuclear Waste Storage Investigations under contract to DOE. In the latter position, he was responsible for managing six research projects supporting waste-repository siting at the Nevada Test Site. He was also responsible for starting the Survey's groundwater modeling project for the Nevada Test Site and environs.

From 1966 to 1971 , Dr. Leap worked as a Geologist/Hydrologist for the South Dakota State Geological Survey and was Project Chief for three different projects involving countywide geologic mapping and hydrologic analysis of surface-water and groundwater supplies in eastern South Dakota. He also taught in the Department of Geology at the University of South Dakota.

Dr. Leap's present research involves groundwater tracer studies, groundwater modeling, groundwater resource assessment, and regional hydrogeology. He has been a consultant on groundwater use and pollution for various companies. He has participated in more than 40 symposia and conferences, lecturing or coauthoring papers in more than 30. Topics covered include the geologic disposal of high-level nuclear waste and quality assurance for nuclear waste isolation studies.

Dr. Leap is the author of 15 technical reports and refereed papers, as well as numerous abstracts on groundwater analysis and nuclear waste disposal. He is a member of five professional societies and served as President of the Indiana Water Resources Association in 1982. 


\section{Dennis Z. Mraz}

University of Ostrava, Czechoslovakia: M.Sc., Mining Engineering and Construction (1962)

University of Ostrava, Czechoslovakia: completed one year of a Ph.D. program Mine Managers Certification, No. 523, Province of Alberta

Mr. Mraz is most recently President of Mraz Project Consultants, Ltd., Saskatoon, Saskatchewan. From 1981 to 1984, he was with Denison Mines, Ltd., as Vice President of Operations for Dentherm Resources, Ltd.; with Quintette Coal, Ltd., as Vice President and General Manager-Operations; and with Potacan Potash Company as an internal consultant. As General Manager for Luscar-Sterco, Ltd. (1978-1981), Mr. Mraz was responsible for operating a surface- mining operation and designing the underground mining operation. From 1969 to 1978, he was Engineering Manager for International Minerals and Chemical Corp. (Canada) Ltd., where he was, among other things, directly responsible for engineering research and development for underground mining operations.

His consulting activities have included studying rock mechanics, designing mining methods, preparing guidelines for safety pillars in shafts and exploration holes, and spacing solution caverns in deep salt formations. Since 1982, Mr. Mraz has been advisor to the Department of Earth Sciences, University of Waterloo, on studies associated with testing salt rocks.

Mr. Mraz is a member of five professional organizations and has written seven papers dealing with plasticity and flow of salt and how they affect design of mining methods. 


\section{Sehlomo P. Neuman}

Hebrew University, Jerusalem, Israel: B.S., Geology (1963)

University of California, Berkeley: M.S., Engineering Science (1966)

University of California, Berkeley: Ph.D., Engineering Science (1968)

Dr. Neuman has been a Professor of Hydrology at the University of Arizona since 1975. Previously, he had taught at the University of California, Berkeley (1974-1975 and 1968-1970) and had conducted research at the Institute of Soil and Water, Agricultural Research Organization, Bet-Dagen, Israel (1970-1974).

Dr. Neuman has many years of wide-ranging experience in hydrology and hydrogeology acquired through academic research, consulting work for government and industry, and graduate teaching. His main areas of research and expertise include well hydraulics, design and analysis of pumping tests, computer modeling of groundwater flow and subsurface contaminant transport, fractured-rock hydrology, flow in unsaturated soils, and use of statistics in hydrology. Much of his recent research and consulting activities have been in the area of high-level radioactive waste disposal in geologic environments.

Dr. Neuman has received numerous awards for distinguished contributions to the field of hydrogeology. He is a fellow of the American Geophysical Union and has published more than 80 research papers. 


\section{Robert A. Paddock}

Washington and Lee University: B.S., Physies (1964)

Michigan State University: M.S., Physics (1966)

Micnigan State University: Ph.D., Physies (1969)

Dr. Paddock is a geophysicist in the Hydrologic and Geologic Engineering Section of the Geoscience and Engineering Group of the Energy and Environmental Systems Division at Argonne National Laboratory. For more than 12 years, he has served as project leader or team member investigating physical transport of substances in the hydrosphere by way of natural processes and man-made conveyances in the context of energy resources, wastes, and technology development. Dr. Paddock's primary activities have included definition of data requirements, acquisition techniques, and processing schemes; model applications; and data interpretation for model evaluation.

Bef re joining Argonne as a full-time staff member in 1975, Dr. Paddock was Assistant Professor of Physics at Ripon College. While on the faculty, Dr. Paddock spent several semesters as a Resident Research Associate at Argonne working in the area of physical transport in the hydrosphere.

Dr. Paddock has authored more than 30 scientific and technical publications and has served as a reviewer of technical papers for the Hydraulics Division of the American Society of Civil Engineers. 


\section{Donald M. Rote}

Cleveland State University: B.E.S., Engineering Science (1960)

Case Western Reserve: M.A., Theoretical Physics (1963)

Case Western Reserve: Ph.D., Theoretical Nuclear Physics (1967)

Dr. Rote is a member of the Geoscience and Engineering Group, Energy and Environmental Systems Division, Argonne National Laboratory, where he serves as a core peer review panelist. During the past two years, he has reviewed numerous models proposed by DOE contractors for use in performance assessment of waste package and repository designs. He has also reviewed several technical reports concerning the corrosion testing of waste package materials and the mathematical methods used to analyze accelerated life test data. Concurrently, he has served as a member of the laboratory director's task force for developing and applying electromagnetic technology to the continuous casting of sheet steel. As part of that group, he has been responsible for the conceptual design of both bench-scale and full-scale systems for handling and electromagnetically shaping molten metals.

During Dr. Rote's time at Argonne, his research efforts have shif ted more toward applied research problems. He has served as principal investigator on numerous research and assessment programs concerned with developing, verifying, validating, and documenting models used for air pollution assessment. Sponsors have included the U.S. Environmental Protection Agency, U.S. Air Force, and Federal Aviation Administration. He has also directed field programs requiring the acquisition, analysis, and interpretation of air-quality, meteorological, and source data. Dr. Rote has concurrently served as an advisor to the above agencies on model validation, model application, monitoring, and data-analysis techniques. As leader of the Air Resources Section from 1976 to 1983, he was Director of the Atmospheric Impact Assessment Study of the proposed DOE Satellite Power System. Chemical and electromagnetic interactions in the ionosphere and magnetosphere were studied.

Dr. Rote began his career as a professional physicist before leaving graduate school by serving as a part-time employee and consultant to Clevite Research Center, whele he conducted experimental studies of the electromagnetic properties of PZT ceramics. After completing his graduate education, he first served as a postdoctoral fellow and later as an assistant professor in the Physics Department of the University of Illinois at Chicago. During that same period, he served as a consultant to the Physics Division of Argonne National Laboratory, where he conducted basic research in nuclear physics. In 1970, he became a full-time staff member of Argonne.

Dr. Rote is an author or coauthor of $\mathbf{7 0}$ reports, book chapters, and articles. 


\section{James E. Russell}

South Dakota School of Mines and Technology: B.S., Civil Engineering (1963)

South Dakota School of Mines and Technology: M.S., Civil Engineering (1964)

Northwestern University: Ph.D., Theoretical and Applied Mechanics (1966)

Professor Russell joined the faculty of Texas A\&M University in 1978 as Professor of Mining Engineering and Geophysics, and has been a Brockett Professor of Engineering since 1982. He has had extensive experience in the analytical/numerical, laboratory, and field aspects of rock mechanics. Much of his research has related to mining, underground construction, and underground storage, with special emphasis on in situ experiments related to waste repository design, radioactive waste isolation in salt, creep models for salt, thermal loading in waste repositories in salt, benchmark problems in salt using different numerical methods, coal gasification, and lignite mining.

Dr. Russell serves as a rock mechanics consultant to ONWI and Oak Ridge National Laboratory; as a resource consultant for rock mechanics to the Overview Committee for the Basalt Waste Isolation Project; as a coinvestigator of an ONWIsponsored project at Texas A\&M University to develop constitutive equations for salt; and as a member of the Performance Constraints Working Group for RE/SPEC, Inc., and ONWI. During 1979 he served as a member of the Peer Review Group for DOE's Nevada Nuclear Waste Storage Investigations.

From 1977 to 1978 , just prior to accepting the position at Texas A\&M, Professor Russell was the Project Manager for Rock Mechanics at the Office of Waste Isolation, Union Carbide Corporation. From 1972 to 1976, he was Vice President and Resident Consultant at RE/SPEC, Inc. From 1967 to 1976, Dr. Russell served as Assistant Professor of Civil Engineering; Associate Professor of Civil Engineering, Mining and Civil Engineering, and Mining Engineering; and Professor of Mining Engineering at the South Dakota School of Mines and Technology. From 1966 to 1967, he was Senior Research Engineer at Southwest Research Institute.

Professor Russell has published extensively in the fields of rock mechanics, mining engineering, lignite mining, coal gasification, and waste isolation. He is a member of six professional and honorary societies, and has served on 11 national committees. 


\section{Martin G. Seitz}

University of Missouri: B.S., Engineering Physics (1966)

Washington University: Ph.D., Geophysics (1971)

Dr. Seitz is a geochemist in the Geochemistry Group of the Chemical Technology Division of Argonne National Laboratory, where he manages applied and basic experimental programs. Ongoing applied programs related to radioactive waste disposal are to investigate interactions of materials proposed to be used ir. disposing of radioactive waste and to learn how backfill materials would be affected by the conditions of nuclear waste disposal. The basic research program of the group is to study traceelement migration in the earth's crust. Current work focuses on the role of organic compounds in mobilizing heavy metals and on the movement of phenol compounds through water-bearing rock.

Dr. Seitz served with seven others on the Panel to Assess the Technical Basis of 10 CFR 60, the U.S. Nuclear Regulatory Commission rule for licensing a high-level radioactive waste repository. Dr. Seitz also completed experimental work on radionuclide retention in salt (Waste Isolation Pilot Plant) and helped develop logging methods in boreholes to detect petroleum. He has organized workshops on radioactive and hazardous waste disposal and has carried out geologic field work with university and U.S. Geological Survey staff.

Before coming to Argonne, Dr. Seitz was a fellow at the Geophysical Laboratory of the Carnagie Institution of Washington, where he studied the chemical partitioning and solid diffusion of trace elements in igneous rock. Having received a National Defense Act fellowship for graduate work, Dr. Seitz determined rock ages from products of spontaneous fission and studied the distributions of uranium and thorium in igneous rocks.

Dr. Seitz has published more than 60 papers in scientific journals, primarily on geochemical topies. 


\section{John C. Stormont}

University of Wisconsin, Madison: B.S., Mining Engineering (1980) University of Arizona: M.S., Mining Engineering (1983)

Mr. Stormont is a member of the technical staff at Sandia National Laboratories, where he conducts experimental programs related to mining, rock engineering, and radioactive waste disposal. He is responsible for development of plugs and seals for the Waste Isolation Pilot Plant (WIPP) project.

Before joining Sandia, Mr. Stormont was a Research Assistant at the University of Arizona, where he studied the sealing of rock masses as related to disposal of radioactive waste. His thesis research focused on the mechanical strength of borehole plugs. While at the University of Arizona, Mr. Stormont also taught geomechanics.

After obtaining his Bachelor's degree in 1980, Mr. Stormont worked as a field assistant. His duties included logging drill core and measuring in situ stresses using the hydraulic fracturing method. He also worked summers as a Junior Engineer with Climax Molybdenum Co. (1979) and as Assistant City Engineer for Monroe, Wis. (1978).

In $1982 \mathrm{Mr}$. Stormont received the Sulger Memorial Scholarship from the University of Arizona; in $\mathbf{1 9 8 0}$ he reseived the Kerwin-Patterson Award from the University of Wisconsin. Mr. Stormont has published several reports on borehole plugs and seals for geologic repositories, including the program plan for the WIPP plugging and sealing program, and on stress measurement techniques in salt. 


\section{Robert R. Interberger}

Syracuse University: B.S., Physics (1943)

Harvard and Massachusetts Institute of Technology: Radar School (1944)

Duke University: Ph.D., Physics (1950)

Dr. Unterberger has been a Professor of Geophysics at Texas A\&M since 1968. From 1950 to 1968, he was Senior Research Associate for Chevron Oil Field Research Company, where he applied geophysical methods to well logging and petroleum exploration.

Specializing in exploration geophysics, Dr. Unterberger is an expert in borehole geophysies and radar and sonar penetration of rocks. He has received more than 21 major grants to study electromagnetic and ultrasonic wave propagation in rocks, electron paramagnetic resonance, and optical pumping. In addition to his research and teaching, Dr. Unterberger is consultant to more than 20 petroleum and mineral companies.

Dr. Unterberger's most recent work has involved probing salt domes with radar, sonar, and nonlinear sonar. He has published 40 papers related to these techniques. Dr. Unterberger holds 10 U.S. patents concerning geophysical methods of mapping formations and numerous foreign patents. He is a member of eight professional societies. 